\title{
Feedback in New Zealand Classrooms: Do students get the message?
}

\author{
By \\ Deidre Carol Vercauteren
}

A thesis submitted to
Victoria University of Wellington
In partial fulfilment of the requirements for the degree of Master of Education

2005

Victoria University of Wellington

Te Whare Wananga o te Upoko o te Ika a Maui 


\section{Abstract}

There is increasing evidence that feedback is a key factor in successful teaching and learning. It is also clear that there are effective and less effective forms of feedback. To be most effective, feedback should incorporate assessment for learning principles.

Although there is a large body of literature on feedback, there is limited use of the student's voice, and little from a New Zealand context. This thesis investigates students' understandings of feedback in New Zealand classrooms. A feedback typology is used to categorise and analyse examples of teacher feedback given by the students.

Individual student interviews were conducted with responses informing the kinds of questions used for the teacher interviews. Advisory work in schools that involves classroom observations on feedback was also used to substantiate the findings. The sample used for this research came from two schools, four classrooms and focussed on sixteen students. The classes ranged from Years 3-6, which meant that the students were aged between 7 and 10 .

The analysis concludes that while New Zealand students can describe a range of both evaluative and descriptive feedback their understandings do not always match what the teacher intended. The feedback typology was found to be a useful tool but was problematic in that there was no assurance that feedback was against shared expectations of the task. 


\section{Acknowledgements}

I would particularly like to thank Dr Geraldine McDonald and Dr Joanna Higgins for sharing their knowledge and expertise, and for their skill in asking the right questions. Their encouragement and patience has been very much appreciated.

I am grateful to the two primary school principals who agreed to my working in their schools and so willingly organised my time there. My gratitude also goes to the teachers and students who allowed me to interview them. Without their cooperation, none of this would have been possible.

To my family, and particularly my husband, my thanks for your encouragement and support, and your understanding of my need to focus. Also, to my friends and colleagues who have shown interest in my progress, have been so positive and have lifted my spirits when needed, thank you. You will know who you are.

Finally, I would like to thank Victoria University of Wellington College of Education for the opportunity and resources made available. I acknowledge the privilege that has been extended to me. 


\section{Contents}

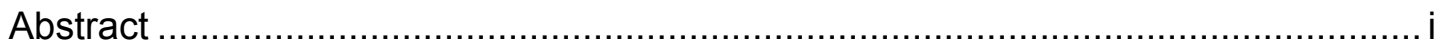

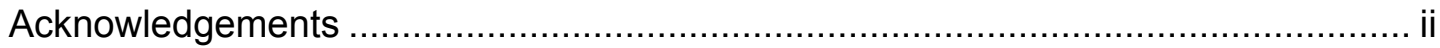

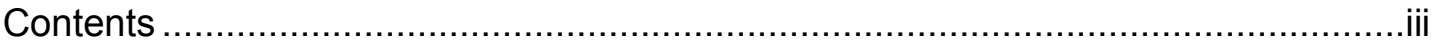

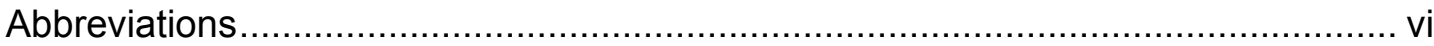

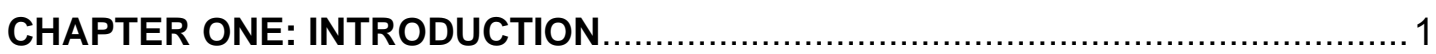

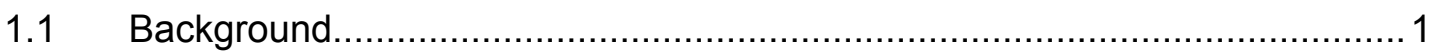

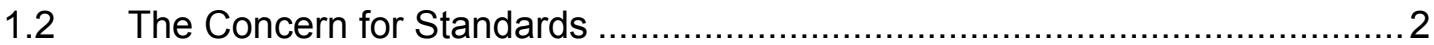

$1.3 \quad$ Feedback and Quality Teaching ............................................................... 4

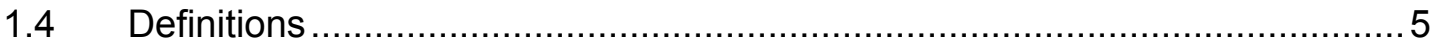

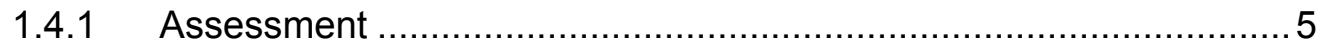

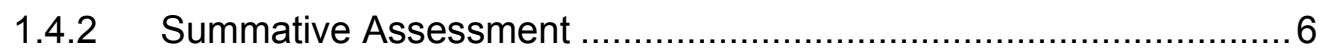

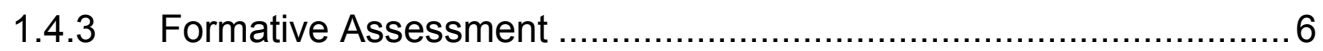

1.4.4 Defining Feedback .............................................................. 7

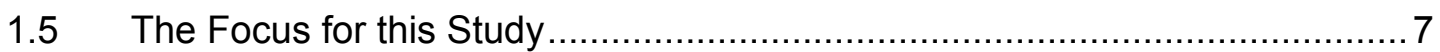

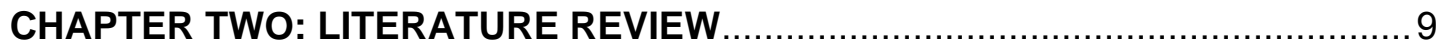

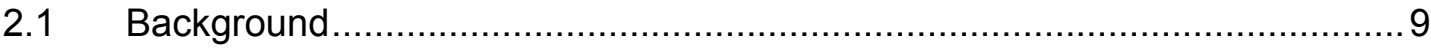

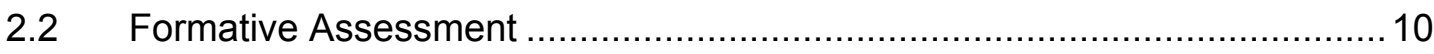

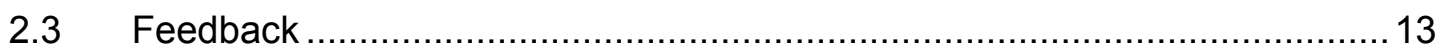

2.3.1 Types of Feedback ............................................................. 15

2.3.2 Feedback and the Student Voice ........................................... 19

2.3.3 Feedback and Instruction..................................................... 22

2.3.4 Feedback and Underachievement ........................................ 23

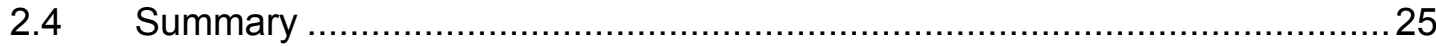

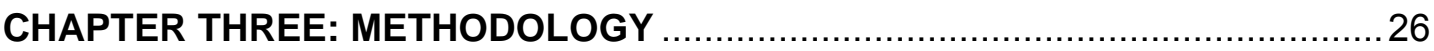

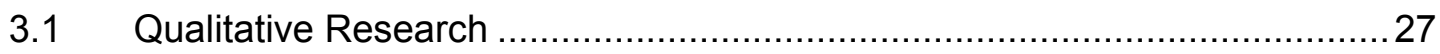

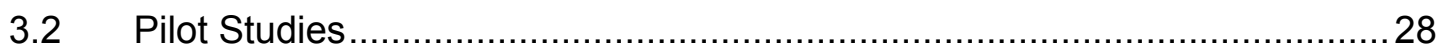

3.2.1 Analysis of Data from Pilot Studies ......................................... 29

3.2.2 Findings of the Pilot Studies ...................................................... 29

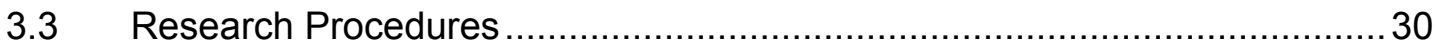

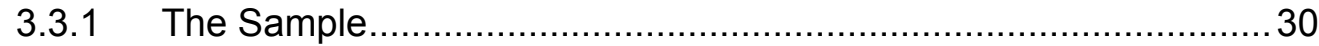

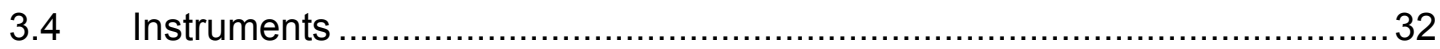

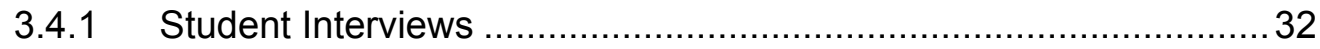

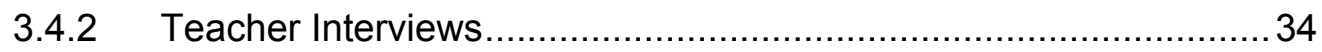

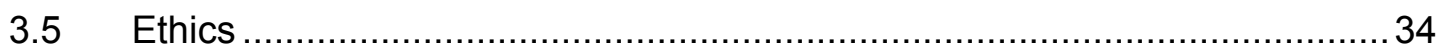

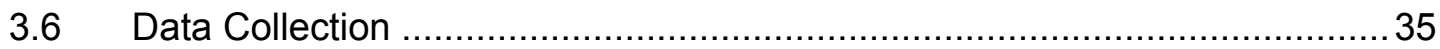

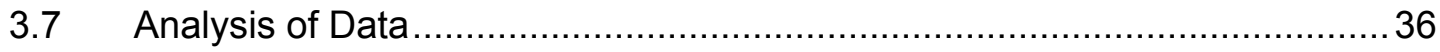

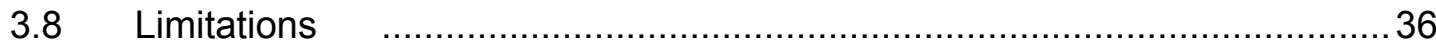




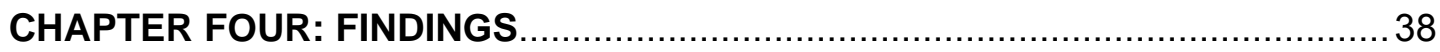

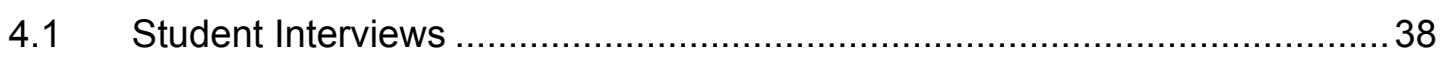

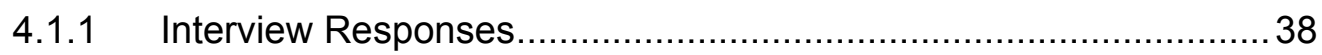

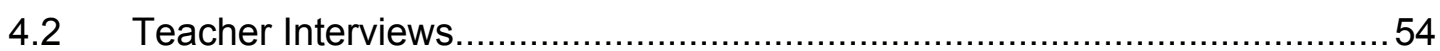

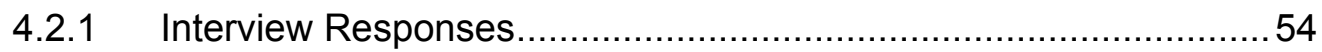

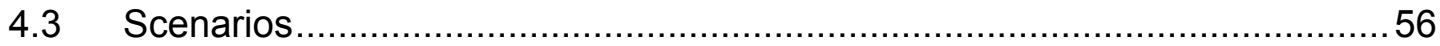

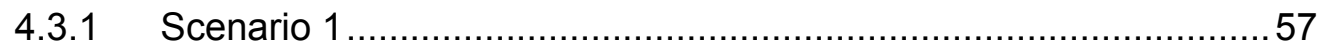

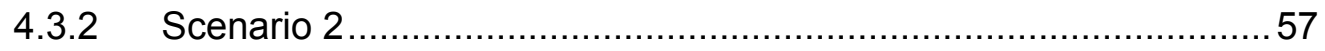

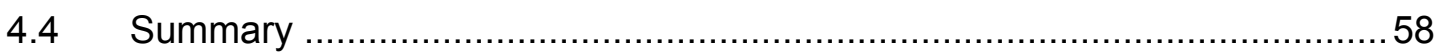

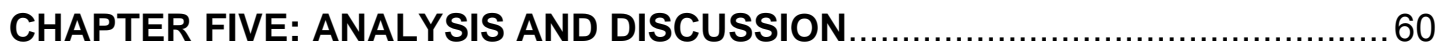

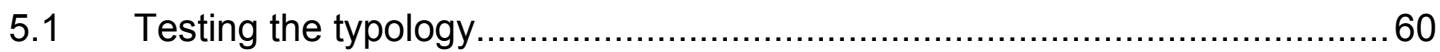

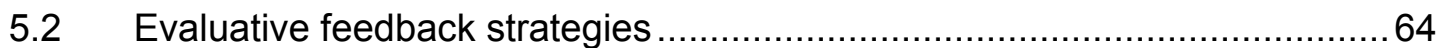

5.2.1 You've got another sticker; add it to your 'ten card' .......................65

5.2.2 Three more warnings and then you're out ..................................66

5.2.3 Good work, you're getting good at this ......................................6 66

5.2.4 I can hear her raising her voice. Why can't she keep it down? .......67

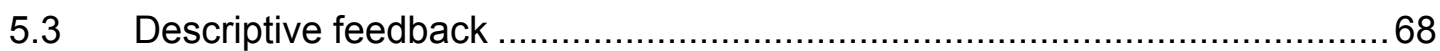

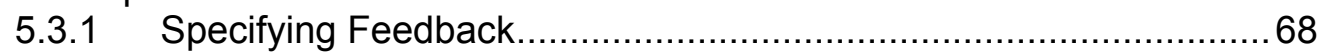

5.3.1.1 That's a terrific story .......................................... 69

5.3.1.2 Practise, practise, practise!......................................... 69

5.3.2 Constructing feedback .....................................................69 69

5.3.2.1 Lovely metaphors, that gives me a mental picture .........70

5.3.2.2 What's your next step? ............................................. 71

5.4 Is there a match between student understandings and teachers' intentions? ...72

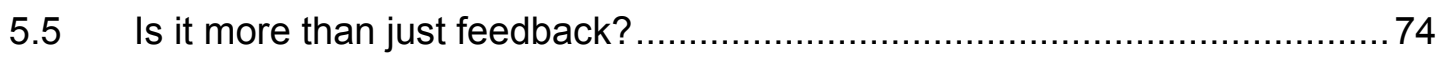

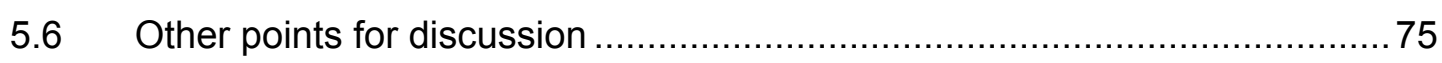

5.6.1 Is there a relationship between enjoyment, feelings about ability, and feedback? .................................................................... 75

5.6.2 Are teacher decisions influenced by Government Priorities and do these decisions impact on students? ...................................... 77

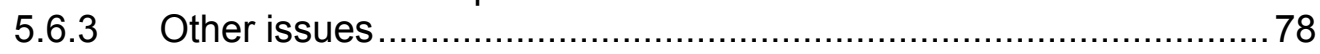

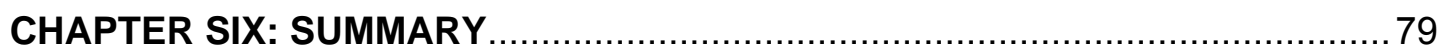

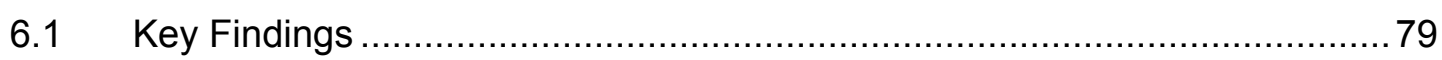

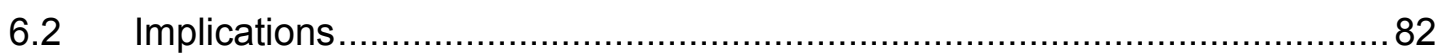

6.2.1 For Policy and Practice ...................................................... 82

6.2.2 For Further Research............................................................ 83 


\section{APPENDICES}

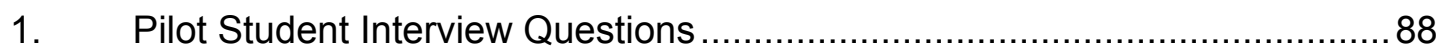

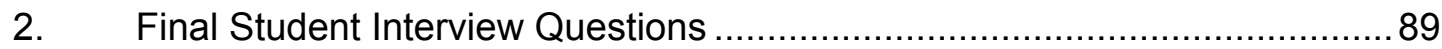

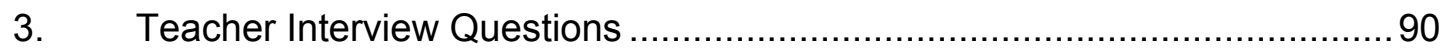

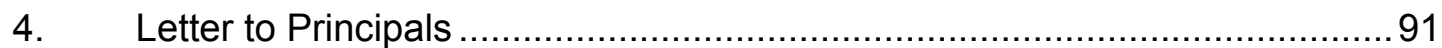

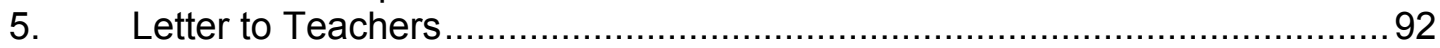

6. Letters to Parents/Caregivers .............................................................. 93

\section{TABLES}

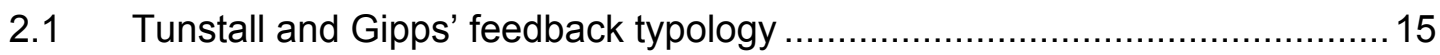

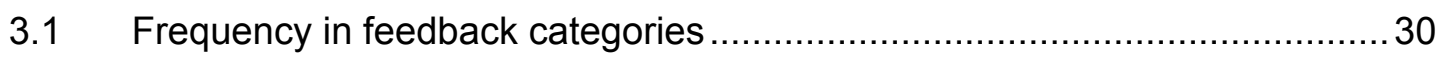

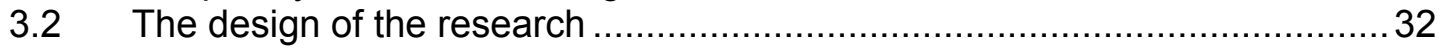

3.3 Principles relating to research participants .......................................... 35

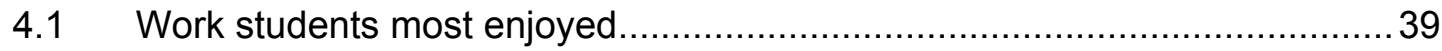

$4.2 \quad$ Work students thought they were best at............................................ 41

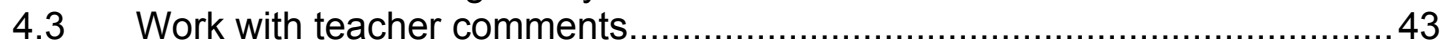

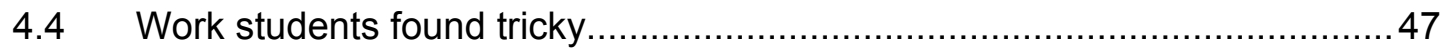

4.5 Work students had been told they needed to get better at ........................50

4.6 Students' ability to define feedback ...................................................... 54

5.1 A brief outline of the Tunstall and Gipps' feedback typology .......................60

5.2 Students' examples of teacher evaluative feedback mapped onto Tunstall and Gipps' typology...............................................................................61

5.2 Students' examples of descriptive teacher feedback mapped onto Tunstall

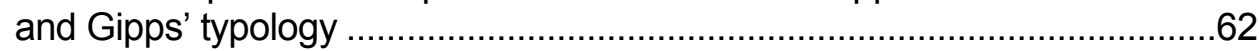

5.3 Categorising feedback using the Tunstall and Gipps' typology ....................63

5.4 An adaptation of the Tunstall and Gipps' typology.................................... 75

5.5 The relationship between enjoyment, feelings of ability and teacher comments

\section{FIGURES}

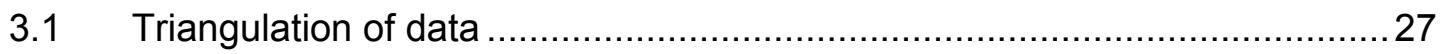

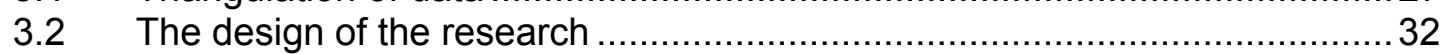

5.1: Categorising Feedback using the Tunstall and Gipps' typology ...................... 63 


\section{Abbreviations}

ABeL

ARBs

asTTle

AtoL

BES

ERO

LEA

LEARN (project)

NAGs

NEMP

NZARE

NZCER

TGAT
Assessment for Better Learning

Assessment Resource Banks

Assessment tools for teaching and learning

Assess to Learn

Best Evidence Syntheses

Education Review Office

Local Education Authority

Learners' Expectations of Assessment for Learning Nationally

National Administration Guidelines

National Education Monitoring Project

New Zealand Association for Research in Education

New Zealand Council of Education Research

Task Group on Assessment and Testing 


\title{
CHAPTER ONE
}

\section{Introduction}

\subsection{Background}

\begin{abstract}
Assessment for learning is any assessment for which the first priority in its design and practice is to serve the purpose of promoting pupils' learning. It thus differs from assessment designed primarily to serve the purposes of accountability, or of ranking, or of certifying competence (Black, Harrison, Lee, Marshall \& Wiliam, 2002, p.2).
\end{abstract}

The New Zealand Curriculum Framework (Ministry of Education, 1993) clearly states, "The primary purpose of school based assessment is to improve students' learning" (p.24). As clear as this statement is, assessment has been a fuzzy undefined area of teachers' work, and has possibly been the aspect of the New Zealand Curriculum causing most concern. Prior to current Ministry initiatives ${ }^{1}$, primary school teachers appear to have been confused and frustrated by the lack of clear official guidelines for assessment and understanding the difference in practice between summative and formative assessments has been particularly difficult for some. Briefly, summative assessment, or assessment of learning, is usually undertaken at the end of a unit of work. Formative assessment, or assessment for learning, is ongoing during a unit of work and should inform what the student and the teacher do next. (These terms are defined more fully at the end of this chapter.) The distinction between formative and summative assessment has been the focus of considerable debate, and their practical applications have not always been clearly understood. Moreover, traditional summative tests available to teachers have not necessarily been useful, and frequently the information provided by such tests appears not to have been used for the purpose of the day-to-day guidance of learning.

Since the introduction of the new National Curriculum documents, schools and teachers have been expected to monitor student progress against specific curriculum achievement objectives. As a part of implementing the new curriculum,

\footnotetext{
Ministry initiatives work towards achieving the Schooling Strategy (2005-2007) goal that "all students achieve their potential". http://www.minedu.govt.nz They are also reflected in the National Administration Guidelines (NAGs) 1999 also on http://www.minedu.govt.nz
} 
the Education Review Office (ERO) has required written evidence of student achievement and as a result large amounts of data have been gathered by schools for management or accountability purposes rather than to inform teaching and learning. This problem is not confined to New Zealand (Black \& Wiliam, 1998b).

\subsection{The Concern for Standards}

A concern for "standards" and the intention to establish a National Curriculum for England and Wales led to the Secretary of State for Education and Science setting up a Task Group on Assessment and Testing (TGAT) in 1987 to advise on the practical considerations governing assessment within the national curriculum. In particular the Task Group was asked to devise a framework for assessment of achievement at what were called the key stages of 7,11 , and 14 . The chairman of this group, Professor Paul Black from King's College London, has continued to be one of the key figures in promoting changes to assessment practices internationally. The recommendations of the report and all subsequent statements of government policy have emphasised the importance of formative assessment by teachers.

The New Zealand government set up a Ministerial Working Party on Assessment for Better Learning. Its report, Tomorrow's Standards (Ministerial Working Party on Assessment for Better Learning, 1990), took the view that monitoring national performance was best achieved by light sampling and tasks that reflected a broad range of goals. This proposal was eventually achieved with the establishment of the National Education Monitoring Project (NEMP) under the direction of $\mathrm{Dr}$ (now Professor) Terry Crooks who was a member of the Ministerial Working Party.

In the mid 1990s the educational research community expressed increasing concern that the potential of assessment to support learning was being ignored. In 1997, as part of an effort to reassert the importance of formative assessment, the British Educational Research Association Policy Task Group on Assessment (with the support of the Nuffield Foundation) commissioned Black and Wiliam (1998a,b) to undertake a review of the research on formative assessment. What they found was that the improvement of formative assessment is not a simple matter and that there is no "quick fix" that can be added to existing practice with the promise of rapid reward. They stress that improvement can only happen slowly and through sustained programmes of professional development and support. 
The New Zealand Ministry of Education responded to international trends and initiatives and acknowledged problems surrounding student assessment. As a result, assessment projects for teacher development introduced across the country since the mid 1990s have emphasised developing teachers' knowledge of assessment, fostered partnerships between teacher and student, encouraged setting specific and challenging goals and focussed on the use of information to improve teaching and learning. These more recent projects are one aspect of the National Assessment Strategy brought together into current education policy by teaching, research, and policy sectors of the Ministry of Education. Assessment evidence should be used to inform the next steps in our enterprise. Assessment data should inform formative practice.

The implementation of formative assessment strategies, in the projects referred to, has depended on the development of new tools. Considerable resources are being put into New Zealand schools by way of professional development projects and national assessment tools such as "Assessment Tools for Teaching and Learning" (asTTle), "The National Curriculum Exemplars", the "National Education Monitoring Project" (NEMP) and the "Assessment Resource Banks" (ARBs) to name just a few. All these assessment tools have a formative purpose and provide teachers with feedback information.

Teachers have been supported, challenged and encouraged to think critically about their teaching and to build on existing good practice. There has also been a need to align classroom and school-wide assessment with school systems, so that summative pressures do not undermine teachers' formative work. Furthermore, taking full advantage of formative assessments has resulted in a shift from an historical emphasis on summative requirements, which were the practice in the past. While monitoring student achievement against specific levels of the New Zealand Curriculum (summative assessment) is a necessary requirement for teachers, its purpose is different from the teaching and learning assessment opportunities on a day-to-day basis in the classroom.

A key component of formative assessment deals with student and teacher feedback and its complexities. Feedback gives specific information about current achievement, the next step (or goal) and how to reach that goal. It then requires thought and some kind of response or action from the student. Traditional practices have been challenged and Sadler's (1989) feedback definition, and Tunstall and Gipps' (1996b) feedback typology ${ }^{2}$, have been significant in changing these practices.

2 An outline of the feedback typology can be viewed in Chapter 2. 
The aim of the research reported in this thesis is to investigate student feedback in New Zealand primary school classrooms. The purpose was to investigate the elements of feedback and in particular look at how students get their information about how well they are doing. Despite the interest in assessment and feedback there has been limited research on the process of feedback, its elements, and students' understanding of it. There has also been a limited amount of research that investigates students' perceptions and views of their learning, and the relationship of their perceptions to the feedback they receive.

\subsection{Feedback and Quality Teaching}

Feedback can be considered as one of the elements of quality teaching and is a contributor to an evidence-based approach to learning. The challenge for teachers and schools is to make a difference for all their students and to provide evidence of shifts in achievement. To support this challenge, the Ministry of Education has commissioned a number of reports in a series of Best Evidence Syntheses (BES) ${ }^{3}$. One of these reports compiled by Alton-Lee (2003) is on quality teaching ${ }^{4}$. It aims "to contribute to an ongoing evidence-based discourse amongst policy makers, educators and researchers ... It draws together in a systematic way the available evidence about what works to improve education outcomes, and what can make a bigger difference for the education of all our children and young people" (p.ii). Key messages have been represented by Alton-Lee as shifts in order to provoke consideration of the implications of the BES for educational change. Some of these shifts towards evidence-based teaching include:

- $\quad$ an evidence-based approach that attends to data about students' learning and to research about effective pedagogy to inform professional teaching practice

- a complexity of pedagogy and interactions - inter-dependence of characteristics of quality teaching

- from a dependence on a repertoire of practical strategies to an evidence-based theory as a critical tool to enable teachers to generate pedagogy that is responsive to their learners

- management for learning and self-regulation

- predominant use of assessment practices that are diagnostic, descriptive, formative, motivating and, with quality feedback, improve learning

\footnotetext{
3 There are several BES (Best Evidence Syntheses) completed or in process. Each has a different focus of education, e.g. early childhood, professional development.

This BES focus is "Quality Teaching for Diverse Students in Schooling"
} 
- assessment includes self-assessment and peer-assessment as students take increasing responsibility for their own learning and become more autonomous with respect to their own learning (p.24).

These characteristics have a very clear link to the principles of assessment for learning' that the Assessment Reform Group (2002) have drawn from Black and Wiliam's (1998b) extensive review. They highlight shared control through a partnership between students and teachers in the teaching and learning process. One of the best indicators of this occurring is effective feedback and a vital outcome of forming such partnerships is feedback that is constructive.

The use of evidence to underpin teaching practice should be promoted so that all teachers continually reflect on how effectively their teaching is impacting on students' learning. Black and Wiliam (1998b) suggest they confront the question "Do I really know enough about the understanding of my pupils to be able to help each of them?" (p.13), a question which directs teachers to understand their students both as individuals and as learners.

\subsection{Definitions}

\subsubsection{Assessment}

The word 'assess' is derived from the Latin ad + sedere meaning to sit by, or sit together ${ }^{5}$.

The definition of assessment by TGAT (1987) that informed policy on National Curriculum assessment is that assessment should be both summative and formative.

In a definition offered by Wiliam and Black (1996), assessment is defined by its functions, which can be "characterised at the ends of the continuum along which assessment can be located. At one extreme formative assessment ... and at the other summative" (p.544). According to the same analysis, assessment is formative when it provides a "basis for successful action" (p.544).

This thesis uses the following definitions of assessment terms.

\footnotetext{
${ }^{5}$ Reference: Collins Concise English Dictionary (1982).
} 


\subsubsection{Summative Assessment}

TGAT (1987) defined the summative purpose of assessment "for the recording of the overall achievement of a pupil in a systematic way" (para. 23). Such assessment was usually formal, established by testing, and often used for reporting to parents.

Wiliam (1999) describes summative assessment as "looking back" and Wiliam and Black (1996) as "... assessment that has increasingly been used to sum up learning." Harlen (1998) suggests that summative assessment, “... looks at past achievements, adds procedures or tests to existing work, involves only marking and feedback grades to students, is separated from teaching and is carried out at intervals when achievement has to be summarised or reported" (p.3).

These definitions appear to be representative of those commonly used in New Zealand.

\subsubsection{Formative Assessment}

A suggestion by TGAT (1987) that "assessment should be an integral part of the educational process, continually providing both 'feedback' and 'feedforward"' (para. 4) was the beginning of more recent reforms. The formative purpose is "so that the positive achievements of a pupil may be recognised and discussed and the appropriate next steps may be planned" (para. 23).

There seems to be general agreement that the term "formative" implies that assessment information is used to inform or improve learning. Wiliam (1999) describes formative assessment as "looking forward". In the search for clarity, 'ongoing formative assessment processes' is increasingly referred to as "classroom assessment" (Black \& Wiliam, 1998b; Harlen, 1998; Torrance \& Pryor, 1998; Tunstall \& Gipps, 1996b).

Tunstall and Gipps (1996a) suggest formative assessment “... is used essentially to feed back into the teaching and learning process" (p.186), and Sadler (1989) that it "...includes both feedback and self monitoring" (p.121). Harlen (1998) describes formative assessment that provides feedback, which leads to students recognising the learning gap and closing it, and is forward looking. For Black et al. (2002) the term assessment:

... refers to all those activities undertaken by teachers, and by their students, in assessing themselves, which provide information to be used as feedback to modify the teaching and learning activities in which they are engaged. Such assessment becomes 'formative 
assessment' when the evidence is actually used to adapt the teaching work to meet learning needs (Inside Cover).

Black et al. (2002) give the most comprehensive definition that compares the two functions. This is in the quotation presented at the beginning of this chapter.

Assessment for learning is any assessment for which the first priority in its design and practice is to serve the purpose of promoting pupils' learning. It thus differs from assessment designed primarily to serve the purposes of accountability, or of ranking, or of certifying competence (p.2).

Definitions of formative assessment do not yet enjoy a widely recognised and agreed meaning (Harlen, 1998, p.2).

\subsubsection{Defining Feedback}

The concept of feedback appears to be complex. It is, however, a vital component of formative assessment. Crooks (1988) suggests that feedback "should be specific and related to need. Simple knowledge of results should be provided consistently (directly or implicitly), with more detailed feedback only when necessary, to help the student work through misconceptions or other weaknesses in performance" (p.469).

Ramaprasad (1983) defines feedback as information about the gap between actual and referenced (predetermined) levels. He adds that this information is considered as feedback only when it is used to alter the gap. Sadler (1989) describes these three elements as: desired goal, current position, and closing the gap ( $p .121)$.

\subsection{The Focus for this Study}

Both student and teacher understandings of feedback, given and received, will be explored. Tunstall and Gipps (1996a), who have carried out research on feedback, provide a model for the present study. This particular model was chosen because of the similar age group used and because their framework helped define quality feedback with categories that showed a clear progression. The study differs from theirs in terms of sample size, student ages and some of the questions asked, but their typology has been used to categorise feedback examples given by the students. The research aims to answer the general question: 
What are student and teacher understandings of feedback as it occurs in New Zealand classrooms?

I have been Director and a facilitator of a Ministry of Education project Assess to Learn $^{6}$ (previously Assessment for Better Learning ${ }^{7}$ ), which has been delivered by Victoria University of Wellington College of Education ${ }^{8}$ over the last four years. A major part of my role has been to develop, review, and deliver programmes with a team of advisers. The programme is based on research that focuses on formative assessment, learning (rather than task) and raising achievement for all students. Over four years we have worked in depth ${ }^{9}$ with approximately 50 schools in the greater Wellington area.

Black and Wiliam (2003) believe that "the majority of research in education should be undertaken with a view to improving educational provision" (p.632). It is hoped that the results of this study will inform advisory work in schools.

The structure of the report is as follows. Chapter Two reviews the literature on formative assessment and feedback. Chapter Three discusses the methodology used for the research and Chapter Four summarises the key findings from the student and teacher interviews. Chapter Five discusses the findings in relation to the literature reviewed. Chapter Six gives a summary of the key findings, outlines implications that have emerged and suggests possible areas for future research.

Assess to learn known as 'AtoL'.

Assessment for Better Learning, known as 'ABeL'

The Victoria University College of Education was known as Wellington College of Education up until January 2005.

All in-depth work includes participation of the principal and all teaching staff. 


\section{CHAPTER TWO}

\section{Literature Review}

\subsection{Background}

There is a large and growing body of literature and research both on formative assessment and on classroom feedback. The Assessment Reform Group, a group of academics in the United Kingdom concerned about the increasing emphasis on summative assessment, commissioned Paul Black and Dylan Wiliam to carry out an extensive review of the research literature about formative assessment strategies and their impact on pupil attainment. Black and Wiliam (1998a) acknowledge two previous and substantial review articles in this field, and cite one by Natriello (1987) and the other by Crooks (1988) as baselines for their review. They prepared a lengthy review using material from 250 of these sources. The three questions they set out to answer were:

1. Is there evidence that improving formative assessment raises standards?

2. Is there evidence that there is room for improvement?

3. Is there evidence about how to improve formative assessment?

They wrote a summary booklet Inside the Black Box (1998b) that sets out their findings in a way that is practical and easy to read. They found there was strong evidence to show that formative assessment and frequent feedback helps enhance learning, and that such work actively involves and uses results to adjust teaching and learning. They concluded that, when carried out effectively, informal classroom assessment that provides constructive feedback to students is "at the heart of effective teaching" (p.2). They also found that current practice includes an emphasis on quantity and presentation rather than quality in relation to learning, and suggestions about how work can be improved. They did not find that the third question, "Is there evidence about how to improve formative assessment?" was sufficiently answered by their initial review. As a result, they, with a team of researchers, carried out an investigation in the Medway and Oxfordshire LEAs. ${ }^{10}$ Each authority provided advisory staff and selected three secondary schools each with two science and two mathematics teachers. In addition, there was sustained work with some primary schools. The result was reported as Working Inside the Black Box (Black et al., 2002) and the answer to their third question "is there evidence about how to improve formative assessment?" was again clear and

\footnotetext{
${ }^{10}$ Local Education Authority (LEA), England and Wales
} 
positive; there was evidence that formative assessment could be improved. One of the key teaching strategies identified as evidence for improved formative assessment was feedback, as shown by Ramaprasad (1983) and Sadler (1989).

Black and Wiliam's (1998b) review, with its clear and practical summary reports, has been of significance internationally and has also influenced work in New Zealand. The impact has been a refocusing of attention to the quality of what happens in the classroom (or Black Box). This has influenced policy makers, been the motivation for further research and has informed teacher professional development programmes. It has certainly been of significance to this study.

\subsection{Formative Assessment}

Different assessment terms can cause problems and the extent to which 'formative' and 'summative' assessment purposes can coexist successfully is not always clear. Research, particularly in the United Kingdom, has identified the problem that much practice emphasises assessment of learning rather then assessment for learning and therefore misses opportunities to use assessment to improve learning (Black \& Wiliam, 1998b). An explanation for the difficulty with assessment, identified also by Butterfield, Williams and Marr (1999), may lie not only in processes of contestability, but also in fixed ideas of assessment that may be historical.

According to Gipps (2000), feedback from the teacher to the student, a key link between assessment and learning, can be analysed in terms of the power relationship between teacher and student. She describes traditional assessment as a hierarchical relationship between teacher and student where the teacher sets the task and determines how performance should be evaluated. The student's role is to be the object of this activity and, through the completion of tasks and tests, to be graded. Gipps argues that these traditional assumptions about assessment should be challenged. Perhaps some of the difficulty with assessment could have been avoided had it been realised that, as Black and Wiliam (2003) suggest, "it has been clear from their earliest use that the terms 'formative' and 'summative' applied to the functions they served rather than the actual assessments" (p.624).

While it is not the intention to enter into the debate, the writer acknowledges that summative assessment data should be used, as opposed to just recorded, in some way that benefits the student. The purpose for gathering any classroom assessment information should surely be to have an impact on teaching, learning and 
achievement. The information should be used to inform programmes, choice of assessment tasks, and teacher practice and reflection "how does my teaching impact on my students?" However, the focus of this study is on the principles of formative assessment (assessment for learning) and not on the practice of repeated assessments which tend to be summative.

A number of writers discuss feedback in a formative assessment context, and this will be explored further. The work of Black et al. (2002), Black and Wiliam (1998b), and Gipps (2000), has offered a fresh look at formative assessment. They have moved the thinking from: assessment becomes formative if it happens to take place in the middle of something, to assessment becomes formative if it has certain elements and conditions present. When students undertake new learning or are involved in a learning activity they need to know what the learning is, why it is important and how they will know they have been successful. If these conditions are present, the teacher and students have expectations, or criteria, on which to give feedback.

Dixon and Williams (2000) investigated teachers' understandings of formative assessment. They undertook an exploratory study extending four phases with forty randomly selected primary school teachers. Each phase involved a group of ten teachers at teaching levels between Years 1 and 8 . The teachers were interviewed and were generally found to have a confused notion of the nature, place and purpose of formative assessment in the teaching learning process. The writers suggest that to increase teachers' knowledge of formative assessment there needs to be a more planned approach to professional development which considers in detail theories of formative assessment, which are linked in turn to theories of how children learn. Black and Wiliam (1998b) also identified a need for effective programmes of formative assessment for teacher development. They refer to this as "the evolution of effective teaching" (p.10) and suggest that what is required is careful scrutiny of all components of a teaching plan. In doing so they highlight the key components of formative assessment as: choices of tasks that are justified in terms of learning aims; building in opportunities for students to communicate their evolving understanding; discussion; feedback; marking; questioning; observation; and self and peer assessment.

Whatever aspect of formative assessment is investigated, the reports reflect the same message: formative assessment strategies do raise standards of attainment. It is clear, however, that these aspects are reliant on the existence of each other in 
order to be successful. This is implicit in Black and Wiliam's (1998b) comment that "feedback to any pupil should be about the particular qualities of his or her work, with advice on what he or she can do to improve, and should avoid comparisons with other pupils" (p.9). Gipps (2000) says that ideally, there should be opportunities for tasks and criteria to be discussed, clarified, and even negotiated with the pupil, so that assessment becomes a more collaborative enterprise in which the pupil has some input. An example of this is highlighted in research about feedback and marking which shows that, even if marking is understood, it has more impact on children's progress if it is focussed on the learning intention and suggests explicit strategies for improvement (Black \& Wiliam, 1998b; Clarke, 2000; Gipps, 2000; Hattie, 1999). Feedback focussed on learning intentions will involve shared expectations for the learning or the task. If these expectations are not clear and have not been discussed, what do students use for self-assessment, or assessment of their peers?

Torrance and Pryor (1998) concluded from their study of formative assessment that, "teachers may be better advised to think of formative assessment as part of their pedagogy" (p.152). As a result, they present contrasting models of formative assessment as a way of demonstrating how different teaching approaches fit with different assessment approaches. They identify two conceptually distinct approaches to classroom assessment, which they term "convergent" and "divergent". "Convergent assessment aims to discover whether the learner knows, understands or can do a predetermined thing. Divergent assessment aims to discover what the learner knows, understands or can do" (p.153). The divergent approach as studied in the literature, relates to formative assessment and follows a constructivist, rather than behaviourist, view of learning. This is based on interpretations of constructivism where students are at the centre of the learning process and actively engage in their own knowledge construction.

Gipps (2000) argues that constructive assessment in classrooms can be a valuable impetus for learning and explains that in 'constructing' the teacher shares power and responsibility with the pupil. Such a situation would allow more opportunities for establishing a teacher/pupil relationship based on power with the pupil as opposed to power over the pupil. She also found that, "this type of feedback encouraged students to assess their own work and provided them with strategies that they could adopt to develop their work" (p.6). Bishop, Berryman, Tiakiwai and Richardson (2003) also discuss the importance of relationships, the sharing of roles and power between teacher and student, and an academic focus for feedback. 


\subsection{Feedback}

The literature makes it clear that formative assessment practices can be improved and that an important part of this improvement would be to do with the quality of feedback and use of constructive strategies. There is strong evidence that feedback makes a difference to student achievement. Black and Wiliam's (1998b) analysis reinforces the importance of feedback and the positive benefits for learning and achievement across all levels, knowledge and skill types and content areas. The emphasis on feedback for learning has resulted in a range of research projects investigating feedback quality.

Ramaprasad (1983) established the aspects which determine the quality and effectiveness of feedback. He focussed on necessary conditions, which included helping children to close the gap between current performance and desired performance. He argues that information about the gap is considered as feedback only when it is used to alter the gap. Sadler (1989) simplified this description of the effects of feedback and established three conditions for effective feedback to take place. The learner has to:

a) possess a concept of the standard (or goal, or reference level) being aimed for

b) compare the actual (or current) level of performance with the standard, and

c) engage in appropriate action, which leads to some closure of the gap (p.121).

Sadler suggests that in many educational settings, teachers give students feedback about how their performance compares to the standard, but the feedback often falls short of what is actually necessary to help students close the gap. He argues that for students to be able to compare performance with a standard, and take action to close the gap, they need some of the same evaluative skills as their teacher.

Boston (2002), in her discussion about the purpose and benefits of formative assessment, also mentions feedback. She too highlights how feedback helps learners become aware of the gaps between the desired goal and their current knowledge and guides them through action necessary to obtain the goal.

The focus of a study in Suffolk (Suffolk County Council, 2000) resulted in a summary of 87 hours of classroom observations in 24 schools across the full range of curriculum. The schools were selected at random and then invited to take part. As well as observing teachers in their classrooms, the investigators spoke to students and looked at their work and spoke to teachers and examined related 
documentation. The study was in the context of 'assessment for learning', which is explained by the Assessment Reform Group (2002).

Assessment for learning is the process of seeking and interpreting evidence for use by learners and their teachers to decide where the learners are in their learning, where they need to go and how best to get there (p.1).

The study set out to determine the extent assessment for learning was being used in Suffolk schools; to try and gauge the effect on learning; and to find if there was evidence to indicate how formative assessment could be improved. These questions are similar to those of Black and Wiliam (1998b), and the Suffolk study sought specific information about classroom practice in their own region. The findings in the report (Suffolk County Council, 2001) summarise what was found to make a "discernible difference to pupils' learning" (p.1). The emphasis was on marking and feedback, and the use of questions to promote learning, both from teachers and learners. It was argued that to develop learners' skills of self-assessment, feedback needs to be two-way, and that the classroom culture is one of achievement; that is where acting on feedback has a consequence for students.

Knight's (2003) research was motivated by a lack of definitive research about teachers' feedback in mathematics. She examined the quality of teacher feedback to students in two New Zealand primary schools selected randomly from those involved in the Numeracy Development Project ${ }^{11}$. She gathered 349 examples of oral feedback over six lessons, and collected a total of 62 samples of written feedback from students' mathematics books. Teachers were also asked for their own perceptions of feedback and found that they struggled "to define effective feedback in any detail" (p.42). Knight found that teachers' feedback was mainly general and tended to reflect effort and attitude of the learner rather than the actual learning that had taken place.

All these findings strengthen the view that it is the quality not quantity of feedback that needs closest attention. For the purpose of this study, 'feedback'12 refers to the three key conditions identified in the literature reviewed: current achievement, desired goal, and strategies to succeed.

11 The Numeracy Development Project is a Ministry of Education funded intervention for junior primary, middle primary, intermediate, and early secondary students.

2 Some educators use the terms 'feedforward' alongside feedback. Feedforward refers to next steps comments. 


\subsubsection{Types of Feedback}

The need to develop a stronger conceptual framework for 'feedback' to pupils on the basis of assessments was a motivation for Tunstall and Gipps' (1996a) investigation. Their research resulted in a broad framework: feedback may be evaluative (that is judgmental) or descriptive (that is achievement or competence related) (p.188). Once the data were interrogated and categorised, the following framework, see Table 2.1, emerged. Within the two major categories are four types of what they call "assessment feedback" and each type has been subdivided creating a "dualistic structure" (p.189).

Table 2.1. Tunstall and Gipps' (1996b) Feedback Typology

\begin{tabular}{|l|l|l|l|l|l|l|}
\hline \multicolumn{3}{|c|}{ Evaluative Feedback } & \multicolumn{3}{c|}{ Descriptive Feedback } \\
\hline Positive feedback & \multicolumn{2}{c|}{ Negative Feedback } & \multicolumn{2}{c|}{ Specifying Feedback } & \multicolumn{2}{c|}{ Constructing feedback } \\
\hline & & & &
\end{tabular}

Several other studies also focussed on, or used, different categories of feedback. The same categorisations were used as a framework for Hargreaves, McCallum, and Gipps' (2000) more recent research where they looked in detail at teachers' teaching, assessment and feedback strategies in primary classrooms. They chose, in joint negotiation with school principals and senior advisers, a sample of 'expert' teachers from two LEAs. The research took place in twenty schools with eleven teachers of Year 2 and twelve teachers of Year 6. In mid-1997, the researchers interviewed head teachers and observed lessons and towards the end of 1997, they observed up to five lessons in each of the twenty-three classrooms. They held postobservation interviews and involved teachers in discussion about theories of learning. In early 1998 there was a further visit to ten case study teachers. Two lessons were observed in each classroom and the teachers took part in a 'Quote Sort' activity. Teachers sorted fourteen quotes, which focussed on teaching, assessment and feedback strategies, and on pupil learning. In mid 1998 the 'Quote 
Sort' activity was undertaken with the non-case study teachers and towards late 1998 there were focus group interviews in both LEAs. What they found was that, depending on how teachers perceived learning to come about, and what sort of learning they hoped to encourage, teachers used a repertoire of feedback strategies in order to bring about transformation in learning. This work confirmed that teachers use a repertoire of feedback strategies that are easily placed on the Tunstall and Gipps' (1996b) typology. They conclude that, in part, choice of feedback strategies depends on teachers' beliefs about how children learn.

The difference between evaluative and descriptive feedback is also the focus of a study by Davies (2003). She argues that descriptive feedback supports learning because it reduces the uncertainty by telling students what is working and what is not. In contrast, she suggests, evaluative feedback, which is usually encoded (letters, numbers, other symbols) and includes praise, punishments and rewards, does not give enough information for students to understand what they need to do in order to improve. Alfie Kohn (1993) refers to this as "the praise problem" and states that while some approving comments are not only acceptable (but positively desirable) some are neither. He suggests that the difficulty could be because different people mean different things by 'praise' or 'reward' or 'positive feedback'. $\mathrm{He}$ argues that: "young children don't need to be rewarded to learn; at any age, rewards are less effective than intrinsic motivation for promoting effective learning; rewards for learning undermine intrinsic motivation" (p.96). Crooks (1988) agrees that praise should be used sparingly and where used should be task specific whereas criticism (other than simply identifying deficiencies) is usually counterproductive. He argues that feedback should be specific and related to need (p.469).

Ronayne's (2002) research focussed on written feedback and teachers were asked to give a particular type of feedback. He investigated eight separate occasions, across a range of subjects and secondary school age groups (11-13 years), on which teachers marked their pupils' work and gave written feedback. Each case study followed the same procedure. When the task was completed, the teacher marked the work with formative feedback (no grades) and then the comments were analysed. After the students received the written feedback, they were questioned about the feedback they received. The categories Ronayne identified and used were 'organisational', 'encouraging/supportive', 'constructive', 'think', and 'challenging'. While these appear to be different, there are elements that are very similar to evaluative and descriptive. He describes 'organisational' as dealing with such things as date, title, and correction of spelling, 'encouraging and supportive' with praise 
and ticks, and 'think' when the answer is not corrected nor is there any direct teaching, such as 'unnecessary'. These have clear similarities to evaluative feedback in that there is no focus on quality. He explained 'constructive' comments as showing how something could be done or built on, and 'challenging' as taking a task from explanation to evaluation. These categories are work focussed and similar to descriptive feedback.

In a similar way, Hattie and Jaeger (1998) talk about forms of feedback that are positive, such as reinforcement, corrective feedback, remediation and feedback, diagnoses and feedback, and mastery learning. They also discuss immediate (often verbal) versus delayed (often written) and less effective forms of feedback such as extrinsic rewards, and punishment. The effectiveness of these forms of feedback was also a discussion point for Gipps (2000).

Another investigation to do with the effectiveness of different types of written feedback was undertaken by Butler (1988) and his experiment involved 48 11-yearold Israeli students selected from 12 classrooms across four schools. He investigated effectiveness in terms of actual achievement, as opposed to enjoyment, motivation or preference. The students were given a variety of tasks to complete individually and in pairs and each received one of three types of written feedback on their work. One third of the group were given individual feedback against criteria explained beforehand, a second group were given grades only derived from the scores on the preceding session's work, and a third group were given comments and grades. Scores on the work done in each of three sessions served as outcome measures. For the 'comments only' group, scores increased by about one third between the first and second sessions and remained at this higher level for the third session. The 'comments with grade' group showed a significant decline in scores across the three sessions, whilst the 'grade only' group declined on the first session, showed a gain on the second session but this was not subsequently sustained on the third. The only group that improved was the 'comments only' group and their scores increased by about one third. This established that whilst pupils' learning can be advanced through comments, the giving of marks or grades has a negative effect in that pupils ignore the comments when marks are also given. These findings illustrate conditions by means of which formative feedback can be made more or less effective in normal classroom work. They also reinforce the idea of the quality of feedback. 
While John Hattie (1999) places much on the need for "dollops of feedback" as a key to improving education, he talks of feedback as "providing information how and why the child understands and misunderstands, and what directions the students must take to improve" (p.9). He also highlights the importance of how the student has understood the information and the importance of constant reflection, or self-assessment, "How am I going?" (p.13). It is the kind of feedback that can make the difference.

Whatever the terminology or how the categories are named, what the writers have in common is a strong belief that a 'descriptive' style of feedback is what makes a difference. This view is also reflected by students themselves, an example of which came from the Suffolk study (Suffolk County Council, 2001) when a student said, "I could do better if I was told what could be better" (p.100).

Nicol and Macfarlane-Dick (2004) in their exploration of how assessment might be used to effectively promote student learning found that assessment can generate feedback information that can be used by students to enhance learning and teaching. They used the Black and Wiliam (1998b) review to identify broad principles of good feedback practice. These were intended as tools that teachers might use to analyse and improve their own formative assessment and feedback practices. Their provisional list identifies feedback that:

- Supports the development of self-assessment (reflection) in learning

- Encourages teacher and peer discussions around learning

- Helps clarify what good performance is (goals, criteria, expected standards)

- Provides opportunities to close the gap between current and desired performance

- Delivers high quality information to students about their learning

- Provides information to teachers that can be used to help shape the teaching and learning (p.3).

The New Zealand 'National Assessment Strategy' ${ }^{13}$ aims to enhance teachers' assessment literacy. The strategy focus is on the use of assessment information, gathered from a variety of sources, using quality tools, to inform teaching and learning. Important components of the strategy include the learners: student involvement in goal setting, self and peer assessment, and in giving and receiving feedback.

\footnotetext{
${ }^{13}$ The National Assessment Strategy is on http://www.tki.org.nz/r/ass/strategy e.php
} 


\subsubsection{Feedback and the Student Voice}

There has been a limited amount of research in New Zealand and internationally that probes students' perceptions and views of their learning, or investigates what they think about feedback. Smith (1996) agrees that historically there have been minimal attempts to include children's views and Pollard (1997) reinforces this with his argument that learning must be looked at from a new perspective, from the learner's point of view. Since the late 1990s, this has in fact happened, and there are now suggestions that research approaches, grounded in pupils' accounts, are needed to fully understand feedback (Gipps \& Tunstall, 1998; Pollard, 1997). Bourke (2001) stresses the need to know what the student understands of their learning before the impact of teaching and assessment practices can be understood. Because the student's voice in educational research provides another dimension, their views are being increasingly sought.

Weeden, Winter, Broadfoot, Hinett, McNess, Tidmarsh, Triggs, and Wilmut (1999) for the Learn Project ${ }^{14}$ interviewed over 200 students of different ages (the range was over Years 3-13) to gain insights into their perceptions of themselves as learners and how they think they learn best. They believed that the child's voice is often ignored. They found that most students valued feedback, particularly oral feedback where confusions could be clarified, but that many students commented critically on the quality of feedback. They also found evidence that much feedback was either unfocussed or of little use in improving work and that there was a wide range of forms used, some of which were not understood by students. Students demonstrated the variability of feedback and a sometimes-confused perception of its intention. For instance, several students made the following comment, "She puts A1 or B2. A is very good, I can't remember what the number is for". Or, "One time I did an essay and I didn't think I did very well but he gave me A1. I didn't think l'd written enough but he just said very good" (p.8).

While feedback is seen as a key to improving learning, this notion has yet to be embedded in practice. Isabelle Kearsley's (2002) study looked at one student cohort (Year 7) in Queensland and probed their perceptions of themselves as learners in the context of reading. Her research suggests the need for both teachers and parents to give regular explicit feedback to children and to stress more forcibly the objectives and value of literacy skills. During November 1998, 185 students from 13 Year 7 classes in 11 schools completed the questionnaire. Of the total cohort, $39.5 \%$ of students agreed that they did not know what their teacher thought of their work, and $33.5 \%$ were not sure

14 Learners' Expectations of Assessment for Learning Nationally (The Learn Project) (Weeden et al., 1999) 
whether they knew or not. The implication here is that the majority of students did not know for sure what aspects of their work led to the good marks. Kearsley argues that, "If students have not been trained to evaluate their own performance, they may be unaware of what constitutes 'good' or 'success"' (p.12). She says students must receive early feedback from the teacher that they can understand and act upon. The other $27 \%$ of students in the study disagreed with the statement and were satisfied that they did know what their teacher thought. However, it was clear that this knowledge is not always helpful to the student. The student with the most negative attitude to school was sure about what he believed his teacher thought of his work: "She says it is horrible, disgusting". Kearsley does suggest that it is difficult to know whether this belief is part of the cause or part of the result of his negativity. She asks the question, "had the perceived bluntness of his teacher's feedback brought any improvement, made him determined to show her what he can do, or destroyed his motivation completely?" (p.11).

The advent of Tomorrow's Schools (Lange, 1988) and subsequent education reforms in the late 1980s and early 1990s began a period of dramatic change for New Zealand education. A Ministry of Education was established along with an 'Achievement Initiative' that had an emphasis on three areas, namely, curriculum reform, assessment and learning, and professional development. The Ministry made a considerable long-term investment in NEMP, which has been developed by Terry Crooks and Lester Flockton. The goal of this project $^{15}$ is to provide detailed information about what children can do so that patterns of performance can be recognised, successes celebrated, and desirable changes to educational practices and resources identified and implemented. A number of NEMP publications have been produced since 1993. The low percentage of students who were confident they knew what the teacher thought is similar to what was found by Flockton and Crooks (2001). The reading and speaking survey results of 2000 were of particular interest and came from the questions:

How good are you at reading?

How good does your teacher think you are at reading?

Does your teacher tell you what you are good at in reading?

Does your teacher tell you what you need to improve at in reading?

How do you feel about how well you read?

15 Each area of the school curriculum that is a part of NEMP's assessment and reporting are repeated on a fouryear cycle. The results are then compared in a range of ways for the Year 4 and Year 8 students. 
While $80 \%$ of students were very positive about how good they were at reading, more than a quarter of them did not know how good their teacher thought they were. They said their teacher never told them what they had to do to improve in reading. This raises an important question. What information do these students use to form perceptions about their achievement if they do not get it from their teacher, and is the information accurate?

Of special significance to New Zealand schools is the Te Kotahitanga research project undertaken by Bishop et al. (2003). The project sought to investigate, by talking with Māori students (and others who played a part in their education), about what was involved in improving their educational achievement. The sample included a range of engaged and non-engaged Years 9 and 10 Māori students from four mainstream ${ }^{16}$ schools. Years 9 and 10 students were deliberately chosen because this is where the statistics on low achievement, retention and suspension problems are at their worst (Bishop et al., 2003). On the basis of the suggestions from these students, the research team developed an Effective Teaching Profile. The longerterm project gathered a number of narratives of students' classroom experiences. It was from these stories that the rest of the project developed. The Effective Teaching Profile formed the basis of a professional development intervention, that when implemented with a group of 11 teachers in four schools was associated with improved outcomes for Māori students in those classrooms. They found that when teacher-student relationship and interaction patterns changed, so did Māori students' behaviour. Changes, at times dramatic, included increases in: on-task engagement and work completion; the cognitive levels of the classroom lessons; short-term achievements, and Māori students achieving at an appropriate level along with their non-Māori peers. Further evidence of the increased engagement of students was a reduction in absenteeism.

Several other studies also show firm evidence that innovations designed to strengthen practice produce substantial learning gains. Many of these are to do with strengthening frequent feedback that students receive about their learning. A smallscale intervention study by Shirley Clarke (2000) concentrated on 'distance marking', or the marking of students' work away from the student. Eight teachers across a range of rural and metropolitan areas in England were involved as well as 48 children across the ability range from Year 4 (9-year-olds) to Year 6 (11-year-olds). Teachers were asked to share learning goals orally and visually, use codes to establish success

Māori in the mainstream refers to English medium (or English speaking) classrooms. 
and improvements against the learning goal, and write a 'closing the gap' prompt. Teachers and children were interviewed before and after the trial. During the pre-trial interviews Clarke looked into teacher and student perceptions of marking. Most teachers $(75 \%$ or more) described the purpose of marking as some kind of feedback to the child. Children's perceptions about the purpose of marking varied across the ability range with just under half of the above average, one third of the average, and a quarter of the below average children describing marking as for the child. After the intervention, there was a noticeable shift in student opinion and the ability of the students no longer featured. Two thirds of each group now saw marking as for the child. By the end of the trial period, teachers and children demonstrated a change of emphasis from activity to learning. The new focus made marking accessible for all students and the inclusion of comments to 'close the gap' had the greatest impact in helping children to know how to improve and apply what had been learnt to future writing. Clarke concludes that distance marking has always been a poor substitute for oral, face-to-face marking, because it relies on the child being able to make sense of the words and marks alone.

The research that most influenced the writer's investigation focus was undertaken by Tunstall and Gipps (1996a) who asked two key questions: What sort of feedback do teachers give children? And, How do children interpret, understand and act on this feedback? The study was carried out in six London schools in five local education authorities over 1994-95. The eight teachers of Year 1 and Year 2 students included male and female with a range of teaching experiences and ethnic origins. In six schools, forty-nine children were selected from eight classes on the basis of subject attainment, overall academic ability and underachievement. The research, which involved teachers and children directly through interviews and fieldwork, was carried out throughout the school year with regular classroom observations and recording. Interviews were taken with children twice a year, examination of children's work for written feedback was carried out throughout the year and school policy documentation was collected. Discussions with children provided a range of insights into how they perceived feedback, what they felt about it and how they used it. It was these comments that were categorised and created the typology discussed above.

\subsubsection{Feedback and Instruction}

Hattie and Jaeger (1998) responded to the Black and Wiliam (1998b) review by proposing a model of teaching and learning that demonstrated the tight interplay between assessment, learning and feedback. In his inaugural lecture (August 1999) at the University of Auckland John Hattie explained that the model was based on 
three assumptions one of which was "that student achievement is enhanced as a function of feedback" (p.2). His meta-analysis and research synthesis identified a range of positive and negative effects on schools and teaching. From the positive effects, he identified feedback as the single most powerful moderator. Hattie's belief in the power of feedback remains strong, and in 2002 as guest speaker at the national primary principals' conference, he said, "If there is one systematic thing that we can do in schools that makes a difference to kids learning, it's this notion of feedback. It is the most significant thing we can do that singularly changes achievement" (Cassette).

Later in a paper presented to the NZCER ${ }^{17} 2002$ conference, Hattie contrasted the differences between the expert, accomplished, and experienced teacher. He found that expert teachers monitor students' learning, give students feedback and offer information about their understanding that guides them to higher levels of comprehension. Experts, he says, can detect when students are not understanding, can diagnose students' interpretations, and tailor the feedback they give to correct misunderstandings or help create new learning connections.

There appears to be differing views on whether assessment is part of instruction and whether questioning is part of feedback or part of instruction. Knight (2003) argues there is confusion between instruction and feedback and suggests that the difference of opinion by prominent educators in this area only adds to the confusion. Kearsley (2002) disagrees and asserts that assessment and feedback are part of instruction and influence students' perceptions of their ability. Similarly, Black \& Wiliam (1998b) argue that there is no clear line between instruction and assessment.

\subsubsection{Feedback and Underachievement}

There is a challenge for educators, reflected in the literature, to address underachievement. Underachievement in this context refers to those students who do not achieve to a standard that should be expected of them. These students appear to systematically underachieve with no particular consideration of how this might change.

Timperley (2004), from her research into the sustainability of professional development in literacy, explained that successful professional learning communities based their learning on evidence-based inquiry. She found the students of teachers who shared samples of student work, made comparisons and tested their

\footnotetext{
${ }^{17}$ NZCER - New Zealand Council of Educational Research. 2002 Conference Proceedings.
} 
assumptions had higher levels of achievement. She suggests that evidence about the impact of what is being taught on what is being learned needs to be scrutinised for any significant learning around practice and improving student achievement to occur.

Boston (2002), whose article addresses the benefits of formative assessment to provide feedback over the course of instruction, suggests that "this type of feedback may be particularly helpful to lower achieving students because it emphasises that students can improve as a result of effort rather than be doomed to low achievement due to some presumed lack of innate ability" (p.2). Gipps (1994) argues that an "educational assessment paradigm" (as opposed to a paradigm emphasising testing) is essential to the raising of educational standards and that an educational paradigm depends upon a high level of understanding and involvement by teachers in assessment practices (p.158). "Part of the reason that formative assessment works appears to be an increase in students' 'mindfulness'” (Bangert-Drowns et al., 1991, p.15).

The impact of teachers' beliefs about the learning abilities of their students cannot be underestimated. Black and Wiliam (1998b) state that any 'tail' of low educational achievement is a "portent of wasted talent" (p.4) and outline one study they reviewed that is entirely devoted to low-attaining students and students with learning disabilities. It shows that frequent assessment feedback helps both groups of students enhance their learning and that what teachers believed about their pupils' learning, and their ability to learn, influenced the learning of their pupils.

The education community in New Zealand also has concerns about a tail of underachievement in which Māori students are over-represented. Bishop et al. (2003) sought to investigate what was involved in improving educational achievement for Māori students through the gathering of narratives about classroom experiences. Similarly, they found that the major influence on Māori students' educational achievement lies in the minds and actions of their teachers. The narratives clearly identified that teachers who focus on what is lacking in students have low expectations, and for students creates self-fulfilling prophesies of failure. When teachers increased caring, raised their expectations, interacted meaningfully with more students, and focussed on student learning and their 'learning how to learn', Māori students became more academically engaged, completed more work in class, and attended class more regularly. (This view of teacher effects has not escaped criticism as can be seen in a critique by Nash and Prochnow (2004) in the New Zealand Journal of Educational Studies.) In the discussion about the student-teacher relationship some key approaches were identified that refer to 
the quality of interactions: academic feedback and feedforward rather than behavioural feedback, co-construction of content and the process of learning; and learning interactions increasingly in pairs or carefully constructed groups. They argue that fundamental to these approaches is an understanding that classroom strategies need to be used, practised and perfected to promote power-sharing interactions between teachers, students, and those parenting the students, so that learners can initiate interactions beyond seeking instruction or compliance. This is similar to the argument put forward by Gipps (2000).

Bishop and Glynn's (2002) focus was on the issue of non-participation by many young Māori people and used Kaupapa Māori ${ }^{18}$ schooling as a model. A detailed study of Māori medium primary schooling identified a series of fundamental principles, which they extended into mainstream educational settings. These are similar to principles of formative assessment and include the teacher as a partner in the conversation of learning, learners as co-inquirers, and teachers and learners interacting and changing roles. They discussed critical reflection and learners becoming independent through processes of scaffolding.

\subsection{Summary}

The findings of the studies reviewed in the literature helped to clarify the focus for this thesis. Dixon and Williams (2000) reported that there was little understanding of formative assessment by New Zealand teachers. The comment by Gipps (1994) that formative assessment is an entirely integrated way of thinking about learning and teaching suggested that, as an area of investigation, it was too large for this thesis.

Black and Wiliam (1998b) identified feedback as an essential element of formative assessment and a wide range of the literature explored its complexities. The feedback typology created by Tunstall and Gipps (1996b) gave a useful tool for categorisation that could be replicated in a New Zealand setting.

The literature review has confirmed the focus of this thesis by finding a current shortage of research using the student voice, in a classroom setting, particularly in a New Zealand context.

Chapter Three discusses the methodology used firstly in the pilot study and then in the final research.

18 Kaupapa Māori: Traditional Māori methods of education are used and the curriculum is delivered in Te Reo (Māori language) 


\section{CHAPTER THREE}

\section{Methodology}

This chapter introduces the research method, ethical considerations, and an outline of the pilot study undertaken. It also explores the notion of evidence-base and a personal perspective based on the researcher's separate work in schools and classrooms. The purpose of the research was to probe primary school students' understanding of the feedback they receive. The research focus was determined after several attempts at clarification. While the focus was to be on formative assessment it soon became evident that as a topic it was too broad, and subsequently subtopics such as goal setting and self-assessment were considered. Finally, the focus was narrowed to feedback; to the giving and receiving of feedback; to the feedback received by students. The attention was then given to student perceptions of the range (verbal and written) of feedback they receive. Once the focus had been established a further dimension was added, what had teachers intended by their feedback? A process for the research was established and interview questions were created to answer the following research questions:

What are students' and teachers' understandings of feedback in New Zealand classrooms?

Does feedback given in New Zealand classrooms match the findings of Tunstall and Gipps (1996a, b) and fit into their typology?

The evidence from what the students say in response to the interview questions was triangulated as demonstrated in Figure 3.1. Students' general comments were checked with their teachers who then had an opportunity to respond. The findings were also compared with the research of others. Denzin and Lincoln (1998) suggest that the use of multiple methods, or triangulation, reflects an attempt to secure an indepth understanding of what is being questioned and is not a strategy of validation but rather an alternative to validation. 
Figure 3.1: Triangulation of Data

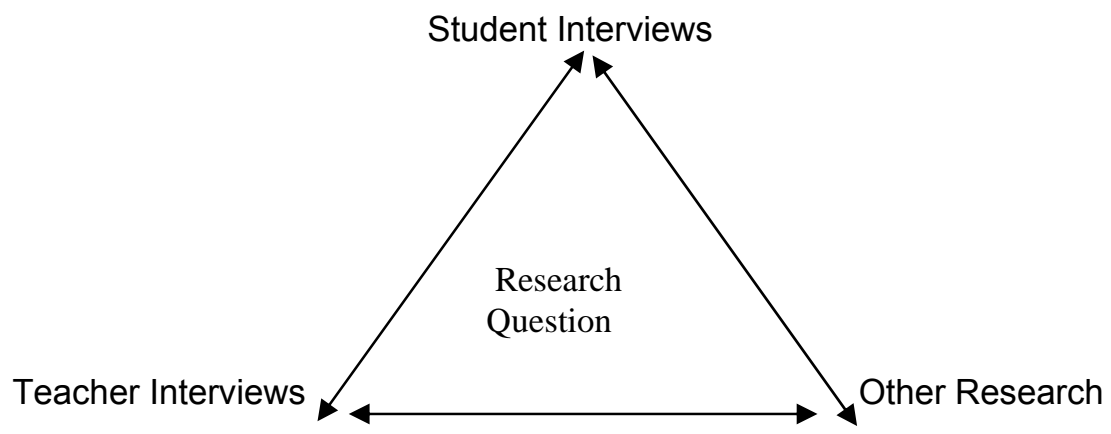

In order to anchor the research, the research question has followed on from work in the United Kingdom. The approach is similar to that of Tunstall and Gipps (1996a) but uses a smaller sample and less fieldwork. There has also been little in the way of similar research carried out in a New Zealand situation, which has opened up this opportunity.

\subsection{Qualitative Research}

Denzin and Lincoln (1998) maintain that qualitative research has no one methodology, no distinct set of methods, and no theory, or paradigm, that is distinctly its own. Qualitative methods are used, for example, in education, anthropology, sociology, cultural studies and evaluation to name a few. There are also many different kinds of approaches and qualitative research uses different strategies of inquiry that include case study, ethnology, grounded theory, applied action research and phenomenology. Denzin and Lincoln (1998) describe phenomenology and ethnomethodology as approaches concerned with "realityconstituting interpretive practices that examine how people construct and give meaning to their actions in particular social situations" (p. xvii). Many researchers in this tradition use interviewing as a way of studying the interpretive practice, and this is where this research design makes its links. Qualitative interpretations are constructed when the writer attempts to make sense of what he or she has learned.

The use of qualitative methods (Denzin \& Lincoln, 1994,1998; Schwandt, 1994), in this study may present particular challenges. This is not a study of any one classroom but a study of a process that takes place within classrooms. My own experience in classroom observation positions me as an insider. Although I had no established relationship with the students involved, accessing the setting, making decisions on "how to present oneself" and establishing rapport were not difficult 
(Denzin \& Lincoln, 1994, p.654). However, qualitative research in the classroom has its own set of difficulties.

There are many factors in a student's life that will impact on how he or she might respond at any given time. There are also many factors in the daily life of a school that can impede the research process or even change its direction. Because the researcher is a guest of the school some control must be handed over to the school. As Denscombe (1998) states, "Sponsors and gatekeepers cannot be disregarded once their initial approval has been attained. In reality, they exercise continued influence over the nature of the research" (p.77). Guests do not take over the arrangements or organisation of the place they are visiting. An example of how the situation can be problematic is outlined further in the chapter.

\subsection{Pilot Studies}

Two trials were conducted before the final study. In order to test the feasibility of the research plan a small pilot study was developed ${ }^{19}$ to test the interview questions.

Before the pilot study was undertaken, several attempts were made to refine the interview questions. Six initial questions for the students were devised in order to answer the research question.

These questions were then reworded and possible probes included so that student responses could be explored. Once these questions were understood by the participants and produced appropriate answers, they were reworked to suit the age of the participants, and were used in the pilot study (Refer Appendix 1).

An initial study was carried out with five students from a school not involved with the final data gathering. All students from a Year 5 and 6 class were given a letter and permission slip to take home. From those returned, five were selected randomly. Each student was withdrawn from the class to participate in a 30-minute taped interview. The collation and analysis of the student responses indicated that the questions were still too broad and the information too general.

The initial inclusion of questions around goal setting was to get information about feedback for the next learning step. In other words, it was important to consider what happened as a result of feedback, and secondly did student goals reflect the feedback they had received? In analysis the questions did not easily make these

\footnotetext{
${ }^{19}$ The ethical guidelines as stated by the NZARE (1999) were followed for these pilot studies.
} 
links. Questions to do with goal setting were omitted and the emphasis returned to the original focus in line with the work of Sadler (1989) and Tunstall and Gipps (1996a, b) (Refer Appendix 2).

A second interview was planned and three different students from the same classroom were selected randomly to carry out the second pilot study. A third draft was used which incorporated two questions using projective techniques. These were added to the data gathering tools because the responses had a clear focus on what the students experienced, what they understood and how they felt about it.

\subsubsection{Analysis of Data from Pilot Studies}

The qualitative method of analysis was applied to the interview data. Although predominantly verbal, non-verbal responses such as facial expressions were noted at the time of the interview. The tapes were examined several times in relation to Tunstall and Gipps' (1996b) categorisations and for other emerging themes. Summaries of student responses were made under each of the questions and both similarities and differences were sought from the comments made.

\subsubsection{Findings of the Pilot Studies}

Firstly the information was examined under each of the questions. The first question was more introductory in nature, and asked the students what they enjoyed doing most in class. The second asked what they were best at and how they knew. Both girls replied that they were best at 'topic work' and one said she knew because "the teacher uses my book as an example ... and I get stickers." Many of the examples were to do with the quality of presentation rather than the quality of content.

The next phase of the data analysis utilised Tunstall and Gipps' (1996a,b) categorisations of 'evaluative' and 'descriptive' feedback, and their definitions of these terms. They suggest evaluative types of assessment feedback are rewarding, punishing, approving, and disapproving. In contrast, descriptive types of assessment specify attainment and improvement, and construct achievement and the way forward. The results such as the correcting and checking approach, and the use of marking codes were similar. There were also some examples of sensitive feedback from teachers suggesting how to improve work by making it more interesting or neater.

In response to the questions about how they knew they were doing well, the students described feedback such as "good work comments and stickers", or "ripping out pages and being told to repeat work". When asked how they knew what 
to do to improve their work they talked about teacher use of codes, abbreviations, or written suggestions. One student was asked to "use nicer words to make your work funny or more interesting". Overall, evaluative elements were the strongest in students' responses and much was positive. Positive feedback included "well done", "wow", giving a certificate and using work as an example for other students. Other negative responses included, staying in after school, and comments such as "you should improve your work" or "this doesn't make sense." A tally of frequency within these categorisations of 'evaluative' and 'descriptive' is shown in Table 3.1.

Table 3.1. Frequency in Feedback Categories

\begin{tabular}{|l|c|c|c|c|}
\hline & \multicolumn{2}{|c|}{ Evaluative } & \multicolumn{2}{c|}{ Descriptive } \\
\hline & Positive & Negative & Feedback & $\begin{array}{c}\text { Improvements/Next } \\
\text { Steps }\end{array}$ \\
\hline Student A & 6 & 2 & 2 & 1 \\
\hline Student B & 4 & 3 & 2 & - \\
\hline Student C & 4 & 3 & 1 & 1 \\
\hline & 14 & 8 & 5 & 2 \\
\hline
\end{tabular}

These small-scale pilot studies revealed some useful data on how students perceive feedback about their learning. There were a significant number of emerging factors that correspond with other research in this area. Although this was a small study, the indication was that students received evaluative feedback more easily and frequently than descriptive feedback and that they were more likely to know where they were in terms of their learning than where they needed to be heading. A high proportion of the feedback appears to deal with either presentation, or marks in competition with others in the class. The pilot studies gave enough information to make final decisions about the research methods and interview questions. At the conclusion of the pilot studies, the main study was initiated.

\subsection{Research Procedures}

\subsubsection{The Sample}

The study was carried out in two contributing primary schools in the greater Wellington area. Both schools were of a similar size and at the time of the interviews School A had a decile ${ }^{20}$ rating of 4 and a roll of 246. New Zealand Pakeha made up $78 \%$ of the students, Māori $11 \%$ and students from other countries $11 \%$. School B, with a decile rating of 10 , had a roll of $232,91 \%$ of which were New Zealand Pakeha, $7 \%$ Māori, and students from other countries accounting for $2 \%$.

20 A school's decile indicates the extent to which it draws from low socio-economic communities. 
Both schools had a slightly higher number of boys than girls. School A with $57 \%$ and School B with $53 \%$. The contrast between the decile ratings of the two schools is to do with the number of students from a low socio-economic background.

The research employed purposive sampling ${ }^{21}$ for the schools and teachers with the researcher asking "Given what I know about the research topic and about the range of people or events being studied, who or what is likely to provide the best information?" (Denscombe, 1998, p.15). The researcher who had coordinated a formative assessment intervention in both schools, and had delivered the programme in one, had developed some knowledge of the two schools and the teachers.

During initial discussions, the principal in each school was asked to select two teachers of Years 5-6 students (ages 9-10) from which a sample would be drawn. Each teacher was then asked to select four students to represent the range of diversity in their classrooms (ability, ethnicity and gender).

Dates were set for the interviews that were suitable for both school and researcher. Students in one class were particularly slow to return their permission slips and for one student selected the slip was never returned. This meant that further dates needed to be set and another student selected. All of this took considerable time and it was some months before the other three interviews could take place and then they had to be on two separate occasions.

The difficulties were still not over. On the first of two occasions it was the teacher who sent a student to the interview room. When the third student was to be interviewed, I went to the classroom myself. I was immediately struck that, at least en masse, the students appeared younger than I had expected. This was confirmed when the teacher informed me that they were Years 3 and 4 and not, as I had requested, Years 5 and 6 . So, I was faced with the need to make a decision before I unnecessarily took up any more of anyone's time. I decided to continue and to turn the situation to advantage. Three of the four students were Year 3. The advantage I saw was an opportunity, even if the sample was small, to look at students from more than one level. A situation where a researcher has had to change direction when dependent on others to make arrangements is not unique.

21 Purpose sampling is 'hand picked' for the research (Denscombe, 1998, p.15). 
Another difficulty I faced was that I did not know the students. It was, therefore, difficult to pick up on clues, like body language or a slow response, especially when clues appeared at times to be contradictory. I realised that I should avoid coming to an early conclusion from what may be simply a perception. I needed to give students time to reflect and respond and to remain aware that my own knowledge must not influence my own perception. The sample is outlined in Table 3.4.

The teacher selection was typical of teachers in New Zealand primary school classrooms. All four were New Zealanders, and all were female.

Figure 3.2: The design of the research

\begin{tabular}{|c|c|c|}
\hline \multirow{2}{*}{$\begin{array}{c}\text { SCHOOL } \\
\text { A }\end{array}$} & $\begin{array}{l}\text { Teacher } 1 \\
\text { (Years 3-4) }\end{array}$ & $\begin{array}{l}\text { Student } \\
\text { Student } \\
\text { Student } \\
\text { Student }\end{array}$ \\
\hline & $\begin{array}{l}\text { Teacher } 2 \\
\text { (Years 5-6) }\end{array}$ & $\begin{array}{l}\text { Student } \\
\text { Student } \\
\text { Student } \\
\text { Student }\end{array}$ \\
\hline \multirow{2}{*}{$\begin{array}{c}\text { SCHOOL } \\
\text { B }\end{array}$} & $\begin{array}{l}\text { Teacher } 3 \\
\text { (Years 5-6) }\end{array}$ & $\begin{array}{l}\text { Student } \\
\text { Student } \\
\text { Student } \\
\text { Student }\end{array}$ \\
\hline & $\begin{array}{l}\text { Teacher } 4 \\
\text { (Years 5-6) }\end{array}$ & $\begin{array}{l}\text { Student } \\
\text { Student } \\
\text { Student } \\
\text { Student }\end{array}$ \\
\hline
\end{tabular}

\subsection{Instruments}

The research instruments used were an interview for the students and a subsequent interview for the teachers.

\subsubsection{Student Interviews}

Interviews were held on the school site, face-to-face and in a quiet room away from others. The interviews lasted approximately 30 minutes depending on the length of introductions at the beginning. The questions were semi-structured to allow for interactive dialogue and clarification. They were planned with probes and follow-up questions were used to obtain clearer responses and greater depth. The decision to incorporate an open-ended interview was guided by the two aspects of the research question, feedback received and feedback given. 
The first question was a general one that aimed to hook the students into the interview and to start the thinking about what impacted on their enjoyment of a particular subject over another.

The second and subsequent questions began probing the student's recollection of feedback and conversations with their teacher. It was not until question 7 , however, that the term 'feedback' was used. This was a deliberate decision to reduce potential problems because of terminology and to avoid 'leading questions' (Denscombe, 1998). It was reasoned that by a later point in the interview, the focus would have become relatively clear to the students.

Projective techniques ${ }^{22}$ were also used. These allowed the students to imagine a situation and to answer questions that were not about themselves or their feelings. Two applicable situations were developed to tell part of a story, or set a scene, that the students could complete or elaborate on. These scenarios deliberately kept away from literacy and numeracy contexts because as government priorities there would be an inevitable school focus in these areas. The students were also asked general unrecorded questions about each scenario. Prior to Scenario 1, initial questions were asked about Lina's success and what the student thought she might have been doing and what the 'course' might have been. Responses were similar and fitness was suggested as the context and the school field as the 'course'. This example is illustrated below.

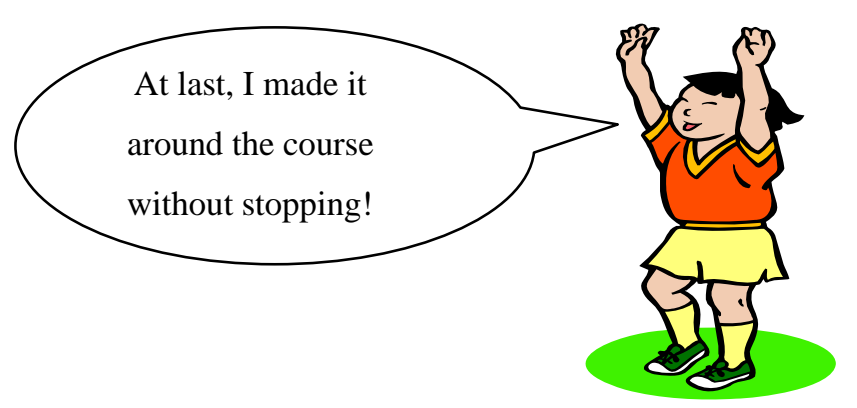

Scenario 1

What would the teacher say to Lina about her success?

What could the teacher suggest to Lina to do next?

Before Scenario 2 students were asked about 'social studies' and 'resources'. Although unrelated to the research this uncovered an interesting piece of

22 Projective techniques use a stimulus to project a person's attitude from the response. http://www.quickmba.com 
information. Only one student thought they had taken part in social studies, and no student could define 'resources'. This scenario is illustrated below.

For social studies Mere's group is discussing natural resources and the importance of managing these resources. The teacher has asked each group member to select a different resource to find information about. Peter has chosen water, Sina has chosen timber but Mere doesn't know where to start.

What would Mere's teacher do next?

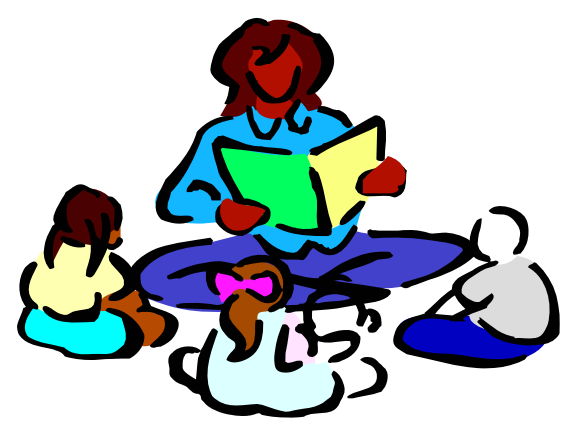

\subsubsection{Teacher Interviews}

Once the student responses were analysed questions were designed to interview each participating teacher (Refer Appendix: 5).

The purpose of the interviews was to discuss, in general, the students' responses (individual students' responses were not revealed) and to explore the teachers' understanding and meaning of feedback they gave. These interviews were also held on the school site, face-to-face and away from others and lasted about thirty minutes depending on how much teachers wanted to comment further about feedback. Because the questions had been developed as a result of student responses they were more structured than those for students.

\subsection{Ethics}

The researcher adhered to the ethical guidelines as stated by the New Zealand Association for Research in Education (NZARE, 1998). These guidelines, stated in the form of principles, ensure the rights and welfare of every person and organisation are protected. The principles relating to research participants have been checked in Table 3.5. 
A letter explaining the research and seeking permission to work in the school was sent to each principal (Appendix 4). A similar letter and permission slip was then sent to each teacher (Appendix 5).

A personal task was to develop rapport with the students so that responses given could be assumed to be honest. Experience as a teacher and adviser to schools had assisted with this. A letter seeking permission was carefully worded so that the parents would know their children could not be harmed and that the data would be kept secure (Appendix 6).

Confidentiality was assured in that no names or titles had, or would be, reported or revealed to any other party. All recordings have been locked away and will be destroyed one year after thesis completion.

Letters and information sheets, along with the research proposal, were submitted to the Ethics Committee of Victoria University of Wellington College of Education and subsequently approved.

Table 3.3: Principles relating to research participants (NZ Association for Research in Education, 1998, p.1-2)

\begin{tabular}{|ll|l|}
\hline \multicolumn{1}{|c|}{ Principles } & \multicolumn{1}{|c|}{ Indicators } \\
\hline 2.1 & $\begin{array}{l}\text { Harmful effects and } \\
\text { unintended } \\
\text { consequences }\end{array}$ & $\begin{array}{l}\text { Researcher care and sensitivity. One researcher } \\
\text { involved. Use of colleagues and participants to } \\
\text { check interview summaries and draft reports. }\end{array}$ \\
\hline 2.2 Informed consent & $\begin{array}{l}\text { Written research description and report details to } \\
\text { all concerned. Participants' consent with right to } \\
\text { withdraw. Parent consent for student involvement. }\end{array}$ \\
\hline 2.3 Confidentiality & $\begin{array}{l}\text { Results confidential - at no time would real } \\
\text { names of people, or organisations, be disclosed. }\end{array}$ \\
\hline 2.4 & Time taken & Student interviews 30-minutes maximum. \\
\hline 2.5 & Institutional \\
responsibilities & Researcher followed school suggestions. \\
\hline
\end{tabular}

\subsection{Data Collection}

Data were collected through the questioning of participants by interview. Tools included audio recorders and question sheets with probes and room for comments. At the completion of the interviews transcriptions of audiotapes were made for analysis. As indicated in the previous chapter, information gained generally as part of formative assessment advisory work was also included where it added to the evidence base. 


\subsection{Analysis of Data}

The research followed a qualitative approach (Denzin \& Lincoln, 1994; Heath, 1997) and the evidence came from what the students and teachers recalled about feedback through formal questioning. The teachers' questions matched those asked of the students and the responses could have been analysed in two different ways. If the sample had been larger, calculations could have been made but in fact, the work was placed in a qualitative paradigm, which meant that the research design did not depend on quantitative analysis.

The student and teacher responses were compared and analysed through interpretation.

The researcher used the transcriptions to undertake a content analysis and: cluster topics into categories; analyse the categories; code elements within the categories; and use explanations to answer research question/s (Denscombe, 1998, p.167).

For triangulation purposes, student responses were checked by their teachers who then had an opportunity to respond. The findings were also compared with the research outcomes of others.

\subsection{Limitations}

The results are based on a small-scale study and can only be viewed as an initial investigation into teacher feedback and students' understanding of this. To get a more accurate picture nationally a larger sample should be used. The research involved only two primary schools, four teachers and sixteen students from a restricted age range. The schools were urban city schools and therefore do not represent all New Zealand schools.

The teachers had all been, with varying levels of involvement, participants in a formative assessment professional development project. This means that their comments cannot be seen as typical of all New Zealand teachers, as many have not been involved at all in any assessment programme. It could be argued that random sampling would have increased the credibility of the data.

Only one interview was carried out with each of the participants. Planning for other opportunities to gain information would have made the findings even richer. While 
insights from adviser work in schools were included in the results, these only added to the picture and could not become a formal part of it.

The majority of research and literature in this area has been based particularly in the United Kingdom. It could be argued that conditions are not always the same as for New Zealand.

The findings of the student and teacher interviews are summarised in Chapter 4. 


\section{CHAPTER FOUR}

\section{Findings}

\subsection{Student Interviews}

This chapter examines the responses to the interview questions from the student interview and the subsequent teacher interview. The major focus was on the students and their understanding of feedback given and received. The explicit purpose of the teacher interviews was to compare what the teachers intended with what the students understood. The information is reported under each question and then presented in tabular form.

\subsubsection{Interview Responses}

Question 1: You do lots of different kinds of work in class. What class work do you enjoy doing most? ${ }^{23}$

\section{Students}

Table 4.1 identifies the choices made by each student. Reading and writing have been given the broad heading of literacy. Responses by Years 3-4 students ${ }^{24}$ were reported separately so that any comparisons with the older children could be made. Three of the four students referred to success in moving up a reading level, their ability to spell correctly, and completion of work as factors that enhanced enjoyment. Over half of the Years 4-6 students ${ }^{25}$ enjoyed writing most. Dana and Michelle thought it was because they could "make it up" and Helena and Michelle talked about being able "to remember things about the past". Three suggested the enjoyment was to do with being creative and two thought they were "good at it". Reasons for liking maths included "it's challenging" (Allan); "competitions, yes I'm very competitive" (Cameron); and Ruby "I'm taking it on board because I'm at Intermediate next year". Only two curriculum areas outside the government priorities $^{26}$ were mentioned, technology and art. ${ }^{27}$ Matt enjoyed technology challenges because "it's cool, bits of things and you get to build and you can work with a partner". Dana mentioned art because she's "always enjoyed it" and Benjamin because "I like drawing ... I'm in an art family."

\footnotetext{
Probe questions not included

The Year 3-4 students will be referred to in the text using the pseudonyms of Anna, Erika Michael and Sandi.

The Year 4-6 students will be referred to in the text using the pseudonyms of Dana, Helena, Michelle, and Matt.

Allan, Molly, Jayne, Tamara, Cameron, Benjamin, Ruby and Jessie.

The Government priorities for education include Numeracy and Literacy.

27 Because the Arts Curriculum is still relatively new many schools have had recent professional development in the four disciplines of the curriculum: music, drama, visual arts, dance.
} 
Table 4.1: Work students most enjoyed

\begin{tabular}{|c|c|c|c|c|c|}
\hline \multirow[b]{2}{*}{ Years 3-4 } & \multicolumn{2}{|c|}{ Literacy } & \multirow[t]{2}{*}{ Mathematics } & \multirow[t]{2}{*}{ Art } & \multirow[t]{2}{*}{ Technology } \\
\hline & Reading & Writing & & & \\
\hline Anna & & $\sqrt{ }$ & & & \\
\hline Erika & $\sqrt{ }$ & $\sqrt{ }$ & & & \\
\hline Michael & & $\sqrt{ }$ & $\sqrt{ }$ & & \\
\hline Sandi & $\sqrt{ }$ & & & & \\
\hline \multicolumn{6}{|l|}{ Years 4-6 } \\
\hline Dana & & $\sqrt{ }$ & & $\sqrt{ }$ & \\
\hline Helena & & $\sqrt{ }$ & & & \\
\hline Michelle & & $\sqrt{ }$ & & & \\
\hline Matt & & & & & $\sqrt{ }$ \\
\hline Allan & & & $\sqrt{ }$ & & \\
\hline Molly & & $\sqrt{ }$ & $\sqrt{ }$ & & \\
\hline Jayne & $\sqrt{ }$ & & $\sqrt{ }$ & $\sqrt{ }$ & \\
\hline Tamara & & & & $\sqrt{ }$ & \\
\hline Cameron & & $\sqrt{ }$ & $\sqrt{ }$ & & \\
\hline Benjamin & & $\sqrt{ }$ & $\sqrt{ }$ & $\sqrt{ }$ & \\
\hline Ruby & & & $\sqrt{ }$ & & \\
\hline Jessie & & $\sqrt{ }$ & & & \\
\hline Total & 3 & 10 & 7 & 4 & 1 \\
\hline
\end{tabular}

\section{Teachers}

Connie, ${ }^{28}$ teacher of the Years 3-4 students was not surprised at the student responses because the school had had a major focus in literacy and numeracy and that was "what's on top" for everyone.

Liana, teacher of Years 4-6 was surprised because she "didn't feel that it had gone so well this year". Neither of the other Year 4-6 teachers was surprised. Rae commented that there had been a real focus on literacy and that the students had gained so many skills and had had "lots of feedback". She had seen the students openly enjoying it and thought that they were "probably feeling quite empowered. They have an audience for writing and so have a purpose". Suzie also commented on the focus of writing, speaking, and thinking topics in her classroom. She said there had been an emphasis on personal voice and a lot of discussion and informal debate. Her students received specific feedback from their peers and she thought they felt valued as a result.

$\overline{{ }^{28} \text { All teachers names have been changed. }}$ 


\section{Comment}

All teachers spoke of a numeracy and literacy focus in their schools. While the Years 3-4 students gave reasons such as moving up a reading level, their ability to spell correctly, and completion of work, their teacher thought it was because these curriculum areas were 'on top' for them all. Two Year 4-6 teachers thought reasons for enjoyment were to do with lots of discussion and specific feedback. They thought students felt valued and empowered as a result. Their students gave reasons such as opportunities for creativity, remembering the past and because they thought they were good at it. It is difficult to know how much enjoyment is enhanced because of quality feedback or because of growth in teachers' knowledge, confidence and use of teaching strategies as a result of professional development.

\section{Question 2: Think about your work in class and tell me what you are best at}

\section{Students}

All Years 3-4 students identified aspects of literacy as what they are best at. Table 4.2 summarises the students' responses under curriculum areas and again the Years 3-4 student comments have been kept separate to allow for comparison. When asked if their teacher had spoken to them about their 'best' subject, the answers varied. Teacher comments about neatness, that it was "good", and about completion and readiness to publish were most common. One student talked about the teacher suggesting improvements such as remembering to use speech marks. Six Years 4-6 students identified maths as what they were best at with Dana and Molly highlighting basic facts, Dana because "I get sixty out of sixty", and Molly because "I get five out of five". Helena thought maths because "I know a lot" and Ruby "I'm very good at maths. I can do my times tables very quickly. I'm in the extension class." Allan and Jayne spoke about their involvement in the Otago problem-solving competition ${ }^{29}$ and Allan's teacher had asked him to help others in the class. Jayne could not remember her teacher talking to her much about maths apart from "she kind of just says compliments sometimes [like] 'you'll be able to do this because you're good at maths"'. Dana said the teacher had not spoken to her about her basic facts. Helena said the teacher had sometimes spoken to her about maths but "not to make me think I'm best at it". Cameron said he was often asked for help by others in the class and was often asked for feedback. Benjamin used lots of good vocabulary and Michelle thought she had neat handwriting. When asked if their teacher had talked with them about these Michelle said "not really...for my homework 'neat' for my story 'that's great'". Cameron could not think when the teacher had spoken to him about his

29 The Otago Challenge is a problem-solving competition aimed primarily at students in Years 7-8 but may be of interest to mathematically gifted children in Year 6 . It has been offered to schools throughout New Zealand since 1991 and is organised by the University of Otago Department of Mathematics and Statistics. 
maths separately: "we get talked to in groups" but said, "writing, yes often. I go to her and we have a one on one." Benjamin said yes to both story writing and maths but commented that he probably was not the best at maths, "there's a top group and I'm probably at the bottom ... we have these little exams and I got the least out of everyone." For writing his teacher "normally tells me if it's not that great. Once she told me 'that's quantity not quality'". Tamara thought she was best at art because "sometimes I do really good drawings...people comment on it". Her teacher has told her "it's really good, it's coming along well." Matt thought he was best at reading, because he reads a lot, can read hard books and doesn't think it's work. His teacher had told him "you read a lot" but said he got "too much [of those comments]" and that "it's boring". Ruby found it hard to isolate a curriculum area:

Um, that's hard. I'm pretty good at most things. I'm better at things on different levels... one part of the taxonomy I might be good at and not so good at another part. I'm pretty good all round. Um, yes.

Table 4.2: Work students thought they were best at

\begin{tabular}{|c|c|c|c|c|c|c|c|}
\hline \multirow{2}{*}{ Years 3-4 } & \multicolumn{3}{|c|}{ Literacy } & \multirow[t]{2}{*}{ Maths } & \multirow[t]{2}{*}{ Art } & \multirow[t]{2}{*}{ Handwriting } & \multirow[t]{2}{*}{ Sport } \\
\hline & Reading & Writing & Spelling & & & & \\
\hline Anna & $\sqrt{ }$ & & & & & & \\
\hline Erika & & $\sqrt{ }$ & & & & & \\
\hline Michael & $\sqrt{ }$ & & $\sqrt{ }$ & & & $\sqrt{ }$ & \\
\hline Sandi & & $\sqrt{ }$ & & & & $\sqrt{ }$ & \\
\hline \multicolumn{8}{|l|}{ Years 4-6 } \\
\hline Dana & & & & $\sqrt{ }$ & & & \\
\hline Helena & & & $\sqrt{ }$ & & & & \\
\hline Michelle & & $\sqrt{ }$ & & & & $\sqrt{ }$ & \\
\hline Matt & $\sqrt{ }$ & & & & & & \\
\hline Allan & & & & $\sqrt{ }$ & & & \\
\hline Molly & & & & $\sqrt{ }$ & & & $\sqrt{ }$ \\
\hline Jayne & & & & $\sqrt{ }$ & & & \\
\hline Tamara & & & & & $\sqrt{ }$ & & \\
\hline Cameron & & $\sqrt{ }$ & & $\sqrt{ }$ & & & \\
\hline Benjamin & & $\sqrt{ }$ & & $\sqrt{ }$ & & & \\
\hline Ruby & \multicolumn{7}{|c|}{ I'm pretty good at most things...on different levels. I'm pretty good all round } \\
\hline Jessie & & & & $\sqrt{ }$ & & & \\
\hline Total & 3 & 5 & 2 & 7 & 1 & 3 & 1 \\
\hline
\end{tabular}




\section{Teachers}

Connie suggested that her feedback would help students know what they were best at. She explained that feedback relates to guidelines and that "they know what they need to do to be successful". Lisa's comment was similar, they would know "probably because I tell them. I tell them what they're really good at, I tell them they are clever collectively as a class and then target kids one-to-one". Suzie also commented on feedback but "peer feedback particularly". Rae said that her students could measure themselves against criteria that they should know specifically. She commented that they also get teacher and peer feedback and were able to accept constructive feedback and in fact often asked for it by saying "I've got...can you help?" For those who thought they liked maths best Rae thought it was because the feedback was a bit more immediate and often about process as well as the answer.

\section{Comment}

All teachers thought that their feedback was a key to students making decisions about what they were best at. They talked about giving constructive feedback, having criteria for feedback, and commenting on process as well as correctness. Two also mentioned feedback through peer or self-assessment. Years 3-4 students' reasons were correct spelling, length, speed and neatness and said that their teachers had commented on these by saying it was good, or they were ready to publish. Years 4-6 students also talked about getting work right, and that they knew a lot and read hard books. Only one student said the teacher had suggested improvements, the others said the teachers either hadn't spoken to them about it, or "not really" or "not to make me think I'm best at it".

\section{Question 3: Does your teacher write about anything on your work?}

\section{Students}

Table 4.3 illustrates the different curriculum areas that students said they got written feedback for. Not all Years 3-4 students said the teacher wrote in their books. Sandi said "sometimes" and Anna said "no". Three mentioned writing, one maths and two English. For Years 4-6 students, apart from Dana who said the teacher did not write anything in her books, and Allan who said the teacher wrote in all his books, a range of curriculum areas was mentioned. Again the most frequently commented on was story writing, and while six students mentioned maths three suggested this was sometimes and that the teacher usually called out the answers and they marked the work. Molly particularly highlighted maths as an area the teacher did not write comments on. 
Table 4.3: Work with teacher comments

\begin{tabular}{|c|c|c|c|c|c|c|c|}
\hline \multirow[b]{2}{*}{ Years 4-4 } & \multicolumn{4}{|c|}{ Literacy } & \multirow[t]{2}{*}{ Maths } & \multirow{2}{*}{$\begin{array}{l}\text { Anything } \\
\text { Book I } \\
\text { camp } \\
\text { book }\end{array}$} & \multirow[t]{2}{*}{ Handwriting } \\
\hline & Reading & Writing & Spelling & English & & & \\
\hline Anna & \multicolumn{7}{|l|}{ No } \\
\hline Erika & $\sqrt{ }$ & $\sqrt{ }$ & & & & $\sqrt{ }$ & $\sqrt{ }$ \\
\hline Michael & & $\sqrt{ }$ & & $\sqrt{ }$ & $\sqrt{ }$ & & \\
\hline Sandi & & $\sqrt{ }$ & & $\sqrt{ }$ & & $\sqrt{ }$ & \\
\hline \multicolumn{8}{|l|}{ Years 4-6 } \\
\hline Dana & \multicolumn{7}{|l|}{ No } \\
\hline Helena & & & & & $\begin{array}{c}\sqrt{ } \\
\text { (Sometimes) }\end{array}$ & $\begin{array}{c}\sqrt{ } \\
\text { Portfolio }\end{array}$ & \\
\hline Michelle & & $\sqrt{ }$ & & & $\sqrt{ }$ & & $\sqrt{ }$ \\
\hline Matt & & $\sqrt{ }$ & & & $\sqrt{ }$ & $\sqrt{ }$ & \\
\hline Allan & \multicolumn{7}{|c|}{ All work } \\
\hline Molly & & $\begin{array}{c}\sqrt{ } \\
\text { (Draft) }\end{array}$ & & & & $\sqrt{ }$ & \\
\hline Jayne & & $\sqrt{ }$ & $\sqrt{ }$ & & $\begin{array}{c}\sqrt{ } \\
\text { (As a class) }\end{array}$ & & \\
\hline Tamara & & $\sqrt{ }$ & & $\sqrt{ }$ & & & $\sqrt{ }$ \\
\hline Cameron & & $\sqrt{ }$ & & $\sqrt{ }$ & & & \\
\hline Benjamin & & $\sqrt{ }$ & & $\sqrt{ }$ & $\begin{array}{c}\sqrt{ } \\
\text { (Normally } \\
\text { not maths) }\end{array}$ & $\sqrt{ }$ & $\begin{array}{c}\sqrt{ } \\
\text { (Signed) }\end{array}$ \\
\hline Ruby & & $\sqrt{ }$ & & & & $\begin{array}{c}\sqrt{ } \\
\text { (Homework) }\end{array}$ & \\
\hline Jessie & & $\sqrt{ }$ & & & $\sqrt{ }$ & $\begin{array}{c}\sqrt{ } \\
\text { (Homework) }\end{array}$ & \\
\hline Total & 1 & 12 & 1 & 5 & 7 & 8 & 3 \\
\hline
\end{tabular}

Two Years 3-4 students said that teachers writing in their books took the form of stickers or smiley faces, and three references were made to comments such as "excellent" or "neat work". Sandi said that the teacher sometimes told them what is 'great' about the work and Erika talked about teacher suggestions or next steps comments. They also said they felt "ok" or "good" about the comments and reacted in some way such as fixing it up or "try to do better writing if that was what was said". The Years 4-6 students also identified a range of feedback, which included teacher signature, a rating out of 10 , stickers, and positive comments such as "good work", "fantastic", and "cool". Helena and Michelle identified more descriptive feedback that specified or constructed attainment and improvements such as "she says how I did [and] how she thinks I can improve and 'see me later"'. There were also negative feedback examples such as "she gets angry", "ripping out pages", "write it out again", and "be sensible". Helena was happy with the feedback and preferred the signature because she did not always get to read the comments and 
so did not get to do anything as a result. Molly said she quite liked the written comments because they said more, and told her what the teacher liked and did not like. Michelle thought 'excellent' meant it was neat and when she read "see me" she thought 'oh, no'. If there were suggestions she followed them and showed the teacher who then said "good, put it away". Matt felt good but didn't know what he felt about the 'bad comments' and said he felt confused. He said, "I just try to succeed in my goals".

\section{Teachers}

Connie (teacher of Years 3-4) thought what she would say or write would depend on what it was the child had done. She thought it would more likely be written and that if she used an Assess to Learn framework ${ }^{30}$ her comments would be about the bits that were successful and what they could do next time. Otherwise, she said she would probably give a sticker but that she would comment on why they were given the sticker. Connie's feedback changed according to the curriculum area. She said that if it is basic facts or spelling then the feedback is "very black and white"; however, for writing she thought feedback was more personal and more likely to be a verbal conference. Liana said she would comment on the habits of persistence, accuracy and precision as well as success criteria. She said she would make a "song and dance and jump around and say 'you're so good'". Suzie said that she would comment on "exactly what it was that I liked about that piece of work". She also spoke about having a personal goal, which she had set in front of the class, to never just say 'excellent', or 'I like this'. Rae thought what she said or wrote varied but that it would usually be to do with the success criteria. "I might say 'well done' but I would say why". "I would comment on what they did well, what their next step was." When asked if the type of feedback changed according to the curriculum area Liana first said "yes" and then changed to "No it doesn't, what does change is what I'm addressing. For example in maths, 'I liked the way you solved that, how did you do it?" Suzie talked about the feedback depending on whether the activity is a test, formative, summative, or next step. She thought that generally the type of feedback didn't change but did particularly mention swimming, sport and art where the feedback needs to be "oral and specific or precise". Rae thought that the type of feedback depended on the criteria. She said that:

Good quality feedback has similar characteristics. It is specific and identifies where the child is at and where they are heading. It clearly states what was done well and any improvements [needed].

30 While the teacher used the term 'framework' she is actually referring to the AtoL professional development programme in her school and the process of giving feedback only against shared/negotiated success criteria. 


\section{Comment}

Not all students agreed that their teacher wrote comments on their work. In one class two Years 3-4 students said "yes", one said "sometimes" and one said "no". For the Years 4-6 students, ten said "yes", one "no", and one changed "no" to "sometimes". All Years 3-4 students gave examples of evaluative comments with two of them also mentioning descriptive comments. The Years 4-6 students also gave examples of evaluative feedback but these were separated into positive and negative comments. The negative examples included punishing and disapproving comments. For all students the most commented on work was story writing and in particular work in draft. No teacher particularly mentioned writing but several suggested that their feedback differed according to what the students were doing rather than the curriculum area and that changes were more to do with whether the feedback was written or oral.

\section{Question 4: Do you show people at home the teacher's comments?}

The purpose of this question was to use another setting where feedback could be interpreted and its meaning gauged. It also served to identify further ways of giving feedback such as interviews, portfolios and rewards at a school level rather than at a classroom level. There was no corresponding question or clarification needed from teachers. ${ }^{31}$

\section{Students}

Years 3-4 students said that their parents knew about teacher comments if they told them or took home certificates. One also mentioned a portfolio that went home each term. Michael and Sandi said that they weren't allowed to take their books home. All four reported responses from their parents that suggested they thought their children were doing well. These included comments such as "great", "it's wonderful" "that's very good" or responses such as treats like a bought lunch. Three felt "good" about that, one felt "pretty happy". Tamara, Cameron, Ruby, Jayne, and Michelle all commented that they did not take their books home. Dana, Helena, and Molly said that they showed teacher comments to people at home who responded by saying their work is "good" or "ok", "great presentation" and "positive things like 'that's great". Molly also quoted her mother as sometimes saying "you haven't done your hardest this week" or "it's not up to the standards you can do" and said she totally agrees. Allan, Michelle and Jessie only showed their parents a folder or portfolio each term. Allan knew his parents were pleased with his 100/100 for basic facts and Jessie said her parents "normally comment about the pictures" and tell her what she

\footnotetext{
${ }^{31}$ No teacher comments are included under this question.
} 
should work on "like spelling". Tamara and Cameron mentioned parent interviews when they could look through their books and the teacher could tell them how they're going. Benjamin's response was that he shows people at home what he did "like I read them my stories". Jayne talked about her homework log and that her parents knew she was in the Otago Challenge. Ruby told her parents if she had a good day and said that they "encourage me." Matt said he only shared comments if they "are really good" and said his dad did not say anything. Most, apart from Michelle and Allan who made no comment, said they felt "good" or "ok" about parent responses.

\section{Comment}

A limited amount of classroom work went home on a regular basis. Aside from homework books, students reported that parents found out about their work through portfolios ${ }^{32}$, interviews, or by what they told them themselves. The parent comments shared by the students were all evaluative and included positive comments and rewards (money to buy lunch). One example of a disapproving comment was when a parent compared the student's work with previous standards and said, "you haven't done your hardest this week".

\section{Question 5: Is there any work you have found a bit tricky?}

The students identified what they found tricky and what was done or said about it. This question not only highlighted particular curriculum areas but also sought responses to indicate if the teacher was aware of the difficulties and what action resulted.

\section{Students}

Suggestions by the Years 3-4 students for what made their curriculum area tricky included "it was hard" or "confusing", "I can't do it fast" or that they "didn't get it correct". Only two suggestions were more specific; "graphs, mostly all graphs...the way you do the lines..." and "thinking, we have a sheet and "[it says] how was this made?' and look it up in the dictionary." When asked what they did about it, Anna and Erika said they told their mothers. Erika said she works with a friend, and Michael worked individually "I try to make it happen. I just try and try again". Only two commented on what the teacher did to help. Erika said, "she told me how to do it [English] and how to fix it", and Michael said "she ruled up the bottom and helped me with the lines." Anna does not think the teacher knows what she finds tricky and Sandi said, "I don't know." Half of the Years 4-6 students found maths tricky but with different aspects of maths identified. Matt identified tests, Allan and Tamara problem solving and Ruby fractions. Dana said she leaves it or comes back to it and Matt said, "I just

32 A student portfolio is a collection of work. Portfolios serve different purposes that range from a showcase of student work to a real assessment record that tracks achievement. 
try." Tamara said that her teacher "kind of explains it to you so you understand it and if you still don't understand you miss out" and Ruby said that if she doesn't understand she puts up her hand and the teacher "might give a little pointer." For those who identified spelling, Matt again spoke of tests, and Jessie found it difficult using very long words and said she normally looks up the dictionary or asks her mum and dad. Once when there was a tricky long word she asked her teacher who gave her the big dictionary. Jessie also mentioned production ${ }^{33}$ and Cameron homework; he said, "I don't really see the point" and "unless pushed I won't slope and I won't link". Molly mentioned art, "whenever we do things like portraits it ends up looking nothing like me" and Benjamin science, "probably getting the information." Molly said that she tries to look as if she enjoys it so "she [the teacher] doesn't come around and lecture me or say... get her started on why I should like it" and did give an example of the teacher giving improvement prompts. Michelle said she didn't really find anything tricky.

Table 4.4 highlights curriculum areas that were found to be difficult for these students.

Table 4.4: Work students found tricky

\begin{tabular}{|c|c|c|c|c|c|c|}
\hline \multirow{2}{*}{ Years 3-4 } & \multicolumn{2}{|c|}{ Literacy } & \multirow[t]{2}{*}{ Mathematics } & \multirow[t]{2}{*}{ Other } & \multirow{2}{*}{$\begin{array}{l}\text { Thinking } \\
\text { Homework }\end{array}$} & \multirow[t]{2}{*}{ Handwriting } \\
\hline & Reading & Spelling & & & & \\
\hline Anna & & & $\sqrt{ }$ & & & \\
\hline Erika & & & & $\sqrt{ }$ (English) & $\sqrt{ }$ (Thinking) & \\
\hline Michael & & & $\sqrt{ }$ & & & \\
\hline Sandi & $\sqrt{ }$ & & & & $\sqrt{ }$ (Thinking) & \\
\hline \multicolumn{7}{|l|}{ Years 4-6 } \\
\hline Dana & & & $\sqrt{ }$ & & & \\
\hline Helena & & & & & & $\sqrt{ }$ \\
\hline Michelle & \multicolumn{6}{|c|}{ "No not really" } \\
\hline Matt & & $\sqrt{ }$ (Tests) & $\sqrt{ }$ (Tests) & & & \\
\hline Allan & & $\sqrt{ }$ & $\sqrt{ }$ & & & \\
\hline Molly & & & & $\sqrt{ }($ Art $)$ & & \\
\hline Jayne & & & $\sqrt{ }$ & & & \\
\hline Tamara & & & $\sqrt{ }$ & & & \\
\hline Cameron & & & & & $\begin{array}{c}\sqrt{ } \\
\text { (Homework) }\end{array}$ & \\
\hline Benjamin & & $\sqrt{ }$ & & $\sqrt{ }$ (Science) & & \\
\hline Ruby & & & $\sqrt{ }$ & & & \\
\hline Jessie & & $\sqrt{ }$ & & $\begin{array}{c}\sqrt{ } \\
\text { (Production) }\end{array}$ & & \\
\hline Total & 1 & 4 & 8 & 4 & 3 & 1 \\
\hline
\end{tabular}

33 'Production' refers to a school wide performance of a show that had been a recent focus. 


\section{Teachers}

Connie commented on a way of gauging students with difficulties by their body language, the lack of work being done and by off-task behaviour. She suggested that she would firstly comment on what was successful. She would then talk (more likely to be verbal) about improvements, refer back to the criteria and talk it through more. Liana said she would usually say, "This is what we need to work on" and set a goal and "say ok now we have to get better". She commented that she had had a big push for this at the beginning of the year to "make this a safe thing to come down to the mat if they don't understand". Suzie, suggested that she would "try to break [the difficulty] up in chunks and try to say at the time, 'the next step for this is..." She said that modelling was important "not necessarily by me but in peer or buddy work". Rae talked about "a shift l've made to buddy them up with someone who can" and how she would go back to smaller steps and get them to clarify what is difficult by asking lots of questions.

\section{Comment}

Most students, when identifying tricky areas, said they just kept on trying. Three talked about asking their mothers. Only two students suggested that they would put up their hand or ask the teacher. While students did not seem to think the teachers knew what they found difficult, the teachers said they knew "through clues, such as body language", or that they "used [preventative] teaching strategies such as breaking down the learning steps and 'buddying' up students".

\section{Question 6: Is there anything your teacher has said you need to get better at?}

This question followed on from the notion of what was tricky to ascertain if there was any match with what the teacher said to them about what needed to be improved.

\section{Students}

All four Years 3-4 students gave examples of what their teacher said they needed to get better at. Anna said in writing she had "missed out all the bits and needed to read it over and fix it up a bit". Erika thought it was "probably speech marks" because she was told to fix them and remember to put them "here and there". Michael identified homework (multiply by and divided by) because on Friday they mark it and the teacher looks at the marked work, and then writing because the teacher said to "write neater". For Sandi it was spelling because she had been told to "work on it a bit better" and to practise her words. All four felt "ok" about the teacher response, two went back and fixed it, one was working with a partner on spelling and one said that "multiply by and divided by is improving". Five out of the 
eight Years 4-6 students mentioned handwriting, neatness or presentation as something the teacher had told them they needed to get better at. Helena said it was her linking and that she "felt ok and tried to write better and neater". Matt said his work was "ripped out once (last year) because he had used the wrong book and had spelling mistakes". He agreed it was the wrong book so he started again. Allan set a goal with his parents because he wasn't holding the pencil correctly "and I'm still working on it". He said he had got a lot better but forgets when he is tired or relaxes. Molly identified presentation and said that she had to rub it all out and start again. She said, "I felt like being a smart alec, but I didn't" and even though she didn't want to, she did do it again. Cameron had been told about neatness in all work. Benjamin also mentioned spelling and said that his teacher told him he was getting too hard words and that "I kind of knew that others get 18/20 and I get 13/20." He felt "stink" but as a result chose easy words. Dana and Tamara said their teacher told them they needed to get better at writing. Dana particularly mentioned editing and said the teacher "didn't exactly say it but kind of like, she's always telling me to read it twice." She felt that sometimes it might mean she had missed out something and it does not make sense. The teacher told her the first two letters and she looked it up in the dictionary. Tamara identified draft writing and the need to put in speech marks. The teacher wrote a 'c' for capital, which she found helpful so she fixed it and tried next time. Jayne said that her teacher hadn't said it to her but that for reading she was in the top group but a bit slow and for tables tests they had this "race thing" and she was trying to get stickers so she didn't have to do it anymore. The teacher had told the group to learn their tables more and so she carried on doing the tables and got her parents to test her at random. Michelle, Jayne, Ruby and Jessie said there wasn't anything they could think of although Ruby thought they "kind of do it, our goal, in a class discussion and we draft it up." Table 4.5 shows the curriculum areas these students were told they needed to get better at. 
Table 4.5: Work students had been told they needed to get better at

\begin{tabular}{|c|c|c|c|c|c|}
\hline \multirow{2}{*}{ Years 3-4 } & \multicolumn{3}{|c|}{ Literacy } & \multirow{2}{*}{$\begin{array}{l}\text { Homework } \\
\text { Other }\end{array}$} & \multirow{2}{*}{$\begin{array}{l}\text { Handwriting } \\
\text { Neatness }\end{array}$} \\
\hline & Reading & Writing & Spelling & & \\
\hline Anna & & $\sqrt{ }$ & & & \\
\hline Erika & & $\sqrt{ }$ & & & \\
\hline Michael & & & & $\sqrt{ }$ & $\sqrt{ }$ \\
\hline Sandi & & & $\sqrt{ }$ & & \\
\hline \multicolumn{6}{|l|}{ Years 4-6 } \\
\hline Dana & & $\sqrt{ }$ & & & \\
\hline Helena & & & & & $\sqrt{ }$ \\
\hline Michelle & \multicolumn{5}{|l|}{ "Nothing" } \\
\hline Matt & & & $\sqrt{ }$ & & $\sqrt{ }$ \\
\hline Allan & & & & & $\sqrt{ }$ \\
\hline Molly & & & & & $\begin{array}{c}\sqrt{ } \\
\text { (Presentation) }\end{array}$ \\
\hline Jayne & \multicolumn{5}{|c|}{ "Nothing to me" } \\
\hline Tamara & & $\sqrt{ }$ & & & \\
\hline Cameron & & & & & $\sqrt{ }$ \\
\hline Benjamin & & & $\sqrt{ }$ & & \\
\hline Ruby & \multicolumn{5}{|c|}{ "No, not really" } \\
\hline Jessie & \multicolumn{5}{|c|}{ "Not off the top of my head" } \\
\hline Total & & 4 & 3 & 1 & 6 \\
\hline
\end{tabular}

\section{Teachers}

Connie talked about "next time" comments and having a checklist of success criteria stuck in the students' books for writing. She or the child could tick these off and see what needed to be added or improved. She said she also talked about what individuals need to get better at during conference time by questioning like, "how could you...?". Liana gave the example of handwriting and said she would give a comment like, "this is [what was done well] but we need to look at this". She would get the student to make this their goal and write it on the next page, model for them and then get them to go and try. Suzie said that students in her class know what they need to get better at through feedback. She gets them to listen to examples by other children, which she believed had been "very powerful" and they debate, and discuss and ask each other for feedback. Suzie observes that the "effects on others is evident". Rae suggested that her students know what they need to get better at by the criteria and that it "becomes quite clear". She said they have a lot of discussion and lots of working with partners to identify what they don't know. She said, "I recently asked them what they need to get out of school [as a young adult] and they came up with, organisation skills, interpersonal skills, self-discipline and persistence." 


\section{Comment}

The teachers' intentions did not seem to have been completely understood by the students. Most students' comments focussed on presentation and yet this linked directly to the comments of only one teacher. Teachers otherwise responded using assessment for learning principles such as the use of criteria, next time comments, improvements, and goals.

\section{Question 7: Do you know what feedback is?}

It was not until the interview was well underway and students were familiar with the focus around teacher comments, marking and their own understandings, that the term 'feedback' was used.

\section{Students}

All but two of the students who responded that they knew the term were able to give examples. Others responded "sort of", or "no". Michael did not reply and when questioned further said he was unsure. All students who were not sure were given an explanation and once it had been explained they were able to give negative and positive examples. The Years 3-4 students were less able to define the term 'feedback' and only Anna related it to an action and suggested, "yeah, it's when somebody says, um, you're good at something". The other suggestion for this age group was "people talk back to each other about other people, mean things and stuff." Once the term was explained and they were asked subsequent questions about negative and positive feedback all four were able to give examples. Nine of the Years 4-6 students were able to elaborate with Helena saying:

\footnotetext{
It's feedback, when someone has told you about something you've done, and how to improve it now you've done it.
}

And Allan

It's like almost telling you what the next step is and usually giving quite good comments.

One student said, "feedback? No", and two said "yes" but gave no further information. The next two questions asked the students to comment on how they felt about negative and positive feedback they observed. 


\section{Negative Comments}

For the Years 3-4 students, Anna felt sad when others got negative feedback such as "why didn't you win the game?" or when the teacher shouted or sent them to another room. Erika said, "I know they can fix it" but also mentioned boys being told off for talking "you have three more warnings and then you're out". Michael talked about rubbish duty and lines and Sandi said she "felt ok but tried to help them". Years 4-6 responses to negative feedback ranged from feeling sorry, "the teacher might yell at them and send them to a corner away from the others" (Dana), and upset or angry, "that's not very good, try again" (Michelle), to "Alright, but it's not really feedback" (Matt), and "I hate it. I don't call it negative I call it critical. I don't like this bit" (Cameron). Jessie commented, "that word [negative] doesn't belong here. Put constructive on the end of negative".

\section{Positive Comments}

Year 3-4 student Anna felt great when she heard positive feedback like "you've got another sticker, add it to your [card]." Erika knew it was good for them and knew she could do that too if she tried hard as well. Michael felt happy for them when he heard "this is super work" and Sandi felt good when others got stickers and certificates or comments like "great" and "keep it up", although she added "not that it makes me want to do anything." Positive feedback identified included stickers, sticker cards, certificates, signatures, visiting another teacher and comments such as "great", "well done", "this is super work", "great poem" and "keep it up". Anna and Erika elaborated further with comments such as "great portrait...it looks like him" and "well, done, you can put that on the wall now." For Years 4-6 students, five said they felt "happy", "good", or "ok" about positive feedback; Dana when they got a principal sticker or a pizza award and Matt when he heard "I'm impressed" or "that was terrific reading". Molly felt good but didn't want to change, "I let it go". Jessie felt that she wanted to give some feedback too like "Hey that's good." Cameron said that his teacher does say why it's good and "she writes a question like "what colour was it?" Both he and Ruby thought they would like to go and see what "good alliteration", or "a lot of personal voice" looked like. Two said they didn't feel anything. Seven students spoke of comments that included improvements. For example, Helena said "it's feedback when someone has told you about something you've done and about how to improve it now you've done it." Ruby said, "We do feedback a lot. At the end of term one we had a focus on it because we don't say 'great' we like to have something to work on." Jessie responded with "it can be positive, negative or constructive." 


\section{Teachers}

Connie said her Years 3-4 students "definitely like cards and sharing work with the principal. Some ask if they can go and I see their heightened confidence". She also said "some value verbal feedback, others value written. Some value stickers and some don't." Liana thought her students liked to hear her affirm children who brought their work from other rooms. She also thought they liked cards and stickers and were able to tell what they got them for. Suzie reasoned that her students liked a positive atmosphere, respect and feedback because "we do reviews about what works in class. The children designed a survey which they analysed and graphed". She commented, "They no longer like certificates, stickers or special cards". Rae's class had a big debate on feedback and the students were split between preferring oral or written. However she said most preferred oral because they "can't pick up the tone in written". She found that the girls liked stickers because they look good but the boys couldn't care less. She added "those who do things for intrinsic purposes said no, those less mature or who wanted to please the teacher said yes. However we don't use them."

\section{Comment}

Of the Years 3-4 students only Anna had some idea about feedback before any explanation. Negative feedback identified was mostly about behaviour (3), or neatness and the quality of the work (1). This included the handing out of cards (2), being sent to another room, being shouted at, told off, given rubbish duty and given warnings. The Years 4-6 students gave examples that demonstrated an understanding of the term that had been the focus of the professional development work with their teachers. A result of this question was an evident link between what the teachers said and what the students understood.

Table 4.6 identifies how each student responded and categorises any examples they gave into either evaluative, or descriptive, feedback. 
Table 4.6: Students' ability to define feedback

\begin{tabular}{|c|c|c|c|c|c|}
\hline Years 3-4 & Yes & Sort of & $\begin{array}{c}\text { Unsure } \\
\text { (questioned) }\end{array}$ & No & Years 3-4 \\
\hline & Response & Able to define & & & \\
\hline Anna & $\sqrt{ }$ & $\begin{array}{c}\sqrt{ } \text { (Evaluative - } \\
\text { Positive) }\end{array}$ & & & \\
\hline Erika & & $\mathbf{x}$ & $\sqrt{ }$ & & \\
\hline Michael & & $x$ & & $\sqrt{ }$ & \\
\hline Sandi & $\sqrt{ }$ & $\begin{array}{c}\sqrt{ } \text { (Evaluative - } \\
\text { Negative) }\end{array}$ & & & \\
\hline \multicolumn{6}{|l|}{ Years 4-6 } \\
\hline Dana & & $x$ & & & $\sqrt{ }$ \\
\hline Helena & $\sqrt{ }$ & $\sqrt{ }$ (Descriptive) & & & \\
\hline Michelle & $\sqrt{ }$ & $\mathbf{x}$ & & & \\
\hline Matt & $\sqrt{ }$ & $\mathbf{x}$ & & & \\
\hline Allan & $\sqrt{ }$ & $\begin{array}{c}\sqrt{ } \\
\text { (Descriptive) }\end{array}$ & & & \\
\hline Molly & $\sqrt{ }$ & $\begin{array}{c}\sqrt{ } \\
\text { (Descriptive) }\end{array}$ & & & \\
\hline Jayne & $\sqrt{ }$ & $\begin{array}{c}\sqrt{ } \\
\text { (Descriptive) }\end{array}$ & & & \\
\hline Tamara & $\sqrt{ }$ & $\begin{array}{c}\sqrt{ } \\
\text { (Descriptive) }\end{array}$ & & & \\
\hline Cameron & $\sqrt{ }$ & $\begin{array}{c}\sqrt{ } \text { (Evaluative - } \\
\text { Positive) }\end{array}$ & & & \\
\hline Benjamin & $\sqrt{ }$ & $\begin{array}{c}\sqrt{ } \\
\text { (Descriptive) }\end{array}$ & & & \\
\hline Ruby & $\sqrt{ }$ & $\begin{array}{c}\sqrt{ } \\
\text { (Descriptive) }\end{array}$ & & & \\
\hline Jessie & $\sqrt{ }$ & $\begin{array}{c}\sqrt{ } \\
\text { (Descriptive) }\end{array}$ & & & \\
\hline
\end{tabular}

\subsection{Teacher Interviews}

The remainder of the questions for teachers were specifically to do with their feedback to determine what was intended so that a comparison could be made with what the students understood.

\subsubsection{Interview Responses}

\section{Q. Have you ever used feedback that you thought wasn't useful?}

Connie admitted that she had used feedback that wasn't useful and it was "probably sticking on a sticker and not saying why." She gave an example of handwriting where it was easy to put a sticker and children would not know why they got it. She also thought she had given global statements like "nice story." Liana said that she “hadn't since a focus on AtoL which gives feedback something to hang on ${ }^{34}$, but

34 Liana was referring to the practice of sharing learning intentions and success criteria and focussing feedback on these. 
probably before". Suzie said she had used unhelpful feedback in the past "all the time". She identified unhelpful feedback as "good work", "excellent" or "thank you for sharing". She reflected on the huge changes she had made because of professional development in Assess to Learn and literacy. Rae thought she had used feedback in the past that had been a bit loose and casual. She commented that students now were less dependent on her for feedback and often get to self assess. She commented "how they feel about themselves is important, it is for them not for me."

\section{Q. What feedback have you found to be particularly effective?}

The kind of feedback Connie has found most useful is "precise with a purpose so the students know why..." For Liana feedback that "addresses criteria is most useful when kids can check the criteria". For this she has used a flip chart [stapled book] since the beginning of the year. Suzie has found feedback "specific and spoken or written at the time" most useful. She has observed that the children like it written because they can show others. Suzie has also set her own goals in front of the class, which she says "keeps you honest, and not [seen to be] right all the time". Rae has found peer feedback to be useful and the children now swap work with a buddy who gives written feedback on the criteria. "It is very specific and we have never had any disagreements."

\section{Q. Do students in your class think feedback is useful?}

Connie thought that students in her class found feedback useful because often she has seen suggestions she has made taken 'on board'. The suggestions back up what has been done in the teaching session. Liana didn't know if her students found feedback useful but then said, "yes they do. They [talk about] 'I've met my goal." Both Suzie and Rae thought their students found feedback useful. Suzie knew this through the class review and survey previously mentioned. She commented that "children say it all the time; they ask for it [feedback] and get miffed if they don't get it. They ask for particular feedback like, 'have I got a good conclusion?' They sometimes act on the suggestions made it's up to them." Rae knew from "a talk the other day about what we next need to achieve and what I need to give them in order to achieve. They said 'feedback'. They feel hard done by without our sharing session when we choose two people to give feedback". She went on to say that the students would often go away then and there (often with a buddy) and fix it. "Sometimes they don't agree and that's the way I like it." 


\section{Q. What do you see is the value of feedback for learning?}

Connie saw the value of feedback for learning as being specific to the individual. She found she could group the kids better and that the focus [for her] was on teaching. Liana found that it "impacts on their focus and that it narrows down what they are trying to do or achieve". Suzie said that having the success criteria written up in the classroom means she could ask them quite often "why are we doing this?" and they know when they succeed and where to go next. Rae saw feedback as "one of the most valuable things we do in the classroom". She said that it allows children to make sense and that without feedback "how would they know how to reach expectations".

Feedback allows them to move on. That's my job.

\section{Q. Is there any other comment you would like to make about feedback?}

Connie thought she had "become more specific" and that reports were more specific. She said that she told the principal "I know more about my kids." Liana said "it has definitely improved my teaching and our learning, and my focus with children". Suzie commented that she is "sick of hearing the phrase", and Rae reflected on workplace feedback stating, "We are not good at giving and receiving feedback."

\section{Comment}

All teachers had used feedback they thought was not useful and identified examples that were evaluative and non-specific. They suggested useful feedback was frequent, oral and written, and included specific criteria. Feedback was seen as highly valuable especially when these elements were present. One teacher talked about setting personal feedback goals that were shared with the students. Students were seen to find feedback useful and in two classrooms specific discussions around feedback issues had been held.

\subsection{Scenarios}

To complete the interviews two scenarios were given for students to comment on. The purpose of this was twofold; firstly to move student thinking away from the familiar ground of literacy and numeracy, and secondly to put them into an imaginary situation where they could comment on the feedback they thought should occur. In the first scenario the students were asked to identify the child's success and suggest feedback and next steps comments that they thought could be given. For the second scenario they were asked to suggest what might happen when a student faced difficulty with a certain aspect of class work and what teacher feedback or action could occur. 


\subsubsection{Scenario 1}

Scenario 1

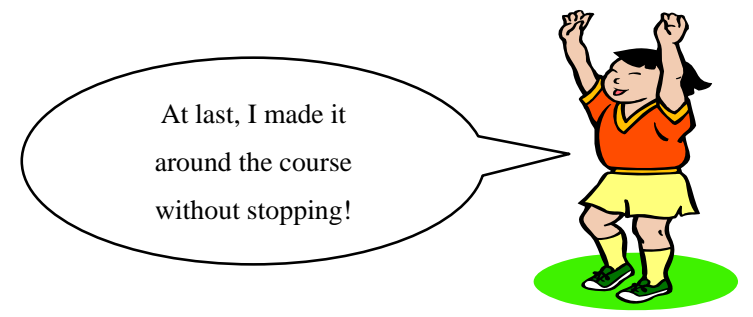

What would the teacher say to Lina about her success?

What could the teacher suggest to Lina to do next?

Three Years 3-4 students identified Lina's success as not stopping, which related directly to Lina's own comment. Two students had no suggestions, one thought her success was "without anyone catching her", and another "running, around the field". All suggested comments were either rewarding or approving. Examples included, "that was wonderful, you're a really fast runner", "good work; you can go to lunch early", "congratulations" and the giving of stickers. Not one suggestion referred to Lina's success of not stopping.

Four Years 4-6 students also suggested Lina's success was in not stopping. One student mentioned "not giving up" and another that she had "finally done what was maybe her goal". All students suggested teacher feedback would be positive with either approving or rewarding comments. However, four suggested that the teacher would give Lina more information about why she did so well (descriptive feedback, specifying attainment) and two had next step comments (specifying improvement). Suggestions for Lina's next step were to do with more of the same, going faster, or trying the same in another sport or activity. One suggested that the teacher might help Lina with her next step and another that she'd "um, give feedback."

\subsubsection{Scenario 2}

\section{Scenario 2}

For social studies Mere's group is discussing natural resources and the importance of managing these resources. The teacher has asked each group member to select a different resource to find information about. Peter has chosen water, Sina has chosen timber but Mere doesn't know where to start.

What would Mere's teacher do next?

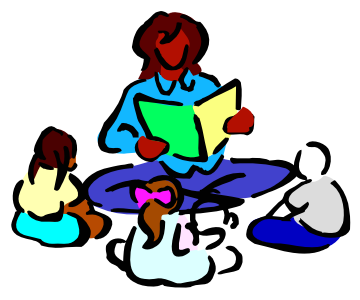


No Years 3-4 students knew what 'social studies' was although one thought they had had it before. Even after it was explained three still could not remember having it and Erika talked about a topic she was about to do even though it appeared to be more to do with oral language. For Years 4-6, three students thought social studies was 'topic', two picked up the word 'social' one explaining the term and the other asking what it meant. Two mentioned science and one geography. Five clearly stated they did not know. Once it was explained, five identified having done social studies. Three talked about "famous people", two about "celebrations", one about topical news around the world, and two about research. Two could name a topic they had covered in the past. For teacher feedback or suggestions to help Mere, fourteen students said the teacher could help with the ideas with three suggesting more explanation, and two that Mere be paired up with others in the group. Three students suggested more in the way of conversation, with Helena recommending more of a one-one situation where the teacher would work with Mere "on a brainstorm". Not all students could offer ways they could help Mere if they were in the situation themselves. Suggestions that were made mostly mirrored the same ideas they had given for the teacher, helping Mere by explaining their own choice, having her work in their group, giving her an idea or sharing their resources.

\section{Comment}

Students' ideas about why Lina was successful differed and their suggested feedback was evaluative and included mention of rewards. Four also added more specific information and two included next steps comments. For Mere's scenario, no students could relate to 'social studies' until the term was explained. Suggestions for helping Mere were descriptive and involved discussion, breaking down the task and the sharing of resources.

\subsection{Summary}

The interview responses from both students and teachers reported in this chapter have, where possible, been compared. There does not always seem to be a match between what the students perceived and what the teacher intended. One example is that students said they enjoyed different curriculum areas because they could be creative or they were good at a specific subject, whereas half of the teachers thought it was because of their specific feedback and lots of discussion. Another example is that most students' comments focussed on presentation and correctness, which only linked to the comments of one teacher. Teachers otherwise talked about using assessment for learning principles such as the use of criteria, 
next time comments, improvements, and goals. Only one student said the teacher had suggested improvements.

The student and teacher responses could be categorised as evaluative or descriptive and placed on the typology with little difficulty. The actual responses of the two different age groups, however, did throw up some differences. While all students gave examples of evaluative comments the younger students did not mention punishing or disapproving feedback. The older students were able to demonstrate their understanding of descriptive feedback and used sophisticated terms such as 'constructive'.

Chapter Five will explore these ideas further and discuss them in relation to the feedback typology and the literature reviewed. 


\section{CHAPTER FIVE}

\section{Analysis and Discussion}

The findings reported in the previous chapter highlighted the range of feedback received by students and their understandings of the feedback. There was also substantial information to enable a comparison with the findings of Tunstall and Gipps (1996a,b), who determined, by questioning the data, that teachers use a range of both evaluative and descriptive feedback (see literature review for a full discussion). The eight categories in their typology are outlined in Table 5.1.

Table 5.1: A brief outline of the Tunstall and Gipps' (1996b, p.394) Feedback Typology

\begin{tabular}{|c|c|c|c|c|c|c|c|}
\hline \multicolumn{4}{|c|}{ Evaluative Feedback } & \multicolumn{4}{|c|}{ Descriptive Feedback } \\
\hline \multicolumn{2}{|c|}{ Positive feedback } & \multicolumn{2}{|c|}{ Negative Feedback } & \multicolumn{2}{|c|}{ Specifying Feedback } & \multicolumn{2}{|c|}{ Constructing feedback } \\
\hline Rewarding & Approving & Punishing & Disapproving & $\begin{array}{c}\text { Specifying } \\
\text { attainment } \\
\text { C1 }\end{array}$ & $\begin{array}{c}\text { Specifying } \\
\text { Improvement } \\
\text { C2 }\end{array}$ & $\begin{array}{c}\text { Constructing } \\
\text { achievement } \\
\text { D1 }\end{array}$ & \begin{tabular}{|} 
Constructing \\
the way \\
forward \\
D2
\end{tabular} \\
\hline
\end{tabular}

The questions and responses have also presented the opportunity to explore and compare other ideas, and because the teachers were also interviewed, what they intended by their feedback has been compared with what students understood.

\subsection{Testing the Typology}

Much of the literature highlights the different kinds of feedback (Black \& Wiliam, 1998b; Hargreaves, McCallum \& Gipps, 2000; Kearsley, 2002; Kohn, 1993; Tunstall \& Gipps, 1996a,b) and it is clear that feedback serves different purposes. The purpose of classroom feedback is to inform learning and the feedback typology created by Tunstall and Gipps (1996b) provided a useful framework to differentiate behaviour-related feedback from task-related feedback. The categories were, however, found to be problematic in a formative assessment, and learning, context because they do not provide evidence that the feedback, even if it is constructive, relates to shared aspects, or the learning intention, of a given task. This will be considered later in the chapter.

The framework worked well in categorising the responses of the Years 3-6 students' (aged approximately 7-10) responses although the Tunstall and Gipps (1996a) research involved younger students (aged 6-7 years). 
Student examples of teacher feedback were categorised and found to be evaluative $^{35}$ or descriptive ${ }^{36}$ (Tunstall \& Gipps, 1996a). These categorisations are also mirrored by other writers who suggest that evaluative feedback can be positive or negative with praise and approving comments, and descriptive feedback can relate to achievement or improvement which can also be constructed with the student (Davies, 2003; Hargreaves, McCallum \& Gipps, 2000; Kearsley, 2002; Torrance \& Pryor, 1998). As for the Tunstall and Gipps' (1996a) study, both categories of 'evaluative' and 'descriptive' were well represented and no student gave examples limited to just one category.

The range of evaluative feedback strategies that emerged from the analysis was consistent with the typology and actual comments have been placed on the framework in Table 5.2. The table identifies what is different between positive (rewarding and approving) and negative (punishing and disapproving) types of feedback.

Table 5.2: Students' examples of teacher evaluative feedback mapped onto Tunstall and Gipps' Typology

\begin{tabular}{|c|c|c|c|}
\hline \multicolumn{4}{|c|}{ Evaluative } \\
\hline Rewarding A1 & Punishing A2 & Approving B1 & Disapproving B2 \\
\hline $\begin{array}{l}\text { The odd sticker (for } \\
\text { better harder work) } \\
\text { Sticker } \\
\text { Smiley face } \\
\text { Certificate } \\
\text { Signature } \\
\text { See the principal } \\
\text { Principal sticker } \\
\text { Pizza certificate at } \\
\text { assembly } \\
\text { You can be in the team } \\
\text { instead of sitting on the } \\
\text { sideline. } \\
\text { I don't have to do tables } \\
\text { tests anymore. }\end{array}$ & $\begin{array}{l}\text { Told off. } \\
\text { You have three more } \\
\text { warnings and you're out } \\
\text { The teacher shouted and } \\
\text { sent him to another room } \\
\text { This is your last chance } \\
\text { Rubbish duty or lines } \\
\text { Send them to a corner } \\
\text { away from the others } \\
\text { Taken outside } \\
\text { Get a B (below) } \\
\text { Do it again } \\
\text { Rips it out } \\
\text { Write it out again } \\
\text { If you still don't } \\
\text { understand it you miss } \\
\text { out } \\
\text { Start again and make it } \\
\text { neat }\end{array}$ & $\begin{array}{l}\text { It is very good } \\
\text { She told the class I had } \\
\text { eight stickers } \\
\text { Excellent } \\
\text { Neat } \\
\text { Cool } \\
\text { That's great } \\
\text { Fantastic } \\
\text { I'm impressed } \\
\text { This is super work } \\
\text { Very neat } \\
\text { Keep on trying } \\
\text { Very nice } \\
\text { Well done } \\
\text { Great work } \\
\text { I get told I'm very good } \\
\text { Good work, you're getting } \\
\text { good at this } \\
\text { P for publishing; You're } \\
\text { ready to publish. } \\
\text { Well done, you can put } \\
\text { that on the wall now } \\
\text { Get an A (best) }\end{array}$ & $\begin{array}{l}\text { Get better } \\
\text { Write neater } \\
\text { Teacher might yell at } \\
\text { them } \\
\text { That's not very good } \\
\text { Be sensible } \\
\text { Gets angry } \\
\text { You haven't tried your } \\
\text { hardest this week } \\
\text { It's not up to the } \\
\text { standards you can do } \\
\text { Give me a lecture } \\
\text { Raising her voice } \\
\text { This isn't up to scratch } \\
\text { That's quantity not quality } \\
\text { Rub it out } \\
\text { Try again, try a bit harder }\end{array}$ \\
\hline
\end{tabular}

5 Evaluative feedback, that is judgmental

36 Descriptive feedback, that is competence-related 
The descriptive examples of teacher feedback given by the students could also be further categorised. This type of feedback is no longer simply positive or negative feedback but is concerned with what has been achieved and what needs to be worked on next. Table 5.3 demonstrates the difference between specifying feedback, which does focus on the task, and constructing feedback, which gives the specific detail. For instance, when 'that's a very good story', becomes 'that's really good work, you've got a lot of personal voice' the feedback is constructing attainment.

Table 5.3: Students' examples of descriptive feedback mapped onto Tunstall and Gipps' Typology

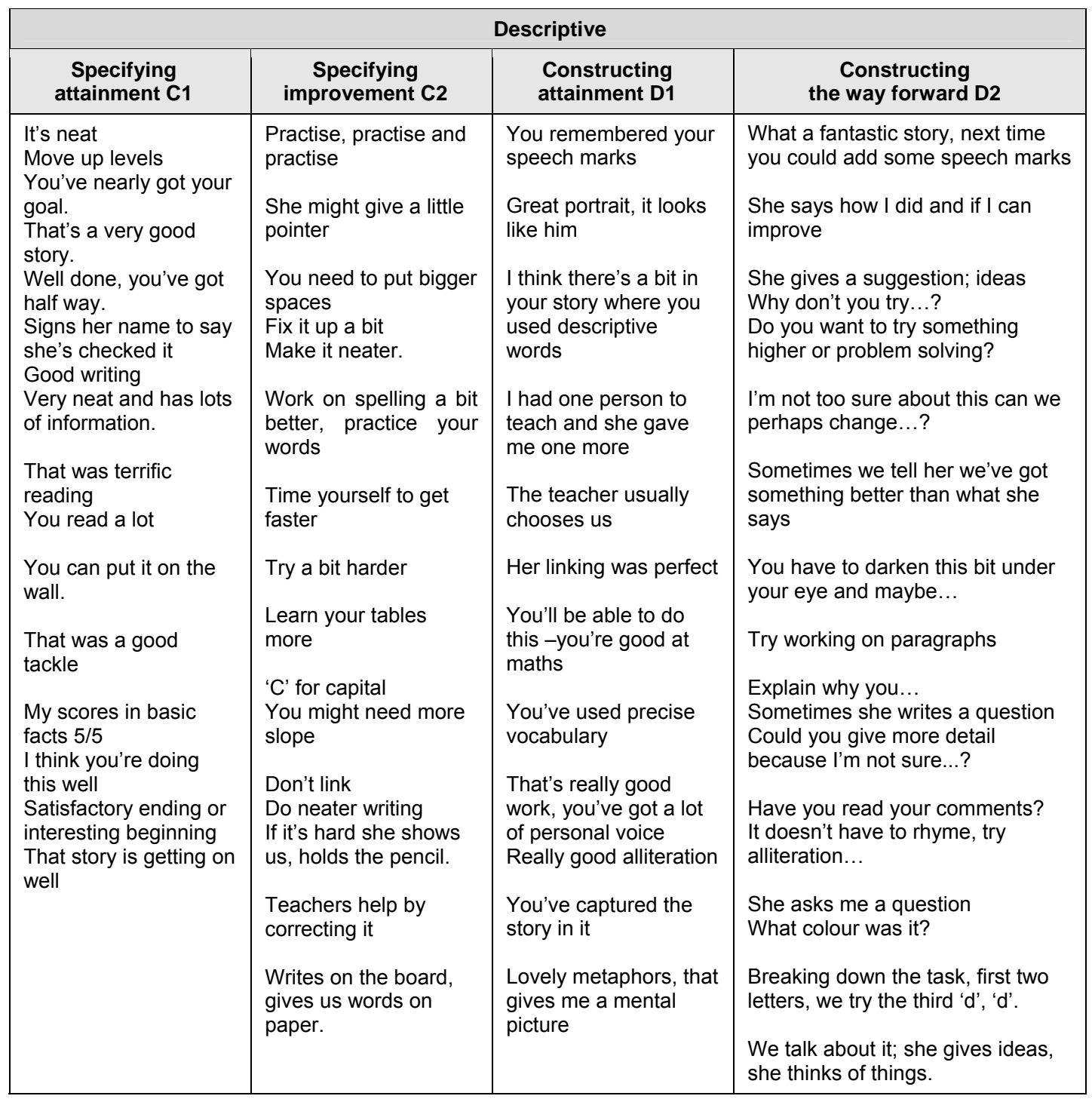

The students' comments were also used to identify the range across the two main categories and the eight sub-groups. Table 5.4 and Figure 5.1 highlight types of feedback given by each student and gives a picture for the two age groups, the four different classes and the sixteen individual students. 
Table 5.4: Categorising feedback using the Tunstall and Gipps' (1996b) typology

\begin{tabular}{|c|c|c|c|c|c|c|c|c|}
\hline & \multicolumn{4}{|c|}{ Evaluative } & \multicolumn{4}{|c|}{ Descriptive } \\
\hline $\begin{array}{l}\text { Years } \\
3-4\end{array}$ & $\begin{array}{c}\text { Rewarding } \\
\text { A1 }\end{array}$ & $\begin{array}{c}\text { Punishing } \\
\text { A2 }\end{array}$ & $\begin{array}{c}\text { Approving } \\
\text { B1 }\end{array}$ & $\begin{array}{l}\text { Disapproving } \\
\text { B2 }\end{array}$ & $\begin{array}{c}\text { Specifying } \\
\text { Attainment } \\
\text { C1 }\end{array}$ & $\begin{array}{c}\begin{array}{c}\text { Specifying } \\
\text { Improvement }\end{array} \\
\text { C2 }\end{array}$ & $\begin{array}{c}\text { Constructing } \\
\text { Achievement } \\
\text { D1 }\end{array}$ & $\begin{array}{l}\text { Constructing } \\
\text { the Way } \\
\text { Forward } \\
\text { D2 }\end{array}$ \\
\hline Anna & $\sqrt{ }$ & & $\sqrt{ }$ & & $\sqrt{ }$ & $\sqrt{ }$ & & \\
\hline Erika & $\sqrt{ }$ & & & & $\sqrt{ }$ & $\sqrt{ }$ & & $\sqrt{ }$ \\
\hline Michael & $\sqrt{ }$ & & $\sqrt{ }$ & & & $\sqrt{ }$ & & \\
\hline Sandi & $\sqrt{ }$ & & $\sqrt{ }$ & & $\sqrt{ }$ & $\sqrt{ }$ & & $\sqrt{ }$ \\
\hline \multicolumn{9}{|l|}{ Years 5-6 } \\
\hline Dana & $\sqrt{ }$ & $\sqrt{ }$ & $\sqrt{ }$ & $\sqrt{ }$ & $\sqrt{ }$ & $\sqrt{ }$ & & $\sqrt{ }$ \\
\hline Helena & & & $\sqrt{ }$ & & $\sqrt{ }$ & $\sqrt{ }$ & & $\sqrt{ }$ \\
\hline Michelle & $\sqrt{ }$ & & $\sqrt{ }$ & $\sqrt{ }$ & & $\sqrt{ }$ & & $\sqrt{ }$ \\
\hline Matt & $\sqrt{ }$ & $\sqrt{ }$ & $\sqrt{ }$ & $\sqrt{ }$ & $\sqrt{ }$ & & & \\
\hline Allan & $\sqrt{ }$ & & $\sqrt{ }$ & & $\sqrt{ }$ & $\sqrt{ }$ & $\sqrt{ }$ & $\sqrt{ }$ \\
\hline Molly & $\sqrt{ }$ & $\sqrt{ }$ & $\sqrt{ }$ & $\sqrt{ }$ & $\sqrt{ }$ & $\sqrt{ }$ & $\sqrt{ }$ & $\sqrt{ }$ \\
\hline Jayne & $\sqrt{ }$ & & & & $\sqrt{ }$ & $\sqrt{ }$ & $\sqrt{ }$ & $\sqrt{ }$ \\
\hline Tamara & & & $\sqrt{ }$ & & $\sqrt{ }$ & $\sqrt{ }$ & $\sqrt{ }$ & $\sqrt{ }$ \\
\hline Cameron & & & $\sqrt{ }$ & & $\sqrt{ }$ & & $\sqrt{ }$ & $\sqrt{ }$ \\
\hline Benjamin & & & $\sqrt{ }$ & & $\sqrt{ }$ & $\sqrt{ }$ & $\sqrt{ }$ & $\sqrt{ }$ \\
\hline Ruby & & & $\sqrt{ }$ & & $\sqrt{ }$ & $\sqrt{ }$ & $\sqrt{ }$ & $\sqrt{ }$ \\
\hline Jessie & & & $\sqrt{ }$ & & $\sqrt{ }$ & $\sqrt{ }$ & $\sqrt{ }$ & $\sqrt{ }$ \\
\hline Total & 10 & 3 & 14 & 4 & 14 & 14 & 8 & 13 \\
\hline Percentage & $62 \%$ & $18 \%$ & $87 \%$ & $25 \%$ & $87 \%$ & $87 \%$ & $50 \%$ & $81 \%$ \\
\hline
\end{tabular}

Figure 5.1: Categorising feedback using the Tunstall and Gipps' (1996b) typology

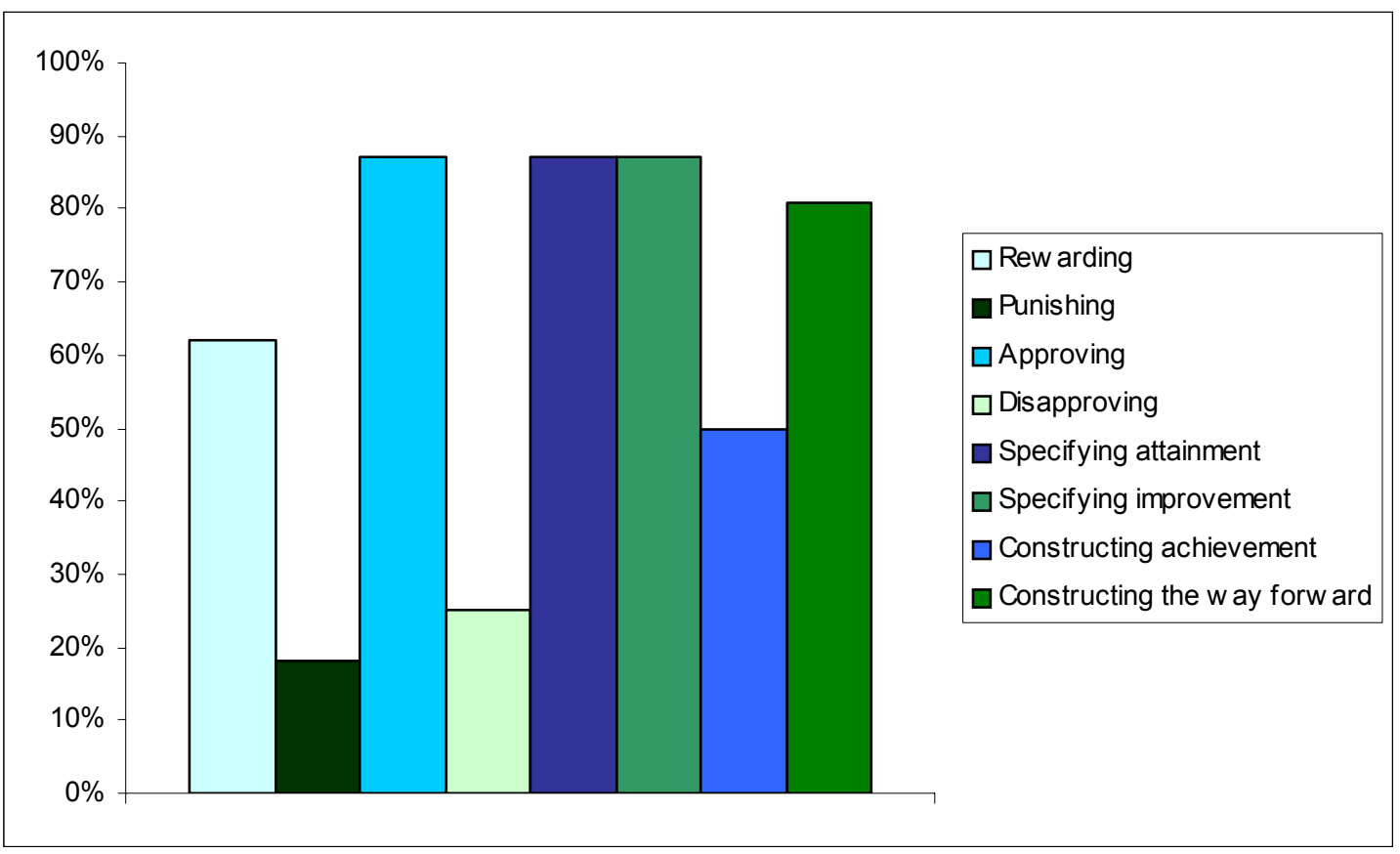


These results will be discussed under the broad headings of Evaluative and Descriptive and each of the more specific feedback strategies that sit beneath each. The eight categories will be discussed separately.

\subsection{Evaluative Feedback Strategies}

Factors that inhibit learning include the tendency for teachers to assess quantity and presentation rather than the quality of learning (Black \& Wiliam, 1998b; Clarke, 2000; Knight, 2003; Sadler, 1989). Table 5.2 demonstrates how the student examples work on the typology and encompass the range of 'rewards and punishments', and 'approval and disapproval'. It shows comments frequently to do with effort (trying hard), presentation (beautiful work), and accuracy (7/10). The examples of evaluative feedback are predominantly positive (rewarding and approving) and in comparison, there were few negative (punishing and disapproving) responses. Evaluative feedback lacks any specific links to either the learning or the task. When the focus moves from the task to the person it moves away from learning and performance (Hattie \& Jaeger, 1998).

Several students gave examples of 'sticker cards' and feedback more often directed at them than at their work. This is what Black and Wiliam (1998b) found; that teacher feedback often serves managerial and social purposes. It was not surprising that some students could not make a connection between feedback and their learning. Some of the feedback examples included marks and grades; however this was less of an emphasis in this study than was reported by Black and Wiliam (1998b).

Practice does not always reflect what is known in theory. All teachers gave examples such as "well done", "excellent", "thank you for sharing", and "nice story" as feedback they thought was not useful. This could indicate a shift in thinking about feedback that may not yet be embedded in practice and therefore not always apparent to, or expected by, the students. Because these comments lack specifics, students do not know how well they are doing (Clark, 2000; Suffolk County Council, 2001) and have no way of making reliable self-assessments. Comments that are problematic for students are also difficult to categorise. An example of this is "see me" and the students concerned had no idea whether this was positive or negative feedback. This comment has not been placed on the typology although it could be categorised as 'evaluative' because it gives no specific information. 


\subsubsection{You've got another sticker; add it to your 'ten card'}

Students perceive positive feedback as receiving rewards such as stickers and smiley faces (Hargreaves et al., 2000). They are used to receiving such feedback and all Years 3-4 students, and half the Years 5-6 students talked about rewards from the teacher and from those at home. While stickers and rewards were also mentioned by three of the four teachers, two stated that although the school still used them they no longer did. The students in one of these classes evidence this in Table 5:4 with no reference to rewards at all.

The reasons teachers give rewards are not always obvious to the students. Teachers were motivated by "I see their heightened confidence" or "I think they like cards and stickers and know what they got them for". However, this is different to how Jayne, for example, views rewards,

I like stickers... but probably comments. Stickers don't say anything but comments say next steps.

This view is consistent with research that found external rewards do not promote a learning culture even though they might be enjoyed (Clarke, 2000).

The lack of feedback clarity is consistent with that found in student interviews ${ }^{37}$ during advisory work in classrooms. When asked what the sticker, smiley face, or reward meant, typical comments were: "I don't know", "it's neat", "it's marked" or even "we always get one". A Year 6 student participating in the LEARN project (Weeden et al., 1999) said, "A star means a sticker, makes me feel that the work is good and neat" (p.8). The risk here, however, is that the student's focus becomes the reward rather than the achievement. Kohn (1993) also suggests this.

Effective feedback strategies need to be embedded in practice to make a difference (Black \& Wiliam, 1998b; Kearsley, 2002). When the students were given the scenario of Lina's success and the opportunity to give their own examples of what teacher feedback could be, their suggestions included, "good work; you can go to lunch early", and the giving of stickers. This does not necessarily mean that these students only get evaluative feedback. What it is more likely to demonstrate is that new approaches take time to become the 'norm', and until students get used to receiving specific feedback their responses will mirror what they are most familiar with. On reflection Connie, one of the teachers, said "probably sticking on a sticker

37 A component of in-depth advisory work in schools is in class and includes observations and informal interviews with students about their learning. 
and not saying why" was an example of feedback she had given but now thought was not useful. It should be stressed here that the comment refers to stickers as a form of feedback about learning and not about stickers in general.

\subsubsection{Three more warnings and then you're out}

Punishing feedback stands out as extreme compared with other forms. It is directed more at behaviour, "three more warnings and you're out", at the student (removal from the classroom, sent to a corner, taken outside) or at neatness and presentation of work (rip it out, do it again) rather than lack of achievement. Only one comment was to do with getting a poor grade, which was a different result to other research (Black \& Wiliam, 1998b; Suffolk County Council, 2001; Weeden et al., 1999) and the student saw this as a punishment.

Teachers gave less punishing feedback than any other kind, which was the same for other research (Hargreaves, McCallum \& Gipps, 2000; Tunstall \& Gipps, 1996a). There were only three explicit examples, none of which were from the younger students (Weeden et al., 1999). In their response to the Mere scenario, the students confirmed the lack of 'punishing feedback' when they gave their own examples. No-one suggested that teacher feedback would be negative (neither punishing nor disapproving) which is consistent with what they report happening in their classrooms.

\subsubsection{Good work, you're getting good at this}

Written and verbal feedback is frequently to do with approval (Black \& Wiliam, 1998b; Davies, 2003; Knight, 2003; Tunstall \& Gipps, 1996b). Approving comments were the most common evaluative examples given by the students. This was slightly different than Tunstall and Gipps (1996a) who found a relatively even weighting for rewards and approving feedback.

All students gave examples that expressed approval directed at them or at their work. Typical comments were "good boy", and "I'm proud of you". When comments did refer to the work, there was no indication of what was "good" "excellent", "well done", or "awesome". This was the same during advisory work where traditional feedback was observed to be deliberately 'positive' and more aimed at the person or the quantity and presentation of the work, rather than the quality. For example, as reported in the previous chapter, Benjamin demonstrated his awareness of this by saying, "We don't just say 'great' or 'perfect' because it doesn't help". A middle school student in the Suffolk study (Suffolk County Council, 2001) made a similar comment, "She writes comments like 'this is good' but I don't know what good is" (p.10). 
Not all approving comments have a positive impact (Kohn, 1993). This could be partly because teachers mean different things by 'positive' feedback, and comment on work generally (this is super work), focus on the person (you're getting good at this), or comment on effort (keep on trying) (Butler, 1988; Kearsley, 2002; Kohn, 1993; Weeden et al., 1999). If students do not know what the comments mean they have to construct their own meaning. For instance as reported in the previous chapter, Michelle, a good example of this, thought 'excellent' meant it was neat. This may, or may not have been a correct assumption.

The giving of marks or grades are also used to demonstrate approval, and several students talked about getting marks out of ten, or grades, particularly for spelling and mathematics. However, students do not always know the reason for good, or conversely bad, marks or grades. Getting a ' $C$ ' grade, or a mark '8/10', gives no information to the student about what has been achieved well and what needs further work. In other words, what is missing that would make the shift between ' $C$ ' and 'B' or even 'A'? (Butler, 1988; Davies, 2003; Weeden et al., 1999, 2000).

In the first scenario, when the students were given an opportunity to suggest teacher feedback on Lina's success, several gave approving examples such as "that was wonderful", and "congratulations", which again supports the idea that students will mirror what they are most familiar with. However, there is evidence of some thought going into issues around feedback. Benjamin told of his teacher asking the class if they liked comments such as 'great' or 'good', and that they told her "we didn't really know what to work on" (Suffolk County Council, 2001; Weeden et al., 1999).

\subsubsection{I can hear her raising her voice. Why can't she keep it down?}

Feedback showing disapproval is also frequently more to do with behaviour (the teacher might yell at them, tell them to be sensible) and when it appears to be directed at the work there is no real indication of what was not 'up to scratch' or 'not very good' (Suffolk County Council, 2001).

Students quoted disapproving comments made by other class members as well as their teacher. Comments such as, "they said her writing was messy but it wasn't" indicates the sense of unfairness around this kind of feedback (Kearsley, 2002). Comments can be subjective and change according to the situation and feelings at the time. 
Clearly students do not like negative or critical comments and research backs up what was found in this study. This concurs with a student from the Weeden et al. (1999) LEARN project who said, "It makes you feel sad and doesn't help improve work" (p.9). See Crooks (1988, p.469), who points out that feedback should be specific and related to need.

\subsection{Descriptive Feedback}

The difference between evaluative and descriptive feedback is about the focus of the feedback (Bishop et al., 2003; Butler, 1988; Torrance \& Pryor, 1998). The focus of descriptive feedback is on quality and there are four distinct strategies that fall within this category. Two strategies are to do with specifying attainment ${ }^{38}$ and specifying improvement $^{39}$, the other two are more to do with a partnership between teacher and student in constructing achievement ${ }^{40}$ and constructing the way forward ${ }^{41}$.

The examples of descriptive feedback given by the students were mostly to do with 'specifying attainment', 'specifying improvement', and 'constructing the way forward'. There were fewer examples to do with 'constructing achievement'. This is similar to the findings of Tunstall and Gipps (1996a).

While an evaluative emphasis is still a feature, there is a definite shift by teachers to relate feedback to learning. Several students identified feedback that demonstrated an awareness of their own responsibility and their use of the term 'constructive feedback' indicated there were conversations around learning in the classroom (Gipps, 2000).

\subsubsection{Specifying Feedback}

When the two strategies of specifying attainment and specifying improvement are employed, the student retains a relatively passive role and the teacher retains control and power. There is, however, more of a mastery-orientated approach to formative assessment where teachers acknowledge attainment and have some procedures in place (Tunstall \& Gipps, 1996b). For instance, the student is told how/whether the work is good and where improvements need to be made (Gipps, 2000). While 'specifying feedback' is clearly related to a given task, there is still no detail of what has been achieved, what exactly needs to be improved and how this might happen.

Specifying attainment, telling students they are right or wrong.

Specifying improvement, specifying or implying a better way of doing something.

Constructing achievement, discussions around what has been achieved and why.

Constructing the way forward, discussions around next steps and how to take them. 


\subsubsection{That's a terrific story!}

The shift from evaluative feedback to comments about the actual work or learning focus was evident with conscious efforts by teachers to comment further. 'That's terrific' became 'that's a terrific story, and 'well done' became 'well done, you've got half way'. An example was given by Tamara, who said, "She thinks I'm good at writing because I've got my pen license and she says 'it's really neat' like it's tidy". This comment demonstrates that Tamara had some understanding of what she was doing well. Kearsley (2002) also found a shift to descriptive feedback by teachers whose use of evaluative feedback was followed by an explanation. Several of the students' own suggestions for the Lina scenario were examples that specified attainment such as "you're a really fast runner".

\subsubsection{Practise, practise, practise!}

The specifying improvement strategy implies a better way of doing something. It is often no more than a reminder, "practise, practise, practise", “c' for capital" or even "fix it up a bit". These improvement comments are not viewed in the same way as disapproving comments. For instance, as Ruby explained, 'You could fix this up' is not exactly negative or bad, she does point it out". However, feedback like this assumes the student knows how to go about making the improvements. For some a reminder is enough; however other students are left wondering what they need to practise, and what part of their work they need to "fix up." A response from a middle school student in the Suffolk County Council (2001) survey illustrates this point well,

Marking like 'use paragraphs' is useless. If I knew how to use them I would have done (p.10).

Students were aware when learning conversations took place between them and their teacher. This was illustrated in their responses to the Mere scenario when fourteen (over $66 \%$ of the sample) said the teacher could help her with ideas. Three suggested the teacher would give more explanation, and two that the teacher would pair her up with others in the group. These were similar to how they said they would support Mere, by sharing their choices, having her work in their group, giving her an idea, or sharing resources.

\subsubsection{Constructing Feedback}

When the two strategies of constructing achievement are employed the teacher and student form a partnership (Gipps, 2000; Suffolk County Council, 2001). The students are told what they have or have not achieved and why, and with the 
teacher construct the way forward with suggestions about ways they can improve. Teachers who use this type of feedback shift the emphasis more to the child's own role in their learning, encourage students' self-assessment, and provide strategies for improvement (Bishop \& Glynn, 2002; Clarke, 2000; Torrance \& Pryor, 1998). This draws attention to the importance of teachers' knowledge of their students and their involvement with them, as well as their own knowledge and confidence as a teacher in the learning context.

These two aspects of feedback, 'constructing achievement' and 'constructing the way forward' are seen as the most effective (Black \& Wiliam, 1998b; Gipps, 2000; Tunstall \& Gipps, 1996a,b). Several students made comments that showed this was also their view. For instance, Jessie said "that word, [negative], doesn't really belong there, put constructive on the end of negative". Tamara's comment was,

Most of the time we don't give bad negative feedback. We just give constructive criticism. Constructive is like if you need to 'put in' or 'have a more interesting beginning'. Bad is just 'I don't like it'.

This comment demonstrates that there is such a shift away from what students are doing (the task) to what they are learning (see also Clarke, 2000).

\subsubsection{Lovely metaphors! That gives me a mental picture!}

Feedback that constructs achievement is explicit and relates to what is expected of the learning and/or the given task. The comments made by half of the Years 5-6 students indicated that they were becoming increasingly involved in this category of feedback. They were able to remember and articulate what their achievement was, "Great portrait, it looks like him", "You've captured the story in it", "You've got a lot of personal voice" and "Lovely metaphors! That gives me a mental picture!" When Cameron gave the example, "She does say why it's good; 'it's got personal voice' and 'it's got lots of detail'" he demonstrated his own understanding of aspects of quality writing. At the same time he highlighted a framework for self-assessment. The same understandings were shown by the four students who suggested teachers would give Lina more information about why she did so well.

Overall there was less 'constructing achievement' (66\% of the Years 5-6) than 'constructing the way forward' (50\% of Years 3-4 and $91 \%$ of Years 5-6). It was surprising that no Years 3-4 students gave examples of constructing achievement feedback, which was a different result from Tunstall and Gipps' (1996a) research with younger students. 
The New Zealand Assessment Strategy, through the development of national assessment tools and resources, emphasises the importance of giving next steps, or 'feedforward'. This has clearly become a focus area for teachers. However, a balance between the three elements of feedback, which include detailing what has been achieved, needs to be maintained (Boston, 2002; Sadler, 1989). As Hattie (1999) states, a combination of goal setting plus feedback is most effective.

\subsubsection{What's your next step?}

Constructing the next step with students relies on specific teacher knowledge and skills. Being explicit about moving students forward requires knowledge of progressions within curriculum levels as well as skills in questioning (Black \& Wiliam, 1998b). Students gave examples of teacher feedback that construct the way forward such as, "It doesn't have to rhyme, try alliteration", "I like this, but I'm not sure about that" and "what's your next step?" Feedback like this initiates deeper thinking by, or discussion with, the student. Interestingly, the response in this category was higher than for constructing attainment with examples from $50 \%$ of the younger students and over 91\% from Years 5-6. Most students commented that they would "fix up" their work or "try and succeed in their goals" as a result and showed their preference for this type of feedback. Jayne said, "I like the next steps because you can work on them", and Molly, "It's helpful. I kind of like it how she says 'I like this' and when she says, 'I'm not sure about this'". When Molly added, "It's usually kind of what I'm thinking", she demonstrated her ability to reflect and selfregulate. Cameron said of his teacher, "She digs into the core of your writing instead of just doing it shallow" and continued with, "We can improve ideas in our own way or go with it [the teacher's suggestion]. I try changing, I try having a bit of her idea". Students who have been part of other studies have made similar comments (Suffolk County Council, 2001; Weeden et al., 1999).

Some student suggestions for teacher feedback on Lina's success reinforced the idea of a conversation (three students), and that the teacher could give 'next steps' (two students).

While feedback like this can be categorised as descriptive, and there is no doubt about what needs to be improved, it is what happens next that is important. Once students have been made aware of their next steps, or new goal, they need strategies to ensure they are successful (Clarke, 2000; Hattie, 1999; Sadler, 1989). 


\subsection{Is there a match between student understandings and teachers' intentions?}

The students, ranging from Years 3-6, demonstrated their understanding of different strategies of teacher feedback. They were able to describe both behaviour reinforcement and constructive feedback (Gipps, 2000), and many were able to describe feedback that required self-monitoring or self-assessment. Students like Jessie even use the terminology, "She writes constructive [sic], tells you what you need help on or what you should work on next".

There was not, however, always a match between what the teacher intended and what the student understood (Michelle thinking 'excellent' meant her work was neat) and sometimes the student did not understand at all ('see me' meant 'oh no'). This lack of understanding is consistent with what was found by Weeden, et al. (1999), with two Year 3 pupils saying:

Smiley faces are for working hard, neat handwriting, spelling, the right date (p.3).

And

'Good' doesn't help much - he's just saying that it's not very good. I'd like it if he just told the truth (p.9).

Students do not always know what aspects of their work lead to good marks or positive comments from their teacher. This puts into question the type of feedback they receive and therefore their understanding of it (Hattie \& Jaeger, 1998; Kearsley, 2002; Weeden et al., 1999). An example comes from the students who often saw receiving positive feedback as receiving rewards and yet half the teachers said they no longer used them. Students then make their own meaning from the sticker, smiley face, or reward. Typical comments were: "a sticker means I worked hard", and "excellent means it's neat".

The link between what is received as feedback and students' own perceptions of their work is not always obvious (Kearsley, 2002; Weeden et al., 1999). Their perceptions of 'success' were often more to do with quantity, correctness, completion, and neatness, whereas teachers spoke of constructive feedback, selfassessment, and peer assessment as giving students insight. One teacher said she would give comments on bits that were successful and yet her students talked about these comments in terms of stickers, smiley faces, and evaluative comments such 
as 'good work'. While the teacher said she would say why they got a sticker, there was no recollection of this kind of discussion by the students.

Connie thought that students in her class found feedback useful because her suggestions backed up what had been done in the teaching session. She had also often seen her suggestions taken 'on board'. Liana didn't know if her students found feedback useful but then said, "yes they do! They [talk about] 'I've met my goal'." Both Suzie and Rae thought their students found feedback useful. Suzie knew this through the class review and survey previously mentioned. She commented that "children say it all the time; they ask for it [feedback] and get miffed if they don't get it. They ask for particular feedback like, 'have I got a good conclusion?"'

The students backed much of this up. Ruby spoke of her teacher, "At the beginning of the year we write personal goals. Her [teacher] goal was to give more oral feedback. She doesn't want to put a sticker and 'good'". Rae sought input from her students about what was helpful, "We had a talk the other day about what we next need to achieve and what I need to give them in order to achieve." She said their response was "feedback" and that "They feel hardly done by without our sharing session when we choose two people to give feedback". These examples demonstrate that the teachers value, and expect, their students' input. There is a partnership, or a sharing of control, between teacher and student (Bishop et al., 2003; Boston, 2002; Gipps, 2000).

There was also some match between what teachers and students said happened as a result of feedback. Most students also said they would "fix up" their work or "try and succeed in their goals" as a result of feedback (Bangert-Drowns, 1991; Clarke, 2000; Hattie, 2002). Rae said, "The students often go away then and there (often with a buddy) and fix it. Sometimes they don't agree and that's the way I like it." Cameron echoed this when he said he could improve ideas his own way or go with the teacher's suggestion. Benjamin said of his teacher, "she's trying to write things that help. I'm starting to read the comments, I just didn't like reading things but now I'm more into reading them".

Interestingly, students who spoke knowingly about constructive teacher feedback did not always offer descriptive feedback themselves. This further highlights the need to embed new strategies or approaches so they become 'the way we do things'. Schools need to adopt a planned approach to ensure this occurs (Black \& Wiliam, 1998b). The more the feedback is specific and learning related, the more 
likely there will be a match between what is intended and what is internalised and understood.

While it might not yet be embedded, it is beginning to happen (Dixon \& Williams, 2000).

\subsection{Is it more than just feedback?}

For assessment to be formative, feedback information has to be against expectations that have been shared with, and understood by, the students. This information needs to motivate some kind of response by the students (Davies, 2003; Kearsley, 2002). Any process of feedback must take into account the way students make sense of, and use, feedback information. Students need to be trained, they need to develop the skills and ability to receive feedback and to recognise quality and success (Hattie, 1999; Hattie \& Jaeger, 1998; Kearsley, 2002; Sadler, 1989). It is more than just 'feedback' and care needs to be taken that there is a common understanding about what determines the quality. As noted earlier, 'evaluative' and 'descriptive' categories of feedback do not automatically include assessment for learning principles.

Feedback has more impact on students if it is focussed against learning intentions and success criteria, and suggests explicit strategies for improvement (Black \& Wiliam, 1998b; Clarke, 2000; Gipps, 2000; Hargreaves \& McCallum, 1998). The difference is in the detail; moreover, the same detail students expect to be commented on. It is about transparency; students must know what the learning 'looks like', with the focus and expectations articulated, shared, or even better, negotiated. Only then will they know what they are aiming for (Black \& Wiliam, 1998b; Clarke, 2000; Gipps, 2000). Students find this transparency helpful and are able to discuss elements of their work and what they are focussing on. For instance, "[I would say] what I really liked and really what they could improve on. I look for description, too many of one word and too little detail or description. We have success criteria at the front of our book". Effective formative feedback has students and teachers discussing what has been successful, and taking some action to meet new goals (Sadler, 1989).

Feelings of success and positive attitudes about achievement need to be encouraged and become part of the classroom culture (Bishop et al., 2002). Students in these classrooms are motivated, know what the personal gains are 
(Suffolk, 2002) and are given time to act on the feedback they have received (Black \& Wiliam, 1998b; Clarke, 2000; Suffolk County Council, 2001).

An earlier comment was made about the use of the typology as a research tool. While descriptors of the different categories are made clear, as a tool for organising observed feedback it does not ensure the user checks comments against expectations that have been articulated. Descriptive feedback details what has been achieved but this needs to be the same detail the student has put effort into. For this reason, the typology (refer Table 5.5) has been adapted so that feedback is part of a formative assessment structure, ensuring there is detail against the learning intention and success criteria as understood by the student. This has produced a typology that could be tested in a larger study.

Table 5.5: An adaptation of the Tunstall and Gipps' (1996b) typology

\begin{tabular}{|c|c|c|c|c|c|c|c|}
\hline \multicolumn{4}{|c|}{ Evaluative Feedback } & \multicolumn{4}{|c|}{$\begin{array}{l}\quad \text { Descriptive Feedback } \\
\text { Evidence that feedback relates to a shared } \\
\text { learning intention and success criteria for a } \\
\text { given task. } \\
\text { Circle } \sqrt{ } \text { or } \mathrm{x}\end{array}$} \\
\hline \multicolumn{2}{|c|}{ Positive feedback } & \multicolumn{2}{|c|}{ Negative Feedback } & \multicolumn{2}{|c|}{ Specifying Feedback } & \multicolumn{2}{|c|}{$\begin{array}{l}\text { Constructing } \\
\text { feedback }\end{array}$} \\
\hline Rewarding & $\begin{array}{c}\text { Approving } \\
\text { B1 }\end{array}$ & $\begin{array}{c}\text { Punishing } \\
\text { A2 }\end{array}$ & $\begin{array}{c}\text { Disapproving } \\
\text { B2 }\end{array}$ & $\begin{array}{c}\text { Specifying } \\
\text { attainment } \\
\text { C1 }\end{array}$ & $\begin{array}{c}\begin{array}{c}\text { Specifying } \\
\text { Improvement }\end{array} \\
\text { C2 }\end{array}$ & $\begin{array}{c}\text { Constructing } \\
\text { achievement } \\
\text { D1 }\end{array}$ & $\begin{array}{c}\text { Constructing } \\
\text { the way } \\
\text { forward } \\
\text { D2 }\end{array}$ \\
\hline & & & & $x$ & $\sqrt{ }$ & $\sqrt{ }$ & $\sqrt{ }$ \\
\hline
\end{tabular}

\subsection{Other Points for Discussion}

The relationship between other factors impacting on students' perceptions of their achievement will be discussed in the final section of this chapter. These have emerged as possibilities from the data but have not been the main focus of the report.

\subsubsection{Is there a relationship between enjoyment, feelings about ability, and feedback?}

It was surprising that no students made direct reference to feedback as something that made a particular curriculum enjoyable. In contrast, the two Years 5-6 teachers thought students' reasons for enjoyment were to do with "lots of discussion" and "specific feedback". What was particularly interesting was that there was little correlation between teacher feedback and what students thought they were best at. Less than a third of the sample identified that there was a link between their feelings of achievement and teacher feedback. Students said that teachers either had not spoken to them about it, "not really" or "not to make me think I'm best at it". This 
indicates that more than two thirds of the students appear to have made judgments from sources other than their teacher, even though half the teachers thought their feedback was key to students making decisions about their ability.

Students did not seem to think their teachers knew what they found difficult either, whereas the teachers said they knew through clues, such as body language, or by using teaching strategies such as breaking down the learning steps and 'buddying' up students. While these strategies are effective (Black \& Wiliam, 1998b; Clark, 2000), prevention of possible difficulties is not the same as recognition of actual difficulties. Literature suggests the relationship between feedback and ability should be strong and that assessment and feedback are part of instruction, and influence how students perceive their ability (Kearsley, 2002).

The relationship between enjoyment and achievement was strongest with ten students $(63 \%$ of the sample) identifying the same curriculum area for both. For five students this was for maths, four students for writing and one for art. The notion that success is enjoyable is not surprising but it is disappointing that the teacher did not feature as part of the picture. There is no guarantee that students will make sound judgments about their own ability (Gipps, 2000). Interestingly two teachers (half the sample) made the point that they thought the feedback they gave to their students made them feel 'empowered' and 'valued' (Gipps, 2000). While this is a desirable outcome in a success culture, the student needs to be a partner in the process if 'empowerment' and 'feeling valued' are to result in knowing.

Looking across the range, the relationship between all these aspects (teacher comments, enjoyment and feelings of success) was not strong and only four students ( $25 \%$ of the sample) made links to all three. While feedback frequency was not a focus of this research, the relatively low profile of feedback between these relationships would seem to back up Hattie and Jaeger's (1998) suggestion that "the incidence of feedback in the typical classroom is very low" and even possibly that it is, "usually in seconds at best per day" (p.114). A visual picture that demonstrates the relationship between feedback, aspects of enjoyment, and perceptions of ability is outlined in Table 5.6. 
Table 5.6 The relationship between enjoyment, feelings of ability, and teacher comments

\begin{tabular}{|c|c|c|c|c|c|c|c|c|c|c|}
\hline & \multicolumn{4}{|c|}{ Literacy } & \multirow{2}{*}{$\begin{array}{l}\stackrel{n}{E} \\
\stackrel{\pi}{\Sigma} \\
\Sigma\end{array}$} & \multirow[t]{2}{*}{$\frac{T}{<}$} & \multirow{2}{*}{ 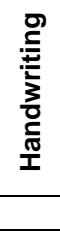 } & \multirow{2}{*}{ 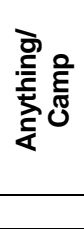 } & \multirow{2}{*}{ 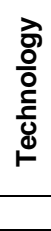 } & \multirow{2}{*}{ के } \\
\hline & Reading & Writing & Spelling & English & & & & & & \\
\hline \multicolumn{11}{|l|}{ Years 3-4 } \\
\hline Anna & $\sqrt{ }$ & $\sqrt{ } \sqrt{ }$ & & & & & & & & \\
\hline Erika & $\sqrt{ } \sqrt{ }$ & $\sqrt{ } \sqrt{ }$ & & & & & $\sqrt{ }$ & & & \\
\hline Michael & $\sqrt{ }$ & $\sqrt{ } \sqrt{ }$ & $\sqrt{ }$ & $\sqrt{ }$ & $\sqrt{ }$ & & $\sqrt{ }$ & & & \\
\hline Sandi & $\sqrt{ }$ & $\sqrt{ }$ & & $\sqrt{ }$ & & & $\sqrt{ }$ & $\sqrt{ }$ & & \\
\hline \multicolumn{11}{|l|}{ Years 5-6 } \\
\hline Dana & & $\sqrt{ }$ & & & $\sqrt{ }$ & $\sqrt{ }$ & & & & \\
\hline Helena & & $\sqrt{ }$ & $\sqrt{ }$ & & & & & & & \\
\hline \multirow[t]{2}{*}{ Michelle } & & $\sqrt{ } \sqrt{ } \sqrt{ }$ & & & & & $\sqrt{ } \sqrt{ }$ & & & \\
\hline & $\sqrt{ }$ & $\sqrt{ }$ & & & & & & $\sqrt{1}$ & $\sqrt{ }$ & \\
\hline Allan & $\sqrt{ }$ & $\sqrt{ }$ & $\sqrt{ }$ & $\sqrt{ }$ & $\sqrt{ } \sqrt{ }$ & $\sqrt{ }$ & $\sqrt{ }$ & $\sqrt{ }$ & $\sqrt{ }$ & $\sqrt{ }$ \\
\hline Molly & & $\sqrt{ } \sqrt{ }$ & & & $\sqrt{ } \sqrt{ }$ & & & $\sqrt{ }$ & & $\sqrt{ }$ \\
\hline Jayne & $\sqrt{ }$ & & $\sqrt{ }$ & & $\sqrt{ } \sqrt{ }$ & $\sqrt{ }$ & & & & \\
\hline Tamara & & $\sqrt{ }$ & & $\sqrt{ }$ & & $\sqrt{ } \sqrt{ }$ & $\sqrt{ }$ & & & \\
\hline Cameron & & $\sqrt{ } \sqrt{ }$ & & $\sqrt{ }$ & $\sqrt{ }$ & & & & & \\
\hline Benjamin & & $\sqrt{ } \sqrt{ }$ & & $\sqrt{ }$ & $\sqrt{ } \sqrt{ }$ & $\sqrt{ }$ & $\sqrt{ }$ & $\sqrt{ }$ & & \\
\hline Ruby & & $\sqrt{ }$ & & & $\sqrt{ }$ & & & $\sqrt{ }$ & & \\
\hline Jessie & & $\sqrt{ } \sqrt{ }$ & & & $\sqrt{ }$ & & & $\sqrt{ }$ & & \\
\hline
\end{tabular}

KEY: $\quad \sqrt{ }$ Work students most enjoyed

$\sqrt{ }$ Work students thought they were best at

$\checkmark$ Work 'marked' by teacher

\subsubsection{Are teacher decisions influenced by Government Priorities ${ }^{42}$ and do these decisions impact on students?}

Numeracy and literacy are two current government priority areas that are very evident in schools. Most schools have made one, or both, a focus for teacher professional development, teaching and learning programmes, and student achievement targets for planning and reporting ${ }^{43}$. This suggests that decisions are influenced by government priorities as all teachers spoke of a numeracy and literacy focus in their schools. They were also at the forefront of students' minds as their examples of feedback were particularly in these areas. A strong relationship between enjoyment and achievement in numeracy and/or literacy was identified by $63 \%$ of the sample as a priority for teacher feedback. Students most frequently mentioned writing as a focus for teacher feedback. Mathematics was the least mentioned of the two, and it was "marked in class", "marked from the board" or when feedback was given it was in the form of marks ("ten out of ten") or similar. Table 5.6 shows a clear weighting for literacy and maths in relation to the other curriculum areas.

\footnotetext{
42 Government priorities have included literacy (Literacy Leadership) and Numeracy (the Numeracy Project) seen as areas of need. They have been specifically added to the National Education Guidelines (NEGs) and have been allocated special funding and resources. http://www.minedu.govt.nz

43 There should be, but not always is, a strong link between a school's strategic planning, student targets, teacher professional development and reporting.
} 
It is difficult to gauge how much student enjoyment and feelings of ability in these curriculum areas is enhanced because of teachers' own growth in knowledge, confidence and the increasing range of teaching strategies used as a result of a school focus.

\subsubsection{Other Issues}

Other initiatives that have been a focus for schools, and are likely to have made an impact, include 'Assessment for Learning' ${ }^{44}$ and work around 'Quality Teaching'. The ten characteristics identified by Alton-Lee (2003) have been integrated into professional learning programmes over the last eighteen months.

The most obvious difference between the different age groups was that Years 3-4 students referred more often to behaviour and presentation whereas Years 5-6 students referred more to aspects of their learning (cf. Weeden et al., 1999). The younger students all responded with positive feedback examples (100\% 'rewarding' compared with $50 \%$ for Years 5-6) with no negative feedback examples, as opposed to the older students with $25 \%$ 'punishing' and 33\% 'disapproving'. There is no evidence that these differences are anything more than developmental. It is worth noting though that there was a discrepancy within year groups and responses varied from students in the same class. One glaring example was that when asked about receiving written feedback one student said "no", another said "maths sometimes", and the others said "writing".

The final chapter will sum up the key findings and outline implications that have emerged as well as possible future research topics.

44 There have been Ministry of Education funded projects in schools that have a formative assessment focus. These will be well known as Assessment for Better Learning (ABeL) and, more recently, Assess to Learn (AtoL). 


\section{CHAPTER SIX}

\section{Summary}

\subsection{Key Findings}

The investigation, which used a sample of sixteen students over four classrooms and two schools, answered the research question, what are students' understandings of feedback in New Zealand classrooms? The findings highlighted the different feedback received by students and their understandings of the feedback. The research also found the feedback typology created by Tunstall and Gipps (1996b), a tool to differentiate the different types of feedback given.

A range of feedback strategies emerged from the analysis that was consistent with the typology to include evaluative and descriptive categories. This study identified a number of trends and enabled transferability. Evaluative feedback is still a feature where teachers assess quantity, presentation, and behaviour rather than the quality of learning. Comments are often to do with effort, presentation and accuracy. Even when disapproving feedback is directed at the students' work there is no information about what is not good.

Marks and grades are frequently used as feedback but add no detail about what has been achieved and what needs further attention. Feedback is predominantly, and deliberately positive, especially for younger children, and teachers steer away from negativity. There is, however, a definite shift by teachers to move away from giving evaluative feedback towards meaningful focussed feedback. This shift is reflected in the comments and attitudes of the students.

Most descriptive feedback examples were to do with 'specifying attainment', 'specifying improvement', and 'constructing the way forward'. Teachers in this study made less reference to 'constructing achievement', which is something that should be investigated further. Much of the research emphasises the need for the three aspects of feedback (current achievement, next steps, closing the gap strategies) to be considered together.

There are two distinct levels within descriptive feedback and many comments, while clearly related to the task, are still not specific about the detail of what is achieved or what needs to be improved. The specifying improvement strategy implies a better way of doing something but is often no more than a reminder, which assumes 
students know how to make the improvements. When students are given constructive feedback, they demonstrate ability to self-monitor and make reliable judgements about their own learning. They clearly prefer this kind of feedback and respond to it by making the improvements and 'fixing it up'.

In-depth feedback of this type relies on the knowledge and skills of the teacher. Effective questioning skills and sound content knowledge of progression through curriculum levels are necessary aspects of this and need to be fostered. Practice and a confident approach would go a long way to eliminate differences between student understanding (and therefore attaching their own meaning) and teacher intention.

When the students were given the opportunity to give their own suggestions for feedback, they did not always offer descriptive feedback. The implementation of new approaches takes time and therefore needs to be given time. Changes to student perceptions of feedback do not start to show until they are used to being part of the feedback process. While there is a shift in thinking about feedback it is not yet embedded and until it is transparent, students will mirror what they are most familiar with.

Because literacy and numeracy are a focus for schools, feedback is concentrated in these areas and the examples students give reflect this. Making connections between enjoyment, difficulties, achievement and feedback in other curriculum areas becomes difficult and students have to use sources other than their teacher to make judgements.

Formative assessment and frequent feedback help enhance learning and inform and adjust teaching and learning. Formative assessment links to a whole network of ideas; how children think about themselves, what they think learning is, how they know when they have succeeded. Informal classroom assessment that provides constructive feedback to students is central to effective teaching.

While the categories of feedback were useful they were found to be problematic in a formative assessment context. Whilst the comments fit into the typology as descriptive feedback, they do not necessarily relate to shared aspects, or the 'learning intention', and the expectations or 'success criteria' of a given task. 
These findings are consistent with those of other studies reviewed. The research literature on formative assessment has made it possible to identify some broad principles of good feedback practice which include:

- Motivation and beliefs that students can achieve

- Clarification and sharing of goals, criteria, expected standards

- Self-assessment in learning

- Teacher and peer conversations around learning

- High quality information to students about their learning

- Opportunities for next steps and support for closing the gap

- Information for teachers and their practice.

The better the complexities of feedback are understood, the better teachers will think about the issue and make or apply changes.

In addition to my formal research, and as part of my work as adviser to schools, I have collected samples and comments on feedback by students in a variety of learning situations. These situations include a range of curriculum areas and a range of teaching levels.

Delivery of the assessment programme in schools has included frequent visits into teachers' to observe verbal, non-verbal, and written feedback, given and received. The observation focus is transparent, that is planned, and lasts thirty minutes with immediate release for the teacher for feedback and discussion.

For these schools, the importance of quality feedback has been a significant focus of the professional development they have been part of. Considerable changes have been observed in teacher practice over the involvement. The biggest change perhaps is when teachers have acknowledged the need to constantly reflect on, and challenge, their own practice (particularly when students are underachieving).

Most schools taking part consider the need for at least two years in-depth support if they are to sustain changes. In order to give teachers feedback, a tool was designed to record in-class observations, take notes about marked work, and to ask students questions informally. In this way student understanding of their achievement and what they needed to work on next was investigated. When relevant, these comments from students and teachers have been included as part of the data. 


\subsection{Implications}

For teachers in New Zealand, where there is a national emphasis on addressing diversity and raising achievement, constructive feedback is a key strategy for developing a partnership with all students.

\subsubsection{For Policy and Practice}

The findings are useful and could be used to support teachers' learning to improve their understanding of feedback and its complexities. The more they are given opportunities to share and discuss issues around feedback the easier they will apply formative feedback principles. While feedback is seen as a key to improving learning, this notion has yet to be embedded in practice.

Some approaches to assessment and feedback remain traditional, have minimal student involvement and give little or no useful information. A balance needs to be found for summative and formative assessments so that all learning is monitored but nothing is measured without learning.

It is much more than just 'feedback' and teachers and students need to have a common understanding about what determines learning and the quality of the learning. Students need to be involved in the assessment process and be encouraged to reflect on their own performance in order to become self-monitoring and self-regulating learners.

There is a definite emphasis on numeracy and especially literacy in schools. Students in this study gave feedback examples mostly within these curriculum areas. The arts, technology and physical education were mentioned independently but almost all students were unaware of any learning in social studies. An opportunity exists, which is not always utilised, for areas such as social studies and science to be used as a context for literacy development.

In the short term, the findings will impact on decisions made about the content of professional development programmes. In the longer term, further areas for development and/or research are likely to emerge.

Policy makers and programme developers should acknowledge the time needed for change. Time needs to be considered at the planning stage if the development of formative assessment strategies and tools is to be sustained as part of classroom practice. 


\subsubsection{For Further Research}

There is a need for further research of students' perspectives in the context of New Zealand classrooms. There are opportunities for researchers to also work alongside teachers employing action research strategies.

The study showed that parents and 'buddies' (peers) are both likely to give feedback. This could be investigated further.

The impact of feedback on student achievement, particularly with a focus on underachievers, would add significantly to an existing body of knowledge. Feedback in the context of formative assessment could be investigated using, for example, the typology adapted and outlined in Chapter 5.

The extent to which better informed feedback works for students from different cultural backgrounds as a research focus could inform future professional development in assessment.

Another subject for research could be to gauge how much student enjoyment and feelings of ability are enhanced because of teachers own growth in knowledge, confidence and the increasing range of teaching strategies used as a result of a school focus. This could be confined to a particular curriculum area.

As an extension of this study, different age groups could be investigated. It would be interesting to test this with older students such as early secondary (Years 9-10) as part of future research. There could also be further investigation using the same schools to explore student understandings, and the number of misunderstandings, as ideas become embedded and sustained. 


\section{References}

Alton-Lee, A. (2003). Quality teaching for diverse learners in schooling: Best evidence synthesis. Wellington: Ministry of Education.

Assessment Reform Group. (1999). Assessment for learning: Beyond the black box. Cambridge: University of Cambridge School of Education.

Assessment Reform Group. (2002). Assessment for learning: 10 principles Retrieved from: http://www.aaia.org.uk

Bangert-Drowns, R.L., Kulik, C-L., Kulik, J.A., \& Morgan, M.T. (1991). The instructional effect of feedback in test-like events, Review of Educational Research, 61, 213-238.

Bishop, R., Berryman, M., Tiakiwai, S., \& Richardson, C. (2003). Te kötahitanga: The experiences of year 9 and 10 Māori students in mainstream classrooms. Hamilton: Māori Education Research Institute (MERI) School of Education, University of Waikato; Tauranga: Poutama Pounamu Research and Development Centre.

Bishop, R., \& Glynn, T. (2002). Kaupapa Māori messages for the mainstream: Professional development (pp.4-7). Set 1. Hamilton: School of Education, University of Waikato

Black, P., Harrison, C., Lee, C., Marshall, B., \& Wiliam, D. (2002). Working inside the black box: Assessment for learning in the classroom. London: Department of Education \& Professional Studies, Kings College.

Black, P., Harrison, C., Lee, C., Marshall, B., \& Wiliam, D. (2003). Assessment for learning: Putting it into practice. Buckingham: Open University Press.

Black, P., \& Wiliam, D. (1998a). Assessment and classroom learning. Assessment in Education, 5 (1), 7-75.

Black, P., \& Wiliam, D. (1998b). Inside the black box: Raising standards through classroom assessment. London: School of Education, King's College.

Black, P., \& Wiliam, D. (2003). In praise of educational research: Formative assessment. British Educational Research Journal, 29 (5).

Boston, C. (2002). The concept of formative assessment. Practical Assessment, Research \& Evaluation, 8 (9). Retrieved March 8, 2005 from:

http://PAREonline.net/getvn.asp?v=7\&n=9

Bourke, R. (2001). Listen to me! Students' voices in educational research on learning. Submitted proposal. Retrieved 2002 from: http://edtech.connect.msu.edu/searchaera2002/viewproposaltext.asp?proplD=3957

Butler, R. (1988). Enhancing and undermining intrinsic motivation: The effects of task-involving and ego-involving evaluation on interest and performance. British Journal of Educational Psychology, 58, 1-14.

Butterfield, S., Williams, A., \& Marr, A. (1999). Talking about assessment: Mentorstudent dialogues about pupil assessment in initial teacher training. Assessment in Education, 6 (2), 225-250. 
Clarke, S. (2000). Closing the gap through feedback in formative assessment: Effective marking in elementary schools in England. Paper given at AERA Conference New Orleans. Symposium Classroom Assessment, Learning and Teaching: Research from Elementary Schools in the UK.

Crooks, T.J. (1988). The impact of classroom evaluation practices on students. Review of Educational Research, 58, 438-481.

Davies, A. (2003). Feed back ...feed forward: Using assessment to boost literacy learning. Online journal. Research in Action. Canada: Classroom Connections International. Retrieved from: www.connectionspublishing.ca

Denscombe, M. (1998). The good research guide. Buckingham: Open University Press.

Denzin, N.K., \& Lincoln, Y.S. (1998). Strategies of Qualitative inquiry. Thousand Oaks, CA: Sage.

Denzin, N.K., \& Lincoln, Y.S. (1994). Strategies of inquiry. In N.K. Denzin \& Y.S. Lincoln (Eds.), Handbook of qualitative research. Thousand Oaks, CA: Sage.

Dixon, H., \& Williams, R. (2000). Formative assessment: Facts, fantasies and falsehoods. Paper presented to the $18^{\text {th }}$ World Congress on Reading, Auckland, July 11-14.

Flockton, L., \& Crooks, T. (2001). Reading and speaking assessment results 2000. National Education Monitoring Report 19. Wellington: Ministry of Education.

Gipps, C. (1994). Beyond testing: Towards a theory of educational assessment. London: Falmer.

Gipps, C. (2000). Sociocultural perspectives on assessment. In G. Wells \& G. Claxton (Eds.), Learning for life in the 21st century (Chapter 6). Available online at: http://www.tki.org.nz

Gipps, C., \& Tunstall, P. (1998). Effort, ability and the teacher: Young children's explanations for success and failure. Oxford Review of Education 24 (2), 149166.

Hargreaves, E., McCallum, B., \& Gipps, C. (2000). Teacher feedback strategies in primary classrooms: New evidence. In S. Arken (Ed.), Feedback for learning. London: Routledge/Falmer.

Harlen, W. (1998). Classroom assessment: A dimension of purposes and procedures. In K. Carr (Ed.), SAMEpapers (pp.75-97). Hamilton, New Zealand: Centre for Science, Mathematics and Technology Educational Research, University of Waikato.

Hattie, J. (1999). Inaugural Lecture, Auckland University.

Hattie, J. (Speaker). (2002). The power of feedback. (Cassette recording No. P.F.8) Recorded by Auckland Recording Service. Keynote address presented at the New Zealand Principals' Federation Conference, Wellington, June. 
Hattie, J. (2002). What are the attributes of excellent teachers? Teachers make a difference: What is the research evidence? (pp.3-27). Wellington: New Zealand Council of Educational Research.

Hattie, J., \& Jaeger, R. (1998). Assessment and classroom learning: A deductive approach. Assessment in Education, 5 (1).

Heath, A.W. (1997). The proposal in qualitative research. The Qualitative Report, 3 (1). March. Retrieved September 11, 2001 from: http://www.Nova.edu/ssss/QR/QR3-1/heath.html

Kearsley, I. (2002). Build on the rock: Teacher feedback and reading competence. The Australian Journal of Language and Literacy, 8, 25 (1).

Knight, N. (2003). Teacher feedback to students in numeracy lessons: Are students getting good value? (pp.40-45). Set: Research Information for Teachers 3. New Zealand: NZCER.

Kohn, A. (1993). Punished by rewards: The trouble with gold stars, incentive plans, $A$ 's, praise, and other bribes. Boston: Houghton Mifflin.

Lange, D. (1988). Tomorrow's Schools: The reform of education administration in New Zealand. Wellington: Government Printer.

McCallum, B. (2000). Formative assessment: Implications for classroom practice. Journal of Curriculum. Retrieved from: www.Itscotland.org.uk.assess/projects.

Nash, R., \& Prochnow, J. (2004). Is it really the teachers? An analysis of the discourse of teacher effects on New Zealand education policy. New Zealand Journal of Educational Studies, 30 (2), 175-192.

New Zealand Association for Research in Education. (1998). Ethical guidelines. Retrieved from: http://www./nzare.org.nz.

New Zealand Ministry of Education. (1993). The New Zealand curriculum framework. Wellington: Learning Media.

New Zealand Ministry of Education. (1999). National administration guidelines. Education Gazette, 78, 29 November. Available online at: http://www.minedu.govt.nz

New Zealand Ministry of Education. (2005). Schooling strategy 2005-2100. Retrieved from: http://www.minedu.govt.na

Nicol, D.J., \& Macfarlane-Dick, D. (2004). Rethinking formative assessment in HE: A theoretical model and seven principles of good feedback practice. Higher Education Academy. Retrieved from: http://www.heacademy.ac.uk/assessment

Pollard, A. (1997). Reflective teaching in the primary school: A handbook for the classroom ( $3^{\text {rd }}$ ed.). London: Cassell.

Ramaprasad, A. (1983). On the definition of feedback. Behavioural Science, 28, 413.

Ronayne, M. (2002). Marking and feedback. SET: Research information for teachers 2, 8-11. 
Sadler, R. (1989). Formative assessment and the design of instructional systems. Instructional Science, 18, 119-144.

Schwandt, T.A. (1994). Constructivist, interpretivist approaches to human inquiry. In N.K. Denzin \& Y.S. Lincoln (Eds.), Handbook of qualitative research. Thousand Oaks, CA: Sage.

Smith, A. (1996). Incorporating children's perspectives into research in New Zealand. Unpublished manuscript, Children's Issues Centre, University of Otago.

Suffolk County Council. (2001). How am I doing? Assessment and feedback to learners. Ipswich: Suffolk Advisory Service. Retrieved from: http://www.slamnet.org.uk/assessment/edp booklet.htm

Suffolk County Council. (2000). Classroom assessment: A survey of current practice in Suffolk schools. Retrieved from: http://www.slamnet.org.uk/assessment/classroomassessment

TGAT. (1987). National Curriculum Task Group on Assessment and Testing: A report. London: Department of Education and Science and the Welsh Office.

Timperley, H. (2004). Enhancing professional learning through evidence-based inquiry. Paper prepared for the Symposium on Teacher Quality, 23-24 June.

Torrance, H., \& Pryor, J. (1998). Investigating formative assessment: Teaching and learning in the classroom. Buckingham: Open University Press.

Tunstall, P., \& Gipps, C. (1996a). How does your teacher help you to make your work better? Children's understanding of formative assessment The Curriculum Journal, 7 (2), 185-203.

Tunstall, P., \& Gipps, C. (1996b). Teacher feedback to young children in formative assessment: A typology. British Educational Research Journal, 22 (4), 389-404.

Weeden, P., \& Winter, J., with Broadfoot, P., Hinett, K., McNess, E., Tidmarsh, C., Triggs, P., \& Wilmut, J. (1999). Learners' expectations of assessment for learning nationally. The Learn Project: Report for the Qualifications and Curriculum Authority, September. Bristol: University of Bristol Graduate School of Education CLIO Centre for Assessment Studies.

Weedon, P., Winter, J., Broadfoot, P. (2000). The Learn Project: Guidance for schools on assessment for learning: Project report, June.

Wiliam, D. (1999). There is no alternative: Mitigating the tension between formative and summative functions of assessment. Paper presented at the $8^{\text {th }}$ conference of the European Association for Research on Learning and Instruction, Gothenburg, August.

Wiliam. D., \& Black. P. (1996) Meanings and consequences: A basis for distinguishing formative and summative functions of assessment. British Educational Research Journal, 22, 537-548. 


\section{Appendix 1: $2^{\text {nd }}$ Pilot Study - The interview questions}

1. You do lots of different kinds of work in class. What class work do you enjoy doing most?

What makes you think you enjoy it?

2. Think about your work in class and tell me what you are best at.

Has your teacher talked to you about it (subject)?

What did the teacher say about it...?

Any other times?

What did your teacher write about it on your work? How often?

What did your parents / people you live with say about it?

How did you feel about that?

3. Is there any work, or subject, that you have found a bit tricky?

What did you do about it?

What did the teacher do about it?

4. Is there anything your teacher has said you need to get better at?

What happened, what did your teacher say? Write? Do?

How did you feel about that?

What did you do as a result of that?

5. Do you have goals about what you need to work on next?

Tell me about a learning goal you have

What made you choose this goal?

Did anyone help you? How, what did she/he do?

How you are getting on with your goal?

How do you know? 


\section{Appendix 2: Final student interview questions}

1. You do lots of different kinds of work in class. What class work do you enjoy doing most? What makes you think you enjoy it?

2. Think about your work in class and tell me what you are best at.

Has your teacher talked to you about it (subject)?

What did the teacher say about it...?

Does your teacher always say that?

Does your teacher write about anything on your work?

What kind of work does your teacher write on?

What does he/she say?

How do you feel about it?

What do you do about it?

Do you show people at home the teacher's comments?

What do they say about your work?

How do you feel about that?

3. Is there any work you have found a bit tricky?

Could you tell me a little bit about that?

What did you do about it?

What did the teacher do about it?

Did he/she...?

4. Is there anything your teacher has said you need to get better at?

What happened, what did your teacher say? Write? Do?

How did you feel about that?

What did you do as a result of that?

5. Do you know what feedback is?

If you hear feedback to others that is not good, (negative), how do you feel?

If you hear good (positive) feedback to others, how do you feel? 


\section{Appendix 3: Teacher Questions}

1. The children in your class were asked what they enjoy most. They almost all identified aspects of either English (in particular literacy) and Maths.

Does this surprise you?

Why? Why not?

Why do you think this is the case?

2. The children were also asked what they thought they were best at. In your classroom what information do they get that would help them know this?

3. If a child in your class has been successful in a given piece of work what would you say/write?

4. If a child in your class has had difficulty with a given piece of work what would you say/write?

5. How do students in your class know what they need to get better at?

6. What sort of feedback do you think students like the most?

Something you say?

Something you write?

Certificates, stickers, positive comments, special cards?

7. Does the type of feedback change according to the curriculum area?

8. Have you ever used feedback that you thought wasn't useful?

9. What feedback have you found to be particularly effective?

10. Do students in your class think feedback is useful?

How do you know?

What do they do? Action?

11. What do you see is the value of feedback for learning?

12. Is there any other comment you would like to make about feedback? 


\section{Appendix 4: Letter to Principal}

28 June 2004

Dear

My name is Deidre Vercauteren and I am an adviser for School Support Services Wellington College of Education. I am Co-ordinator of the primary advisers and also lead an assessment program me we are delivering to schools.

Classroom assessment and the impact of quality feedback is a particular interest of mine.

I am currently working on my Master of Education thesis and would like to ask permission to interview children at your school. The focus of my research is on how students understand feedback they receive in class.

I would like to interview a total of 8 Years 5-6 students, 4 from 2 different classrooms. The only consideration would be to include a range of gender and ability.

Students will be interviewed individually for no more than 30 minutes. I will be taping each interview with the understanding that participants may request to switch off the recorder at any point. Students may withdraw without giving reasons. At a later time I would like to conduct a short interview with each of the two teachers to clarify points that might arise.

My research question is: What are student understandings of feedback in New Zealand primary schools?

Confidentiality is assured and any names used in the final report will be fictitious. A summary of the teacher's interviews will be available to them for comment so that what was said is reflected accurately.

At the conclusion of the study I will provide the school with a brief report. It is intended that the information will be used for publication in teacher journals. All data will be stored in a locked cabinet and will be destroyed after 3 years.

Should you wish for further information please contact me, on 924 2112, or my supervisor Dr Geraldine McDonald, at Wellington College of Education.

Many thanks for your support.

Yours sincerely

Deidre Vercauteren

\section{Consent form for Principals}

I have read Deidre's description of her study and agree to students and teachers my school taking part in an interview conducted by her.

Signed

Date 


\section{Appendix 5: Letter to Teacher}

28 June 2004

Dear

My name is Deidre Vercauteren and I am an adviser for School Support Services at Wellington College of Education. I am Coordinator of the primary advisers and also lead an assessment programme we are delivering to schools. Classroom assessment and the impact of quality feedback is a particular interest of mine.

I am currently working on my Master of Education thesis and would like to ask permission to interview 4 children from your classroom. The only consideration would be to include a range of gender and ability.

Students will be interviewed individually for no longer than 30 minutes and will be taped with the understanding that the recorder may be switched off at any time.

My research question is "What are student understandings of feedback in New Zealand primary schools?"

At a later time I would like to conduct a short interview with you clarify points that might arise. A summary of the interview will be returned to you for comment so that it reflects accurately what you said. All participants may withdraw at any time without giving reasons.

At the conclusion of the study I will provide the school with a brief report. It is intended that the information will be used for publication on teacher journals. All data will be stored in a locked cabinet and will be destroyed after 3 years.

Confidentiality is assured and any names used in the final report will be fictitious.

Should you wish for further information please contact me, on 924 2112, or my supervisor Dr Geraldine McDonald, at Wellington College of Education.

If you agree being interviewed please sign the consent form below.

Many thanks for your support.

Yours sincerely

Deidre Vercauteren

\section{Consent form for Teachers}

I have read Deidre's description of her study and agree to take part in an interview conducted by her. 


\section{Appendix 6: Letter to Parent/ Caregiver}

\section{June 2004}

\section{Dear Parent/Caregiver}

My name is Deidre Vercauteren and I am an adviser for School Support Services at Wellington College of Education. I am Coordinator of the primary advisers and also lead an assessment programme we are delivering to schools. Classroom assessment and the impact of quality feedback is a particular interest of mine.

I am currently working on my Master of Education thesis and would like to ask permission to interview your child. The focus of my research is on how students understand feedback they receive in class. Students will be interviewed individually for no longer than 30 minutes and will be taped with the understanding that the recorder may be switched off at any time if the child asks for this to be done. Students may withdraw without giving reasons.

All material will be treated confidentially and any names in the final report will be fictitious. Your child will not be judged in any way and the results will not affect their progress at school.

If you agree to your child being interviewed would you please sign the consent form below and send it back with them to school.

If you would like any further information please contact me, telephone 924 2112, or my supervisor Dr Geraldine McDonald, at Wellington College of Education.

Yours sincerely

Deidre Vercauteren

\section{Consent form for Parents/Caregivers}

I have read Deidre's description of her study and agree to my child taking part in an interview conducted by her.

Signed

Date 